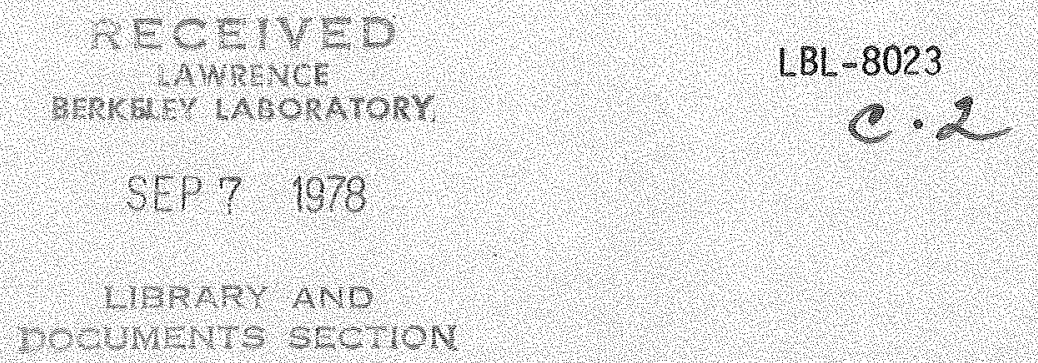

ELECTROCHEMICAL MACHINING OF CARBIDES AND BORIDES

Bernard Antoine Dissaux

(M. S. thesis)

with Rolf H. Muller and Charles W. Tobias

July 1978

Prepared for the U. S. Department of Energy under Contract W-7405-ENG-48

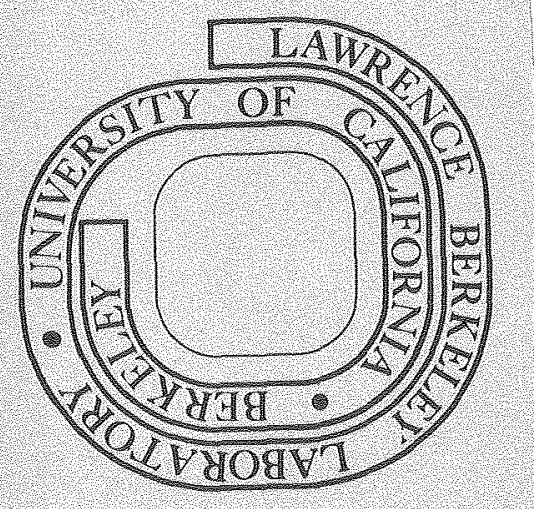

TWO-WEEK LOAN COPY

This is a Library Círculating Copy which may be borrowed for two weeks. For a personal retention copy, call Tech. Info. Division, Ext. 6782 
LEGAL NOTICE

This report was prepared as an account of work sponsored by the United States Government. Neither the United States nor the Department of Energy, nor any of their employees, nor any of their contractors, subcontractors, or their employees, makes any warranty, express or implied, or assumes any legal liability or responsibility for the accuracy, completeness or usefulness of any information, apparatus, product or process disclosed, or represents that its use would not infringe privately owned rights. 
LBL -8023

\title{
ELECTROCHEMICAL MACHINING OF CARBIDES AND BORIDES
}

\author{
Bernard Antoine Dissaux \\ (M.S. thesis)
}

with Rolf H. Muller and Charles W. Tobias

July 1978

This work was done with support from the U. S. Department of Energy. 
TABLE OF CONTENTS

I. INTRODUCTION

A. The ECM Process

B. Characteristics of ECM Operation

C. Electrode Reactions

D. Scope of the Present Work

II. MATERIALS INVESTIGATED

A. Choice of the Materials and their Physical

Characteristics

B. Choice of the Electrolytes

III. EXPERIMENTAI EQUIPMENT AND PROCEDURE

A. ECM Equipment

B. Data Recording System

C. Typical Perfomance of a Run

D. Estimates of Experimental Errors

E. Design of the Toolpieces

1. Choice of cylindrical geometry

2. General considerations for the design of the toolpieces

IV. RESULTS

A. Presentation of the Results

B. Titanium Carbide

1. Apparent electrochemical equivalent and valence of dissolution

2. Frontal gap of dissolution

3. Current-voltage relationship

4. Surface roughness; effect of the flow conditions

5. SEM microphotographs: effect of the current density

C. Zirconium Carbide

1. Electrochemical behavior

2. Frontal gap of dissolution 
TABLE OF CONTENTS (continued)

3. Current voltage relation

4. Surface roughness

5. SEM analysis: effect of the electrolyte and the current density

D. Titanium Diboride

1. Electrochemica1 behavior

2. Analysis of the reaction products

3. Frontal gap of dissolution

4. Current voltage relationship

5. SEM analysis: effect of the current density

E. Zirconium Diboride

1. Electrochemical behavior

2. Frontal gap of dissolution

3. Current-voltage relationship in $\mathrm{KNO}_{3}$

4. SEM analysis: effect of the current density

SUMMARY AND CONCLUSIONS

APPENDIX: Design of the Toolpiece

REFERENCES 
ELECTROCHEMTCAL MACHINING OF CARBIDES AND BORIDES

Bernard A. Dissaux, Rolf H. Mullex and Charles W. Tobias

Materia1s and Molecular Research Division, Lawrence Berkeley Laboratory and Department of Chemical Engineering, University of California, Berkeley, California 94720

\begin{abstract}
The use of high rate anodic dissolution (electrochemical machining) for shaping titanium carbide, zirconium carbide, titanium boride and zixconium boride has been investigated in $2 \mathrm{~N}$ potassium nitrate and $3 N$ sodium chloride under current densities ranging from 20 to $120 \mathrm{~A} / \mathrm{cn}^{2}$ (corresponding to cutting rates of 0.3 to $1.8 \mathrm{~mm} / \mathrm{min}$ ). The dissolution stoichiometry for al1 these materials is independent of the current density in the range 20 to $120 \mathrm{~A} / \mathrm{cm}^{2}$. Both titanium and zixconium appear to dissolve in the +4 state, boron In the +3 state and the weight Loss measurements indicate that carbon is oxidized to $\mathrm{CO}$ and $\mathrm{CO}_{2}$.

The current voltage curves permit to establish that, over the entire current density and flow range investigated, dissolution occurs in the transpassive state.

The surface roughness obtained on $\mathrm{TiC}$ and $\mathrm{ZxC}$ Is within 3-5 Mm and is independent of current density, applied voltage ox flow rate.
\end{abstract}



I. INTRODUCTION

A. The ECM Process

Electrochemical Machining (ECM) is finding increasing use in industry for metal removal. Several authors $(1,2,7,8)$ discuss different designs of equipment and various commercial applications. A thorough review of the state of the art is presented by $J$. Bannard (20). A large number of patents have been issued since the first application of electrochemical methods for the machining of metals (3). Most of these patents relate to improvements in the design of toolpieces $(4,5,6)$ i.e., the machining of special shapes such as turbine blades $(11,12)$, tiny holes (15), teeth of multitooth cutters (16), or to the construction of ECM equipment $(9,10)$. Others pertain to the machining of industrial materials such as sintered tungsten carbide with cobalt as a binder (13), and vanadium steels (14), or to the application of mixed electrolytes $(14,55)$ to dissolve simultaneously a11 compounds present in alloys. The use of alternating current has been proposed to prevent formation of a highly resistive anodic film $(13,26)$.

The ECM technique is of special interest in aerospace industries, in the manufacture of microcomponents, and in some specific area where conventional machining techniques cannot be used and where the machining area is not accessible to common rotating tools. ECM is also of a major advantage in special applications where the surface is to be left undisturbed.' Usually a conventional machining technique utilizes the shearing action of a sharp tool against the workpiece to achieve metal remova1, thereby affecting the physical properties on the surface of the material. In contrast, since in ECM 
there is no contact between the toolpiece and the workpiece, such alterations of the properties do not occur (17).

ECM utilizes removal of a metal by anodic dissolution into a flowing electrolyte according to well-known electrochemical principles (27, 1). Metal ions released by a positively polarized material migrate towards the negatively polarized electrode causing a flow of charge through the cell. The electrical circuit is completed by electrons flowing through the electrical loop outside the cell. Thus, the positively polarized electrode, or anode, dissolves while at the negatively polarized electrode, or cathode, a reduction reaction occurs. The preponderant cathodic reaction is the reduction of hydrogen ions (or of water) to hydrogen gas.

The driving force for the flow of current is the potential applied across the electrodes. Increasing this driving force will enhance the rates of dissolution and of migration of the ions in the electrolyte. The laws governing the rates of dissolution that can be achleved as a function of rate of flow of electrolyte, and the dependence on applied potential are well established. The reader is referred to standard references for a detailed treatment of this subject $(59,60$, $2,42)$

On the anodic side, the metal dissolves according to Faraday's law which stipulates that if a metal of molecular weight A, dissolves according to the half reaction:

$$
M \rightarrow M^{z+}+z e^{-}
$$


the amount of material removed per second is

$$
\Delta M=\left(\frac{A}{z}\right) \frac{I}{F} n
$$

where $F$ is the Faraday's constant $(96,500 \mathrm{clbs} / \mathrm{gram}$-equivalent), $\eta$ the current efficiency of the anodic reaction, and I the current (amps).

As the electrochemical machining of a material in a certain electrolyte depends only on the electrochemical properties of this couple, and not on the physical properties of the material itself, ECM has been considered for use in machining materials with special physical properties widely used in industry. Whereas in conventional machining, the main concern for working on a specific material involves finding a toolpiece which has superior physical properties (hardness, toughness, high tensile strength), there is no need for having such constraints in ECM operations, because the tool (cathode) never comes in contact with the workpiece (anode).

\section{B. Characteristics of ECM Operation}

High flow velocities of electrolyte are needed in order to remove the heat evolved, as well as to supply the reactants in the electrolyte and to remove the reaction products. To obtain a dimensionally accurate replica of the cathode geometry, and to keep the ohmic losses between the electrodes as low as possible, the interelectrode gaps are usually maintained below $1 \mathrm{~mm}$.

The high flow requirements used in ECM are needed to remove the heat evolved by the passage of high currents, Typical current densities 
used in industrial applications vary from 30 to $300 \mathrm{~A} / \mathrm{cm}^{2}$. As calculated in previous work $(22,23,61)$, in the absence of flow, Joule heating may cause the electrolyte to boil almost instantaneously after switching on the current. The flow used in practical ECM operation is always turbulent $(\operatorname{Re} \geqslant 10,000)$, consequently the pressure drop through the machining section is significant.

Another important use of high electrolyte velocities is the removal of the reaction products(usually precipitated in the form of oxides or hydroxides). If they were to stay in the vicinity of the anode, they would cover its surface and, as they are often poorly conductive materials, cause oxygen evolution without dissolution of the metal. If the current efficiency of dissolution were to significantly decline, and the cathodic toolpiece were to advance at a constant rate towards the anode, the two electrodes would eventually get close enough for destructive gaseous discharge to occur.

In normal ECM operation, metal is continuously removed at a constant rate of the workpiece, when steady state is reached. As the tool is moved towards the anode at constant current density and constant interelectrode distance, the final shape obtained on the workpiece is roughly a complementary shape or an imprint of the toolpiece.

\section{Electrode Reactions}

For a practical use of an ECM machine, a complete knowledge of the electrochemica1 reactions occurring at the electrodes is desirable. Several reactions may occur simultaneously at the interface of the two electrodes and in the electrolyte. The main reaction types are reviewed 
below.

\section{Anodic Reactions}

They are the most important features of the process because they are the basic principle of ECM and govern the conditions under which a metal is being electrochemically machined. The anodic material is to be dissolved by electrochemical reactions according to the half reaction

$$
M \rightleftharpoons M^{Z+}+z e^{-}
$$

The number of electrons involved in the reaction governs the amount of electrical charge required and gives the ionic species formed during anodic dissolution which carry a part of the current towards the cathode. (The rest of the current being transported by the ionic species present in the electrolyte.). The dissolved metal ions are carried away from the anode-electrolyte interface into the bulk of the electrolyte by migration and by flow of the electrolyte itself. They either remain in solution or precipitate as solids and are swept away by the flow. Dissolved metal Lons may be reduced if they reach the cathode. Electrolytes are usually so chosen that the dissolved ionic species are precipitated and swept out of the machining section.

The electrolytes usually employed for ECM are neutral salts in aqueous solutions. A possible side reaction at the anode is

$$
\mathrm{H}_{2} \mathrm{O} \rightarrow 1 / 2 \mathrm{O}_{2}+2 \mathrm{H}^{+}+2 \mathrm{e}^{-}
$$

leading to the evolution of oxygen and reducing the efficiency of the 
cutting process. This reaction occurs when certain passivating films form on the machined surface. Usually dissolution occurs in the active state, or in the transpassive state, with little or no oxygen evolution $(23,44)$. When mild steel is machined in $\mathrm{NaClO}_{3}$, less than $8 \%$ of the current is devoted to the parasitic oxygen evolution as compared to $50-96 \%$ in $2 \mathrm{~N} \mathrm{NaNO}_{3}$ (21).

\section{Cathodic Reactions}

The principal reaction is

in acid electrolyte:

$$
2 \mathrm{H}^{+}+2 \mathrm{e}^{-}=\mathrm{H}_{2}
$$

in neutral or basic electrolyte: $\mathrm{H}_{2} \mathrm{O}+2 \mathrm{e}^{-}=\mathrm{H}_{2}+2 \mathrm{OH}^{-}$

The hydrogen formed has to be efficiently removed by fast flow of electrolyte to preclude gas blanketing the surface of the cathode. Reduction of anions (e.g. $\mathrm{NO}_{3}{ }^{-}$) may also occur; this can lead to excessive costs of reprocessing of the electrolyte. The $\mathrm{Na}^{+}$or $\mathrm{K}^{+}$present in the electrolyte cannot interfere with the hydrogen evolution, because the discharge of these ions requires potentials which are far higher than achieved at the cathode/electrolyte interface. Even if the alkali Ion discharge were possible, these metals would instantaneously react with the water present in the electrolyte and generate hydrogen.

If the Ionic species dissolved at the anode reach the cathode in the same state as they lett the anode, they may be reduced on the cathodic toolpiece and thereby change its shape, causing poor dimensional 
control of the cut in the anode. Cathodic deposition of the metal is usually avoided by the use of a low pli or neutral electrolyte (2) and a high velocity through the machining section, sweeping almost instantaneously the insoluble reactions products so that the hydrogen lons present in the solution are the only species able to react on the cathode.

The hydrogen blanketing of the cathodic surface $(60)$ is also responsible for the rise in cemperature of the electrolyte; this effect is reduced by high flow velocity.

\section{Scope of the Present Work}

Among the hardest materials used in industry are the refractory carbides and borides of the transition metals. Most of these are used In the form of cemented composites, enhancing different mechanical properties needed for a specific use. Cobalt, the binder usually employed in tungsten carbide, has been proven to improve the resistance to wear and impact; also a small amount of chromium greatly improves the corrosion resistance.

To eliminate ambiguities resulting from the presence of binders, pure carbides and boxides of titanium and zirconium have been chosen as the vehicles of this work.

The object of this research was to determine the applicability of ECM to these materials and to identify operating conditions (electrolyte composition, cutting rates and tool design) under which these materials are machinable. The choice of $\mathrm{NaCl}$ and $\mathrm{KNO}_{3}$ has been based on previous reports on the suitability of these electrolytes (31, 1). A cylindrical 
toolpiece has been chosen to obtain reproducible results on small machined areas. 


\section{MATERIALS INVESTIGATED}

A. Choice of the Materials and their Physical Characteristics

The choice of the materials investigated in this workwas basically gufded by three considerations: hardness, high temperature stability and electrical conductivity.

The hardness is an important property insofar as a choice between conventional machining and ECM is concerned. Carbide or boride tool bits, grinding heads, etc, are usually manufactured by presintering a powder of the material in a vacuum furnace, then formed to shape by conventional machining techniques (turning or grinding) followed by vacuum sintering. This widely used technique requires a substantial amount of time and, during the last sintering phase of the process, a shrinkage of $30 \%$ to $50 \%$ by volume is unavoldable (28). This means that close dimensional control is the critical point of such a process and a lot of time is required to obtain the final shape. Such critical steps can be shortened by using an ECM technique to machine the final shape, especially if the desired shape is to be reproduced many times (29). High temperature stability is of interest in cases where the materials are used under particularly severe conditions. Because of good oxidation resistance, carbides and borides should be excellent materials for various parts of gas turbines (30), where the use of a working fluid at very high inlet temperature is a factor governing the efficiency of the fluid cycle. Ceramics are commonly used as rotating parts of gas turbines due to their excellent corrosion and oxidation resistance. But ceramics are very brittle, and difficulties arise in shaping them because of chemical and mechanical non-uniformities 


\begin{tabular}{|c|c|c|c|c|c|c|c|c|}
\hline Naterial & Hardness & $\begin{array}{l}\text { Hectrical } \\
\text { conductivity }\end{array}$ & $\begin{array}{l}\text { density } \\
\text { litt. obs. }\end{array}$ & porosity & $\begin{array}{l}\text { melting } \\
\text { point }\end{array}$ & $\begin{array}{l}\text { formula } \\
\text { weight }\end{array}$ & $\begin{array}{l}\text { aspect and } \\
\text { structure }\end{array}$ & $\begin{array}{l}\text { comoosition*** } \\
\left(g^{\prime} \text { oy weight) }\right.\end{array}$ \\
\hline $\begin{array}{c}\text { TiC } \\
\text { : }\end{array}$ & 96 & $1.1810^{4} \quad 2 \% *$ & \begin{tabular}{c:c}
4.93 & 4.33 \\
\hdashline
\end{tabular} & $12 \%$ & $3150^{\circ} \mathrm{C}$ & 59.91 & $\begin{array}{l}\text { grey metalife } \\
\text { NaCl type }\end{array}$ & $\begin{array}{l}\text { Ti : } 80.00 \% \\
C:: 19.5 \% \\
F e, S i, C a, N a, 0, i \leqslant .3 \%\end{array}$ \\
\hline $\mathrm{ZrC}$ & 92.5 & $1.5410^{4} \quad 3 \% *$ & $6.73 \div 4.96$ & $26 \%$ & $3530^{\circ} \mathrm{C}$ & 103.23 & $\begin{array}{l}\text { metallic } \\
\text { f.c.c }\end{array}$ & $\begin{array}{l}\mathrm{Zr}: 38.4 \% \\
\mathrm{C}: 11.6 \%\end{array}$ \\
\hline $\mathrm{TiB}_{2}$ & 99 & $3.5210^{4} \quad 6 \% *$ & $\begin{array}{c}4.50 \\
1 \\
1 \\
1\end{array}$ & $1.5 \%$ & $2900^{\circ} \mathrm{C}$ & 69.52 & $\begin{array}{c}\text { grey } \\
\text { hexagonaI }\end{array}$ & $\begin{array}{l}\text { Ti : } 68.30 \% \\
B: 31.40 \% \\
F e, C, H, N, O 6.3 \%\end{array}$ \\
\hline $\operatorname{ZrB} B_{2}$ & $87-89$ & $10.810^{4} \quad 18 \% * \%$ & $\begin{array}{c}6.09: 5.83 \\
\vdots\end{array}$ & $4.3 \%$ & $3040^{\circ} \mathrm{C}$ & 112.84 & $\begin{array}{l}\text { grey with } \\
\text { cracks } \\
\text { hexagonal }\end{array}$ & $\begin{array}{l}\mathrm{Zr}: 80.4 \% \\
B:=19.15 \% \\
F e, C, 0, \mathbb{N} \leqslant .35 \%\end{array}$ \\
\hline $\begin{array}{l}\text { Copper } \\
\text { metalic } \\
\text { imp. } \\
\leqslant .01 \%\end{array}$ & 27 & $58.810^{4}$ & 8.94 & & $1083^{\circ} \mathrm{C}$ & 63.5 & $\begin{array}{c}\text { red } \\
f \cdot c \cdot c .\end{array}$ & \\
\hline
\end{tabular}

* Rockwell A : $60 \mathrm{~kg}$ load, brale penetrator.

** of the electrical conductivity (ohm $\mathrm{cm}^{\text {* }}$ ) of copper.

** typical analysis obtained from the manufacturer: HASELDEN Co, San Jose, California. 
which develop during the processing of raw materials into finished components (32). Research done during the nineteen-fifties (32) on TiC parts indicated that the design of turbine parts was not adequate and that poor impact resistance was not the actual reason why this carbide did not seem to give adequate performance.

Failures were caused by the attachment of the blades to the rotor which was the critical point at high rotation speeds, and not the blade itself which was able to sustain very high temperatures. To allow ECM, a material needs to have adequate electrical conductivity; high ohmic losses and consequent bad current distribution cannot be tolerated. Carbides and borides are falrly good conductors with conductivities typical1y in the order of 5-50 times lower than that of copper. Obviously, non-conductive materials like nitrides cannot be machined by ECM, although their excellent physical properties are of great interest in some industrial applications.

Table I lists selected physical properties of the materials investigated in this work $(33,34,35,36)$. The physical characteristics of copper are listed for comparison.

\section{B. Choice of the Electrolytes}

From among the numerous electrolytes used for ECM work (nitrates, halides, chlorates, chromates, etc.), $\mathrm{KNO}_{3}$ and $\mathrm{NaCl}$ were selected for this study. Potassium nitrate was chosen for its oxidizing strength and sodium chloride is known to provide high machining rates (48). The comparison of $\mathrm{NaNO}_{3}$ with $\mathrm{NaClO}_{3}$ electrolytes shows that the excellent properties of the latter for ECM of mild steel are due 
to the weakness of the film formed on the anode surface (57). The breakdown of this passivating film is related to the transition from the active to the transpassive regions where ECM is believed to occur. As this anodic film is known to also form in $\mathrm{NaNO}_{3}$ on mild steel in the transpassive regions (18), metal dissolution is not the only anodic reaction: actually, most of the current is devoted to oxygen evolution. Furthermore, since the total anode current efficiency for metal dissolution and oxygen evolution has been found to be less than $100 \%$ (21), it is certain that other side reactions occur in nitrate electrolytes. Potassium nitrate, used earlier for the machining of copper and stainless steel (31) demonstrated interesting properties: good throwing power and high surface finish. This electrolyte was chosen in part because it is safer to handle and it is less corrosive than the chlorate electrolyte.

The second choice was based on the wide-spread industrial use of sodium chloride for the machining of titanium alloys and non-metallic compounds of zirconium (1). The non-passivating nature of $\mathrm{NaCl}$ is related to the attack of $\mathrm{Cl}^{-}$of the anodic $\mathrm{film}$; this permits high machining rates at low potentials. However, ECM with NaCl has been shown to provide very poor dimensional control (55) for mild steel. This behavior is explained by different authors $(21,43)$ to be a consequence of the nature of the anodic polarization curve in the presence of chloride ions.

Sodium chloride is often used with additives such as bromides or fluorides (58). The latter serve to improve the surface characteristics of machined parts. 
III. EXPERIMENTAL EQUTPMENT AND PROCEDURE

A. ECM Equipment

The experimental equipment, a job shop gun drill manufactured by Hanson Van Winkle Munning Company, has already been described in full detail elsewhere (31). The only modifications, made for this work, to the equipment used in a previous work are:

- installation of a large capacitor (300,000 mFd at 50 Volts) across the output terminals of the power supply to reduce the ripple from $10 \%$ to less than $3 \%$.

- installation of the data recording system described in this section.

The schematic diagram $(F i g .1)^{*}$ depicts the power supply [1], capable of delivering 500 amps at 30 Volts maximum; the cutting chamber [2], and the electrolyte filtration system [4 and 5]. The toolpiece [8] is mounted on a feed ram advancing with a variable speed towards the workpiece fastened to a stand [7]. The electrolyte is pumped [3] through the flow lines and filtered [10] before entering the cutting chamber. The flow rate of the electrolyte, controlled by a set of valves, is measured by a magnetic flowmeter [11]. The pressure drop In the ECM gap is measured by the inlet of electrolyte in the cutting chamber by means of a strain gauge [12]. Temperatures are recorded both before and after [13] the machining gap. After passing through the machining section, the electrolyte is recycled [6] in the main tank [4] following filtration through fiberglass insulation material [9].

*The brackets [] in this section refer to areas of Figure 1. 
Figure 1 : Schematic flow diagramm and position of the measuring gauges; power suppl. (1) cutting chamber(2), main tank of electrolyte(4), recycle of electrlyte (5). toolpiece(8), temperature sensors(13), pressure gauge(12), floweter(10).

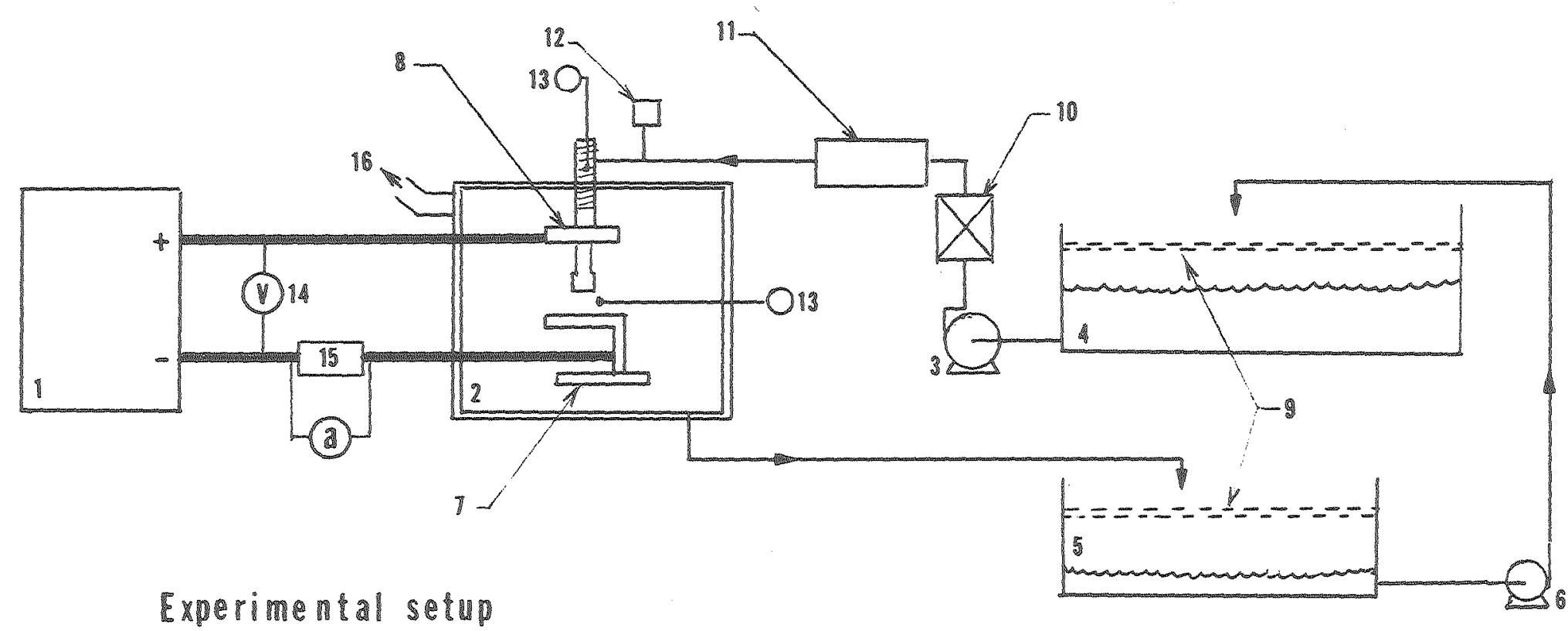

XBL 785.8727 


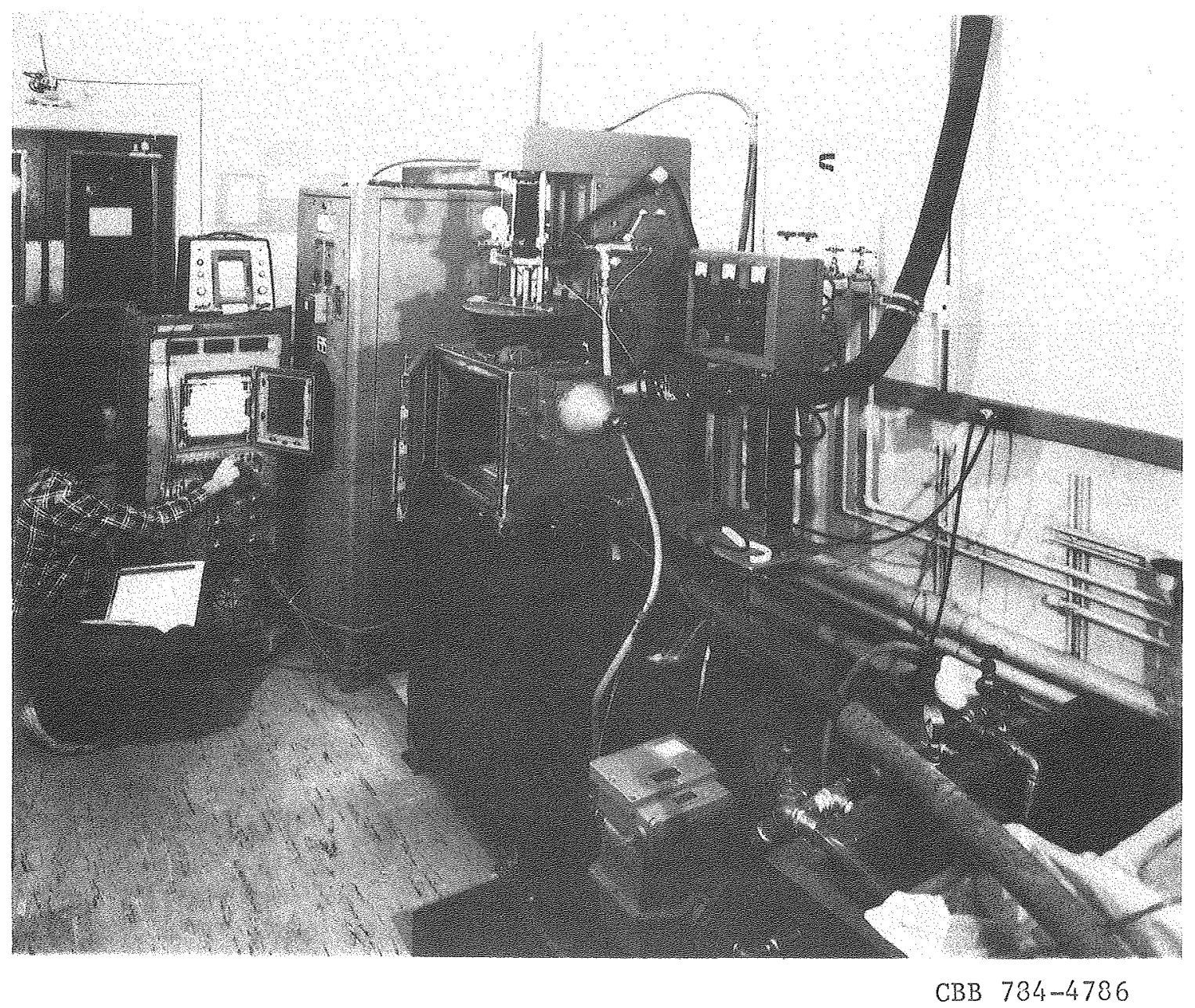

Figure 2. Experimental equipment, from left to right: data recording system, power supply, cutting chambex and electrolyte tanks. 
The gaseous products evolved during ECM are vented to a hood [16]. The cell voltage [14] is recorded and the current [15] is measured through appropriate shunts.

\section{B. Data Recording System}

Experimental data were measured and recorded continuously throughout a11 the runs to follow the different parameters during the machining process and to determine when steady state has been achieved (40). An interesting feature of ECM is that the machining parameters adjust themselves according to the operating conditions. The reason for this is that if the toolpiece is moved towards the workpiece at a faster rate than the metal is being dissolved the gap will decrease. As the gap decreases, the resistance of the electrolyte in the gap is lowered and therefore, the current increases. Thus, the metal removal rate rises until an "equilibrium" value is reached where the gap $(40,23)$, the current and the metal removal rate become constant. At steady state the tool feed rate is equal to the metal removal rate. (The same reasoning is applied if the toolpiece is moved toward the anode-workpiece at a smaller rate than the metal removal rate, leading to the same "equilibrium" in machining parameters).

The continuous recording of the operating parameters allows the operator to recognize problems such as:

-sparking if filtration is not adequate, allowing small metal particles to flow through the machining gap and to shortcircuit the electrodes. (An internal overload switch is provided on the power supply which automatically shuts off the current 


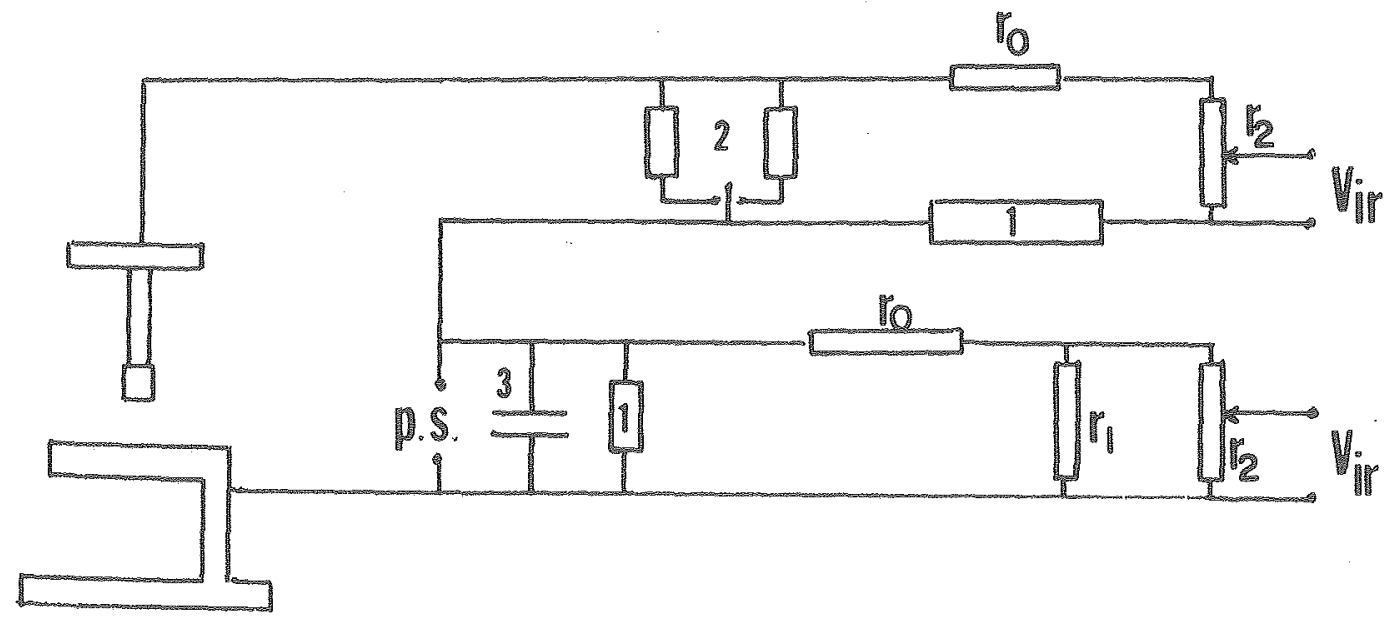

fig A

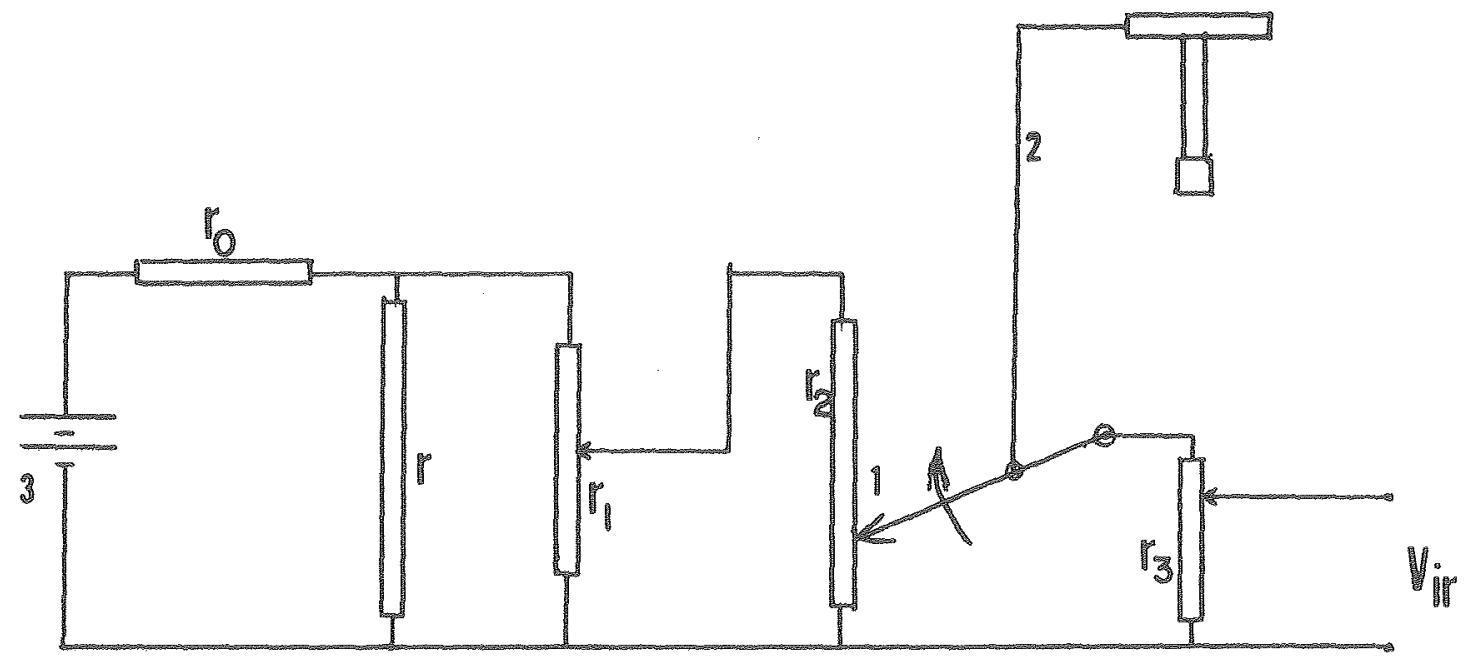

fig B

XBL $785-8726$

Figure 3. Data recording system. A) Schematic of voltage and current recordings: digital display (1), current shunt (2), 300,000 mFd capacitor (3). B) Schematic of the position of the toolplece recording: precision rotary resistor (1), attached to the feed ram (2), separate power supply (2), powex source (3). 
If this happens).

-arcing if the feed rate of the workplece is set too high or when the recycled electrolyte is filtered and recirculated at too low a flow rate, resulting in gas blanketing. A multi-channel strip chart recorder is used to display six variables in a semi-continuous manner (one data point printed in each channel every six seconds). The maximum input for each channel is $10 \mathrm{mV}$, each variable is measured from transducers with d.c. voltage outputs through voltage dividers or amplifiers.

Voltage recording: The voltage dividers are schematically represented by Figure 3A. The use of voltage dividers is necessary to cut down the voltage applied across the electrodes by the power supply from 30 Volts maximum to $10 \mathrm{mV}$. The actual voltage Vo is related to $V_{I R}$, the input to the recorder as follows:

$$
V_{I R}=\left(\frac{R_{1} R_{2}}{R_{1} R_{2 T}+R_{0} R_{1}+R_{0} R_{2 T}}\right) \quad V_{0}
$$

(see the caption of Figure $3 \mathrm{~A}$ for identification of the resistances) The full scale is set at $30 \mathrm{~V}$ maximum, the correlation between the applied voltage and the chart reading being:

$$
V=[0.08+0.30(\% \text { reading })] \text { Volts }
$$

The accuracy of this reading is better than $0.5 \%$ at $20 \%$ reading of full scale. 
Current recording: The power supply is capable of delivering 500 amperes at 30 Volts; the current output can be measured across a 50 or 500 ampere shunt. The maximum available current is large for the size of the machined area used in this work and as the tool surface area was below $0.4 \mathrm{~cm}^{2}$ and the current density not allowed to exceed $120 \mathrm{~A} / \mathrm{cm}^{2}$, the full scale of the current recording was set at 50 amps.

In Figure $3 \mathrm{~A}$ the resulting voltage, $\mathrm{V}_{I R^{2}}$ serves as the input to the strip chart recordex, according to

$$
V_{I R}=R_{2} i=\frac{R_{2} S I}{k}=\frac{R_{2}}{R_{2 T}} \quad S I
$$

where $\mathrm{S}$ is the value of the internal shunt of the power supply, and $R_{2}$ the percentage of the total resistance $R_{2 T^{\circ}}$ Temperature recording: The recording of the temperature allows the knowledge of the heat generation due to Joule effects occurring within the gap between the two electrodes as ECM proceeds. As already shown by various authors (23), the temperature rise in the working gap may be of significance and may affect the dimensional accuracy and surface finish (1, 61). Because of the impossibility of measuring the temperature exactly in the very small machining gap (around 20 mils) without introducing serious perturbations in the flow by the temperature sensor, the probes are placed at the inlet and at the outlet, as close as possible just before and after the machining section.

The voltage drop across the thermistors is measured by a Wheastone bridge as shown in Fig. 4D. The unbalance of the bridge introduced by the change of cemperature is used as the measuring signal. The two 

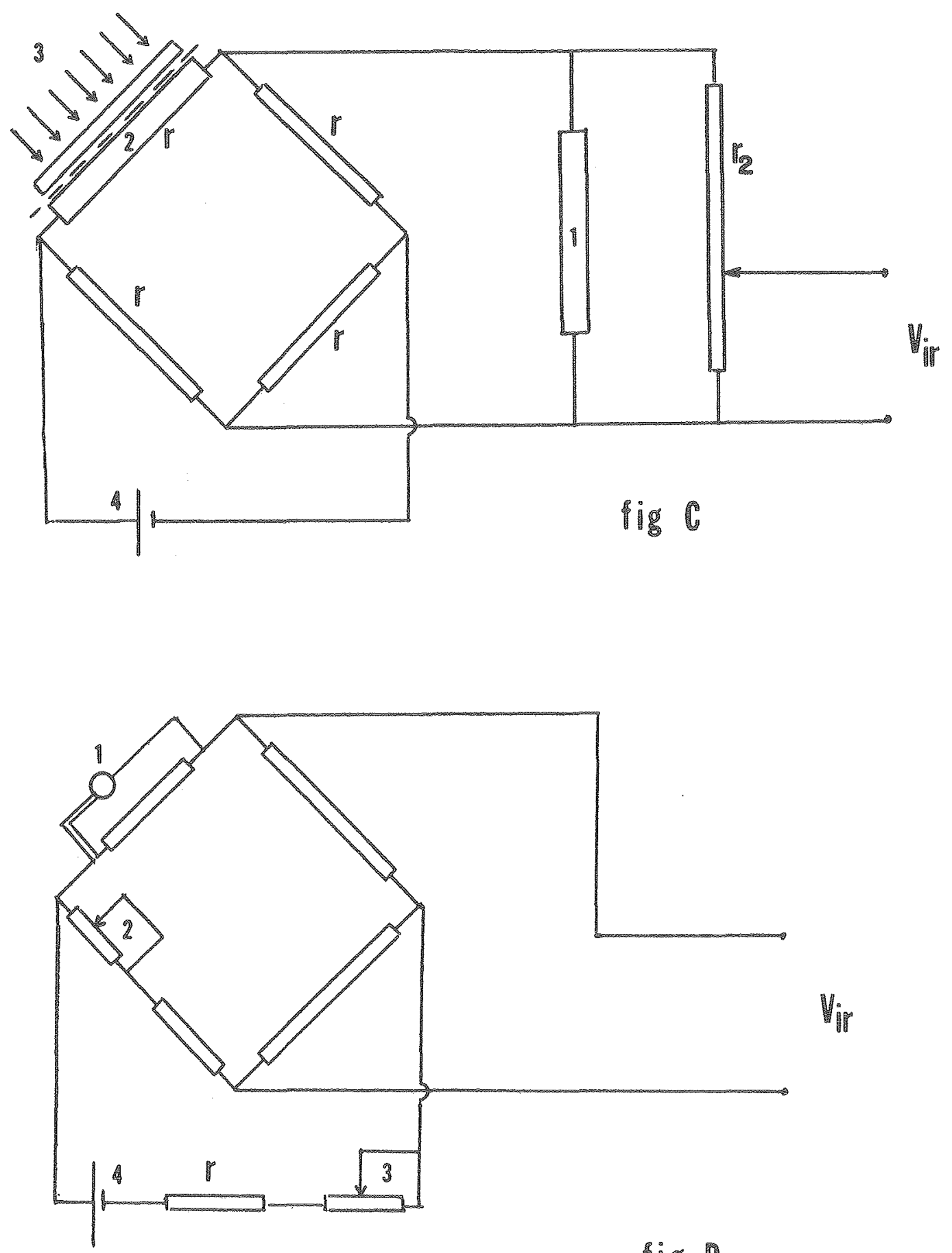

fig D

XBL $785-8725$

Figure 4. Data recording system: C) Pressure recording: sensor element (2), in line pressure (3), digital display (1), power source (4). D) Temperature recording: thermistor (1), the zero (2) and the span (3) can be adjusted. 
variable resistances [2] and [3] in Fig. 40 are used for setting the span and the zexo of the sensing element [1]。

The zeroing and span settings are set so that the exror is the smallest around ambient temperature, and $20 \%$ reading on the chart recorder gives a temperature of $20^{\circ} \mathrm{C}$ with a $0.5 \%$ error. As the response of the temperature probe is linear, the chart can be directly read in degrees Centigrade.

Pressure recording: The inlet pressure of the electrolyte is measured by means of a strain gauge transducer. Four strain gauges, bonded to a strain sensitive element, are connected to a Wheatstone bridge circuit (Fig. 4C). The pressure [3] acting on the diaphragm transmits strain to the sensor [2], and unbalances the bridge circuit; this voltage unbalance is directly proportional to the pressure. Gauge pressures occurring are in the range of $0-100$ psi. The sensitivity of the gauge is $3 \mathrm{mV} / \mathrm{V} \pm 0.015 \mathrm{mV}$. The gauge is supplied by a $+1 \%$ regulated solid state power supply. The voltage divider is set for full scale at 100 psi, the sensitivity of 1 psi.

Position recording: The movement of the toolpiece is transmitted to a precision rotary resistor which moves along a cursor according to the tool position as schematically represented by Fig. 3B. The voltage drop across this varying resistance serves as an input to the recorder. The input voltage to the recorder with the proper choice of resistance to a.low $10 \mathrm{mV}$ d.c. maximum voltage is then:

$$
V_{I R}=\frac{R_{2}}{R_{2 T}}\left(1-\frac{1}{1+\frac{R_{1} R_{2 T}}{R_{0}\left(R_{1}+R_{2 T}\right)}}\right) \quad V_{T}
$$


The position transducer is a precision Iinear resistance $(0.25 \%)$ of $100 \Omega$. The slope of the straight line recorded on the chart gives directly the feed rate of the toolpiece by the relationship:

$$
F x=(\text { chart speed) tang } \alpha
$$

The tool feed ram is also equipped with a dial (graduated in mils) which allows the setting of the starting machining gap and also facilitates the visual observation of the advancement of the tool. Flow rate: As shown in Fig. 1, the velocity of the electrolyte is controlled by a set of valves and recorded by means of a magnetic flowmeter*

The flow meter is calibrated for velocities ranging from 600 to $5000 \mathrm{~cm} / \mathrm{sec}$ corresponding to flow rates up to $121 \mathrm{iter} / \mathrm{min}$.

A typical set of data recorded during an experiment is shown in Fig. 5 .

C. Typical Performance of a Run

The electrolytes were prepared in batches of about 120 liters, dissolving the required weight of analytical reagent solid crystals in low conductivity water (twice delonized in adsorption columns) and adjusting to the specific density corresponding to $2 \mathrm{~N}$ for $\mathrm{KNO}_{3}$ $\left(\mathrm{d}_{20}^{20}=1.1201 \mathrm{~g} / \mathrm{cc}\right)$ and $3 \mathrm{~N}$ for $\mathrm{NaCl}\left(\mathrm{d}_{20}^{20}=1.1182 \mathrm{~g} / \mathrm{cc}\right)$ after complete dissolution.

$*$ * Brooks Instruments: Flowhead Mode1 7187 equipped with the signa1 converter Model 7460 . 


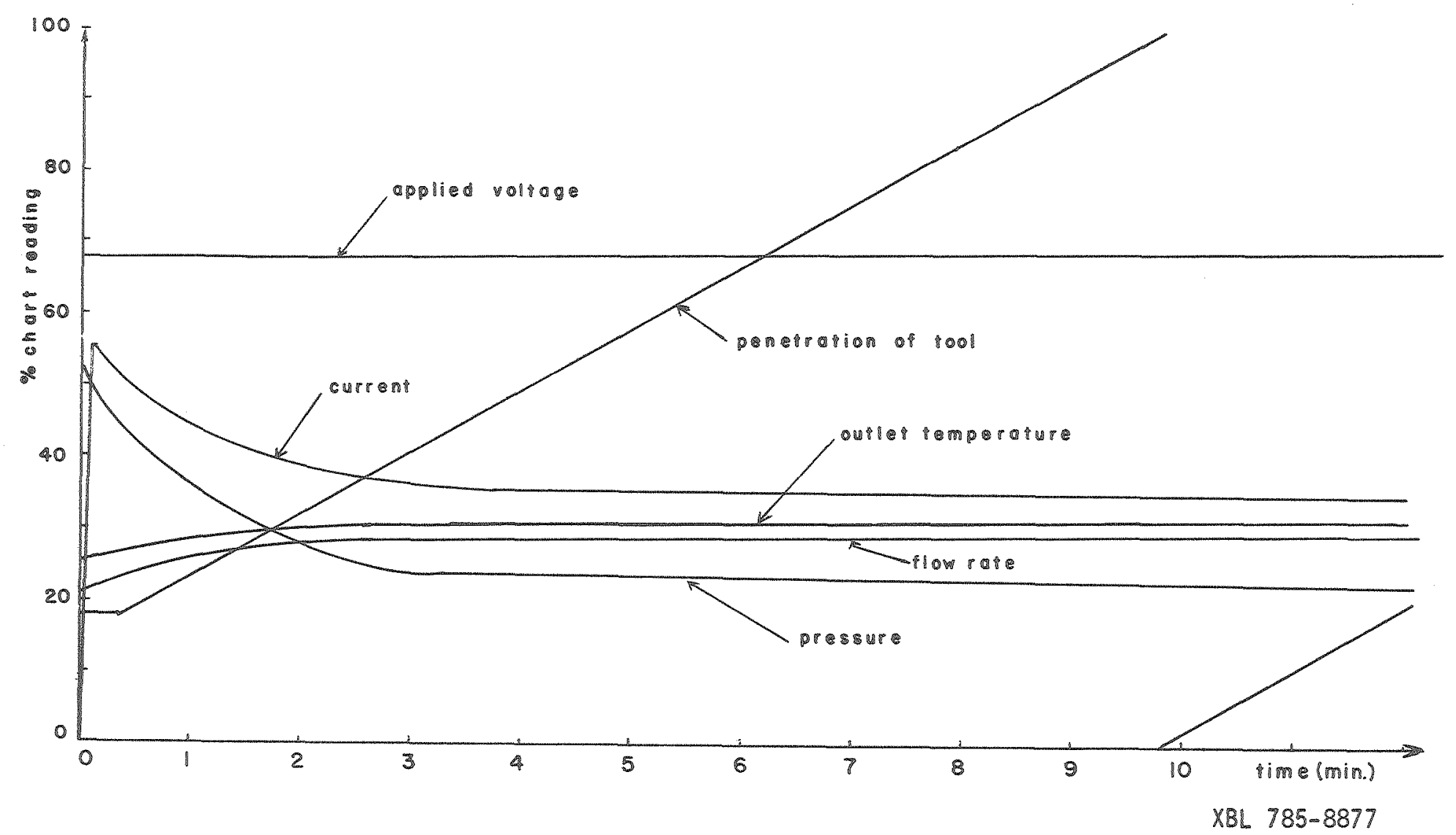

Figure 5. Typical ECM recording by using the toolpiece B. The steady state is attained after 3 minutes. Run 非 64 : TiC in $3 \mathrm{~N} \mathrm{NaCl}, 17.6$ Amps at 25.1 Volts, tool feed rate $=4.4310^{-2} \mathrm{~cm} / \mathrm{min}$, flow rate $=4.27$ liter $/ \mathrm{min}$ at $23 \mathrm{psig}$. 

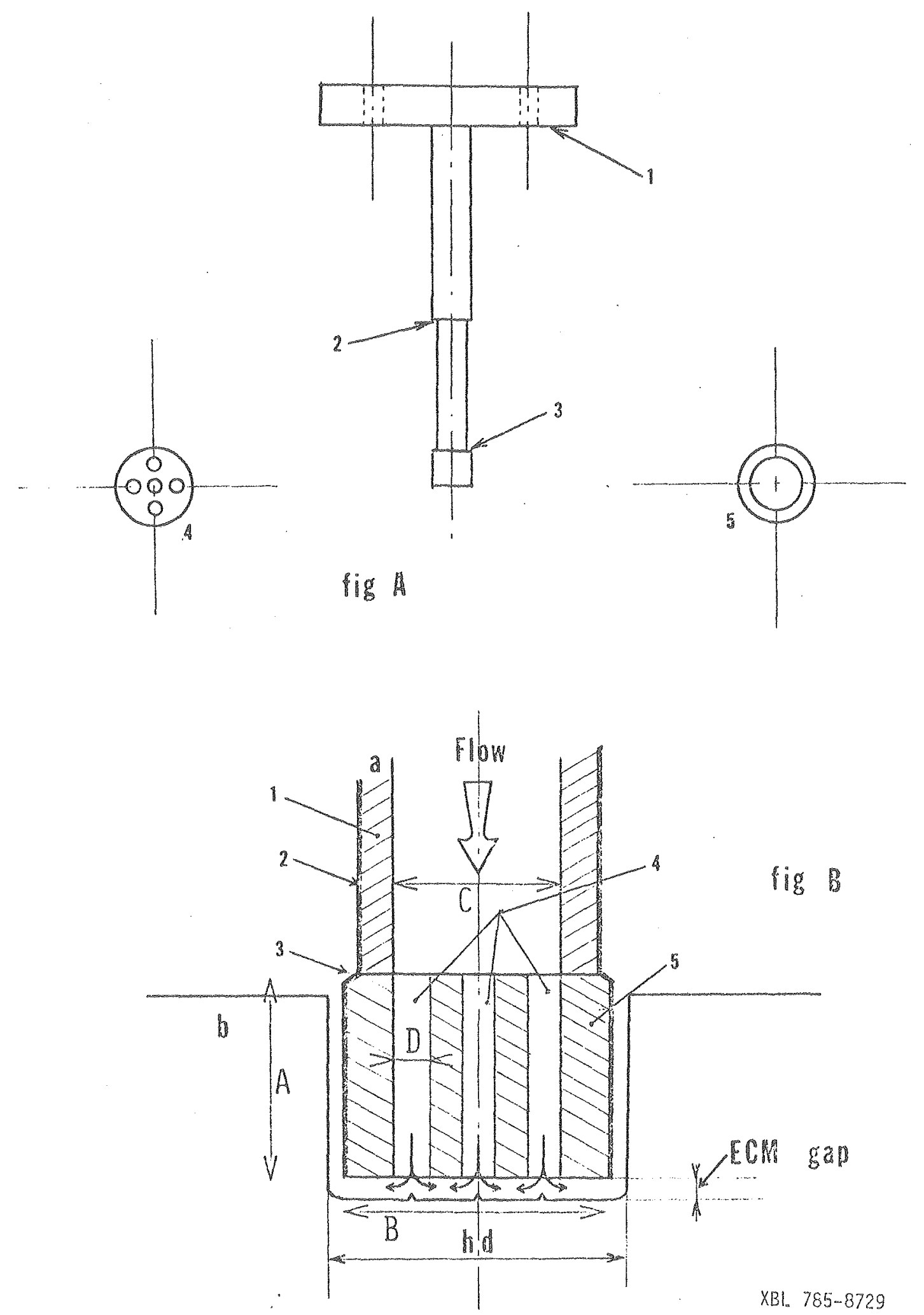

XBI. $785-8729$

Figure 6. A) Design of the toolpiece used in this work: mounting socket (1), step to divert the electrolyta (2), tip of the toolpiece in copper (3), aerial view of design B (4), and of design A (5). B) Cell configuration in this work: a) toolpiece: brass tubing (1), insulator (2), step on the tip of the toolpiece (3), electrolyte entries (4). b) workpiece: $h_{0} d .=$ outside diameter of the hole drilled. $A, B, C, D$ refer to table II. 


\begin{tabular}{|c|c|c|c|c|c|c|c|}
\hline Tool & $\begin{array}{l}\text { overall } \\
\text { length }\end{array}$ & $\begin{array}{c}\text { length } \\
\text { of tip } \\
\text { (A) }\end{array}$ & $\begin{array}{l}\text { outside } \\
\text { diameter } \\
\text { (B) }\end{array}$ & $\begin{array}{l}\text { inside } \\
\text { diameter } \\
\text { (c) }\end{array}$ & $\begin{array}{c}\phi \\
\text { hole } \\
\text { (D) }\end{array}$ & $\frac{\mathrm{S}\left(\mathrm{e} \mathrm{I}_{0}\right)}{\mathrm{S}(\mathrm{ECM})}$ & $\frac{\mathrm{s}(\mathrm{el} .)}{\mathrm{s}(\mathrm{total})}$ \\
\hline $\operatorname{design} A$ & 9.50 & 0.20 & 0.625 & 0.445 & - & 1.03 & $51 \%$ \\
\hline design $A$ & 5.00 & 0.50 & 0.645 & 0.375 & - & 0.51 & $34 \%$ \\
\hline design $B$ & 6.70 & 0.50 & 0.700 & 0.375 & 0.1 & 0.11 & $10 \%$ \\
\hline
\end{tabular}

Table II. Dimensions of the toolpieces; they are listed in cms and represent the design dimensions as referred to figure $6 B$. They may vary due to the different polishing operations before coating and are always carefully controlled. In the last two column, $S$ (total) represents the overall cross sectional area of the tip of the toolpiece, S (ECM) the surface area where current flows and $S(e 1$.$) the surface area of the electrolyte entries.$ 

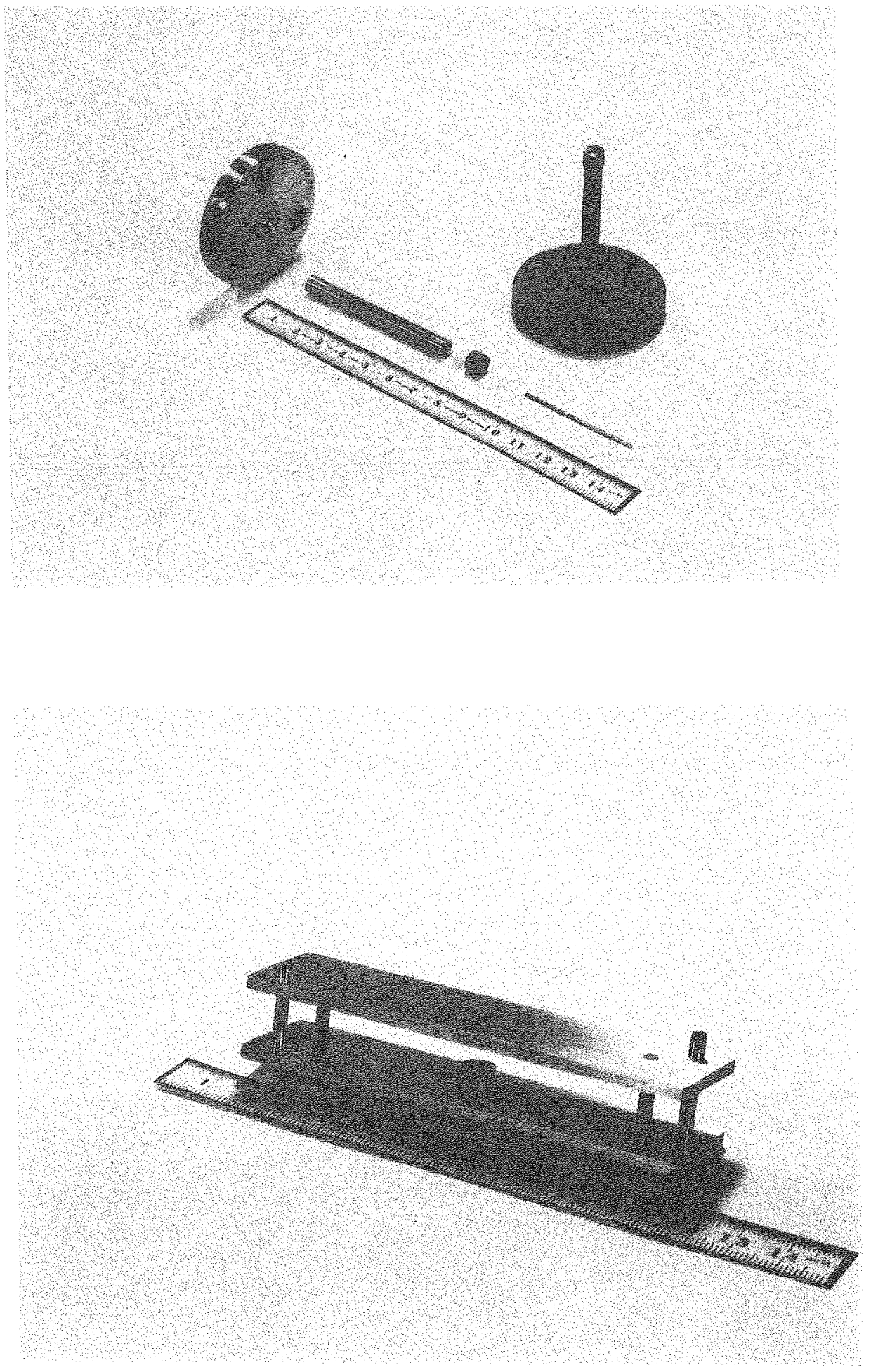

XXBB $\quad 785-6126$

Figure 7. top: Parts of the toolpiece before soldering, from left to right mounting socket, brass tubing, tip of the cathode, drill used for the five small holes.

bottom: Jig used to position the tip and drill the electrolyte entries before soldering on the toolpiece. 
One batch was used for each set of experiments which included one type of anode material in one electrolyte (representing about 30 runs). The electrolyte was renewed after each new material investigated.

The following procedure was followed in each expeximent:

- polishing the tip of the toolpiece with $\|_{1} 600$ abrasive paper and controlling the dimensions:

- mounting the toolpiece on the tool feed ram after cleaning the tip with detergent followed by drying in acetone;

- clamping the workpiece sample on the stand provided in the cutting chamber after weighing the sample;

- setting an initial starting gap by the dial indicator, using a 2 mils copper foil;

- turning on the chart recorder;

- measuring density and Initial temperature fo the electrolyte before the run;

- adjustment of the initial flow rate and pressure by the use of valves;

- flushing the lines for five minutes to stabilize the pressure and the flow rate;

- applying the preset voltage between the toolpiece and workpiece;

- switching on the tool feed rate preset on a $0-100 \%$ dial Indicator.

After the steady state is reached, as checked on the recorder (one to three minutes depending on the toolpiece feed rate and the starting gap), ECM operation is maintained at constant parameters. After the power is turned off, by means of a single switch which 
shuts off the pump, the power supply and the advancement of the toolpiece, the position of the tool is precisely recorded on the ram dial. After removal, the sample is cleaned, rinsed with tap water and dried under vacuum. The sample is then weighed and its dimensions are recorded (outside diameter, depth of hole).

The data recorded for each experiment include:

- applled voltage;

- current at steady state;

- tool advancement rate:

- starting gap;

- position of the tool before and after experiment;

- density and temperature of the electrolyte before the run;

- Ilow rate and pressure of the electrolyte;

- inlet and outlet temperatures of the electrolyte;

- time of the experiment;

- weight of the sample.

After each experiment, the following data are recorded:

- diameter of the hole

- depth of the hole

- weight of the sample used;

- ECM gap. 

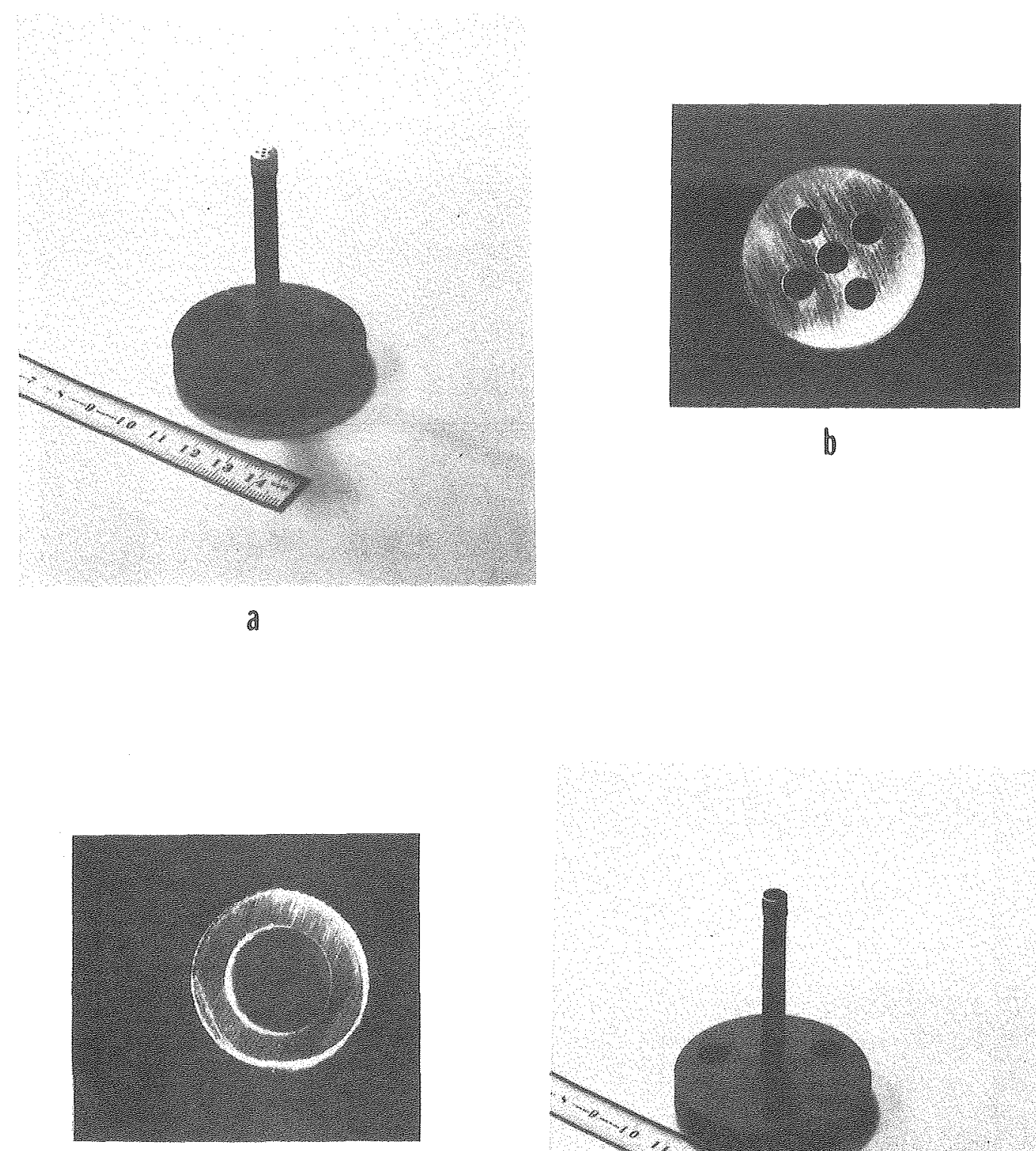

c

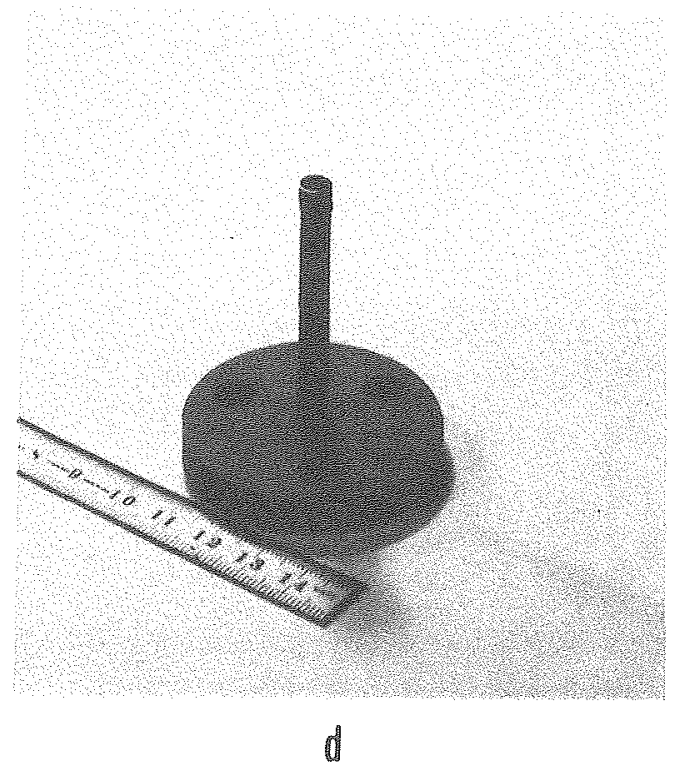

XBB $\quad 785-6125$

Figure 8. Toolpieces used in this work: a) and b) design $B$

c) and d) design $A$ 


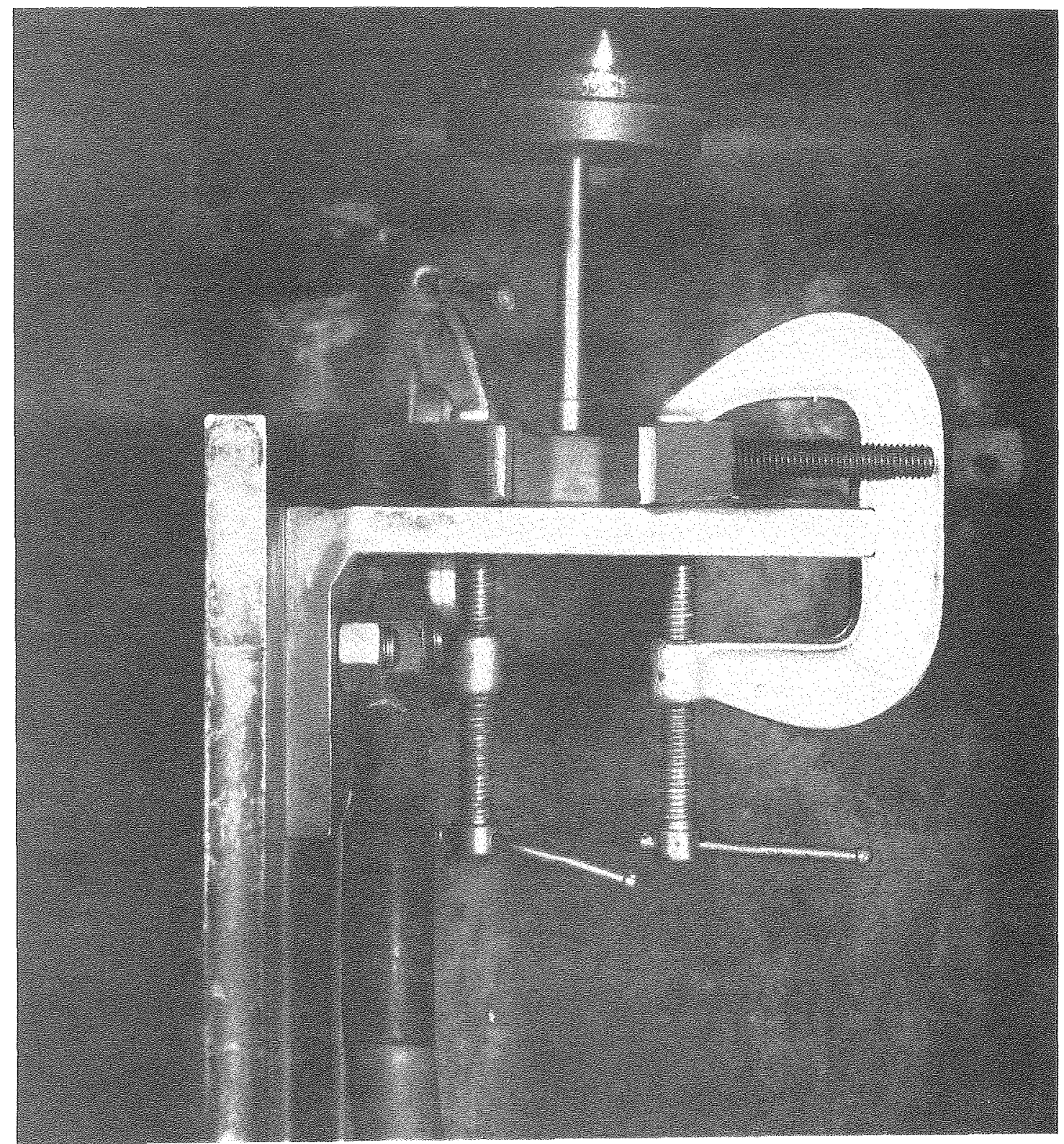

CBB $784-4784$

Figure 9. Assembly of the toolpiece and the workpiece in the cutting chamber. The workpiece is attached in a precision clamp (also coated with Kynar) itself fastened on the stand by two clamps. 
D. ESTIMATES OF EXPERIMENTAL ERRORS

Symbols Absolute Error Relative Error

\begin{tabular}{|c|c|c|c|}
\hline Applied Voltage & $\Delta v$ & \pm 0.1 Volt & $0.4-1 \%$ \\
\hline Current & $\mathrm{I}$ & \pm 0.1 amps & $0.3-1 \%$ \\
\hline Penetration of Tool. & $\delta$ & $\pm 1 \mathrm{mil}$ & $0.2-0.5 \%$ \\
\hline Time & $t$ & $5 \mathrm{sec}$ & $0.3-1 \%^{\% / 6}$ \\
\hline Pressure & $\mathrm{P}$ & $.5 \mathrm{psi}$ & $<1 \%$ \\
\hline $\begin{array}{l}\text { Dimensions } \\
\qquad(\text { diameter and length) }\end{array}$ & $\phi, h$ & $1 \mathrm{mil}$ & $0.1-0.2 \%$ \\
\hline Weight & $M$ & $0.0001 \mathrm{~g}$ & $0.1-0.2 \%$ \\
\hline Temperature & $\mathrm{T}, \mathrm{t}_{1}$ & $0.5^{\circ} \mathrm{C}$ & \\
\hline Density of Electrolyte & $\mathrm{d}$ & 0.00005 & negligible \\
\hline Flow Rate & $\mathrm{Q}$ & 0.05 liter/min & $1 \%$ \\
\hline
\end{tabular}

Resulting experimental errors in combined parameters

$\begin{array}{lllc}\text { Machining rate } & \text { Fr } & \mathrm{cm} / \mathrm{min} & <1 \% \\ \text { Conductivity of electrolyte } & \mathrm{k} & \Omega^{-1} \mathrm{~cm}^{-1} & .5 \% \\ \text { Current density } & i & \mathrm{~A} / \mathrm{cm}^{2} & \leqslant 1 \% \\ \text { Mass removal rate } & \Delta \mathrm{M} & \mathrm{g} / \mathrm{min} & \leqslant 1 \% \\ \text { ECM driving force } & \mathrm{k} \Delta \mathrm{V} / \mathrm{Fr} & \mathrm{Volts} / \Omega \mathrm{cm}^{2} \mathrm{~min} & \leqslant 2 \% \\ \text { ECM gap } & & \operatorname{mils} & 5 \% \\ \text { Electrochemical equivalent } & (\mathrm{A} / \mathrm{z}) & \mathrm{gr} / \text { Faraday } & \leqslant 2 \% \\ \text { Apparent valence of dissolution } & \mathrm{z} & \text { Equiv- é/Mole } & \leqslant 3-4 \%\end{array}$


E. Design of the Toolpieces

E1. Choice of cylindrical geometry

As the shop drill used in this work is constructed to reproduce shapes by vertical downward motion of the cathode tool, cylindrical hole sinking was chosen as the vehicle of this study. Nine experiments could be carried out on each of the flat sides of the $1^{\prime \prime} \times 1^{\prime \prime} \times 1 / 2^{n}$ $(2.54 \times 2.54 \times 1.27 \mathrm{~cm})$ samples. The outside diameter of the holes ranged from 0.7 to $0.9 \mathrm{~cm}$ and the boring depth ranged from 0.4 to $2 \mathrm{cms}$.

\section{E2. General considerations for the design of the toolpieces}

Preliminary experiments carried out using a common toolpiece, featuring a large entxy for the delivery of the electrolyte (design A), were shown not to be reproducible if meaningful at all (see appendix). This tool was used in the computer implemented modeling of the machining process developed by Riggs (31) and permitted the accurate prediction of the profiles of holes sunk in copper and stainless steel.

The tool diameter chosen for the cathode tool had to be such that feed rates up to $2 \mathrm{~mm} / \mathrm{min}$ could be achieved in $T i C$ and $Z x B{ }_{2}$. Because of the high valence of these materials, to keep the current below 50 Amps, the holes diameter had to be approximately $0.7 \mathrm{~cm}$.

The choice of a relatively small hole diameter was also desirable because of the high cost of the carbides and borides employed in this study.

In one of the tool designs, the tubing was cut out of a hollow copper tube (oxygen free copper) and the mounting socket (label 1 on Fig. 6A) was sliced out of a two inch diameter brass rod. In Fig. 6A, 
the 1ip, labeled 3 in Fig. 6A, 5 millimeters upstream from the tool-front served to avoid large pressure drops in the overcut during the machining of very deep holes; the second step, labeled 2 in Fig. $6 \mathrm{~A}$, was intended to divert the flow of the electrolyte exiting from the machining gap, so as to provide a location for the temperature probe, avoiding contact between the toolpiece and the sensing probe. Also, this second step was located as close as possible to the Eront of dissolution in order to obtain exact temperature measurements.

The base part of the toolpiece (labe1 1) was silver soldered to the tubing. The outside surface of the toolpiece was then sandblasted to produce a semi-rough surface and then polished on a lathe with 400 abrasive paper.

Last1y, the two steps were rounded to ensure better adherence of the coating. The entire toolpiece was thoroughly washed with detergent and hot water to remove all traces of grease, then dried with acetone and finally cleaned with methyl-isobutyl ketone. The outside of the toolpiece was then coated with KYNAR, a vynilidene fluoride resin. The coating was applied by spraying the resin mixed with methy 1 -isobuty 1 ketone $(1: 1)$ at $30 / 35$ psi by means of a sma11 spray gun. The resin was cured at $180^{\circ} \mathrm{C}$ for 10 minutes and then at $240^{\circ} \mathrm{C}$ for 15 minutes. Three coatings were successively applied, resulting in a $0.2-0.3 \mathrm{~mm}$ layer of insulation on the sides of the toolpieces. The insulation coating was finally examined under microscope for evenness. 
As shown on Figure $6 \mathrm{~A}$ the simple design A features only two components: the mounting socker and the hollow tube with the sma11 step at the tip of the machining area. The more complicated shape of design B (multiple feed holes) needed three components: the mounting socket, the hollow tube like in design A and a third piece: the tip of the cathode. This third component was machined with the aid of a jig (Fig. 7 bottom) made especially to drill the five feed holes before soldering it to the toolpiece. The tip of the cathode, cut from a $1 / 4^{\prime \prime}$ outside diameter $(0.635 \mathrm{~cm})$ copper rod, was clamped in the $j i g$ after facing $j$ t off and the five $1 \mathrm{~mm}$ moles were easily drilled with a hand drill.

The ECM configuration of the toolpiece and the workpiece is shown on Figure $6 B$, representing a vertical cross section during machining. The arrangement of the toolpiece in the cutting chamber is depicted in Figure 9. 
IV. RESULTS

A. Presentation of the Results

The rate of dissolution, $\Delta M$ in mass unit is represented by equation 1 for a pure element:

$$
\Delta M=\frac{1}{F}\left(\frac{A}{z}\right) \text { In }
$$

$$
\text { where } \begin{aligned}
A & =\text { molecular weight of the element } \\
z & =\text { valence of dissolution } \\
F & =\text { Faraday's constant ( } 96500 \text { coulombs) } \\
\eta & =\text { efficiency of the reaction assumed to be } 1 .
\end{aligned}
$$

In this equation, the ratio $\mathrm{A} / \mathrm{z}$ is the electrochenical equivalent of the element for the reaction, and represents the number of electrons used to dissolve one mole of the element. It depends on the products of the dissolution reaction.

Applying this equation for a compound of formula $\mathrm{XaYb}$, requires the knowledge of the electrochemical equivalent; it is determined by the following way: $a, f_{x}$ and $A_{x x}$ are the stoichiometry, the mass fraction and the molecular weight respectively, of the element $\mathrm{X}$ present in the material. It is assumed that the valence of dissolution of the element $X$ is $z_{x}$ and also that the dissolution of the material occurs in proportion to the presence of each element in the compound (no preferential dissolution of a constituent). The total electrical charge required to dissolve one mole of the material is: 


$$
\begin{gathered}
\frac{z}{A}=\left(\frac{z_{x}}{A_{x}}\right) f_{x}+\left(\frac{z_{y}}{A_{y}}\right) f_{y} \\
\text { also } \frac{f_{x}}{a A_{x}}=\frac{f_{y}}{b A_{y}}=\frac{f_{x}+f_{y}}{a A_{x}+b A_{y}}=\frac{1}{a A_{x}+b A_{y}} \\
\text { thus }\left(\frac{A}{z}\right)=\frac{1}{\left(\frac{z_{x}}{A_{x x}}\right) f_{x}+\left(\frac{z_{y}}{A_{y}}\right) f_{y}}=\frac{\bar{A}}{a z_{x x}+b z_{y}}
\end{gathered}
$$

where $\bar{A}$ is the formula weight of the material $\left(\bar{A}=a A_{x}+b A_{y}\right)$. Equation (4) yields the electrochemical equivalent for the material and is reported in equation (1) to calculate the theoretical lines shown in the results by:

$$
\Delta M=\frac{1}{F}\left(\frac{\bar{A}}{a z_{x}+b z_{y}}\right) I \text {. }
$$

The average dissolution rate of a material is determined from the experiments by the relation:

$$
\Delta M=\frac{M \text { before }-M \text { after }}{t}
$$

where $t$ represents the duration of the experiment. The amount of material dissolved is determined experimentally by the difference in weight before and after the run or by a measurement of the volume dissolved:

$$
\Delta M=h\left(\frac{S d}{t}\right)
$$


$h$ and $S$ are the depth and the cross sectional area of the hole drilled and $d$ the density of the material. Combining equation 1 and 7 , the average tool feed rate is:

$$
\begin{gathered}
F x=\frac{h}{\mathrm{t}}=\frac{\Delta M}{\mathrm{Sd}} \\
F r=\frac{1}{F}\left(\frac{\vec{A}}{a z_{x}+b z_{y}}\right) \frac{I}{S d} \text { (9) } / F r=\frac{1}{F d}\left(\frac{\vec{A}}{a z_{x}+b z_{y}}\right) i
\end{gathered}
$$

where $i=I / S$ represents the current density during the experiment based on the cross sectional area of the hole.

a) Apparent electrochemical equivalent: The results axe presented separately for each material in the two electrolytes used. In order to determine the electrochemical behavior of these materials, the apparent electrochenical equivalent ( $A / z$ in gram per Faxaday) and the valence of dissolution ( $z$ in equivalent-electron per mole) are plotted versus the current density. The experimental correlations (machining rates and dissolution rates) are represented by a least square fit method and the theoretical lines (eq. 10 and 5) corresponding to Faraday's law for known valences of dissolution are also indicated.

b) Frontal gap of dissolution: The frontal gap (a1so referred to as the "machining" or the "ECM gap") of dissolution was plotted versus the current density for different applied voltages and also versus the ECM driving force $(k \Delta V / F r)$. The gap measurements were made after ECM operation using the procedure described in next section.

c) Current-voltage relation: The electrochemical behavior of the different materials is described in terms of polarization. The 
derivation of valid current-voltage curves requires consideration of the electrode separation or frontal gap, which depends on the operating conditions. Since the applied voltage and the tool feed rate (thereby the current) are the only paraneters controlled in this work, it was not possible to control the gap. However, the determination of the size of the gap is possible after ECM operation, by the following experimental procedure:

If $\delta$ is the total movement of the toolplece, S.G. the starting gap set before operation and $h$ the depth of the hole drilled, the frontal gap of dissolution is given by the relation

$$
\mathrm{ECM} \text { gap }=h+\mathrm{S} \cdot \mathrm{G} \cdot-\delta
$$

The resulting error for the difference between these two similar numbers ( $h$ and $\delta$ ) is estimated to be below $8 \%$. The absolute error is .5 mil for (ram dial used on the apparatus), 1 mil for the depth of the hole (accuracy of the caliper) and less than .5 mil for the starting gap (copper precision foil). The depth of the hole was averaged on four or five different measures, neglecting the height of the small peaks left on the anodic surface after operation, and assuming the surface morphology of the bottom of the hole to be flat.

Thus the ECM gap is determined for each experimental run. The collection of data related to the same value of the gap, allows the determination of the relationship between the current and the voltage for each material.

The ohmic drops in the electrolyte were calculated (equation 20) under the assumption of a parallel plates configuration, and are also 
shown on these figures. The conductivity of the electrolytes have been chosen for an average temperature of $27^{\circ} \mathrm{C}$ for $2 \mathrm{~N} \mathrm{KNO}_{3}$ and $3 \mathrm{~N}$ $\mathrm{NaCl}\left(0.179\right.$ and $0.231 \Omega^{1} \mathrm{~cm}^{-1}$ respectively),

$$
I R=I \rho \frac{l}{S}=i \frac{l}{k}=\frac{i}{k}(\text { ECM gap }) .
$$

The extrapolation of the current-voltage curves to zero current density for each material assumes an independence of the overpotential (passivation, concentration) on the current density and that the activation overpotential is only a small fraction of the applied voltage. This is not exactly true for the small values of applied voltages (10 Volts) but the figures obtained for the overall overvoltages are in agreement with the observations made during this work and correspond to the values expected for these materials if they showed a simflax behavior to that of their separate constituants. The impossibility of carrying out experiments at low voltages was due to the cechnical limitations of the apparatus: at the lowest available feed rate, an "equilibrium" gap could not be attained. In these experiments, below $10 \mathrm{~V}$ for $\mathrm{TiC}$ and $\mathrm{ZrC}$ and below 15 Volts for $\mathrm{TiB}_{2}$ and $\mathrm{ZrB}_{2}$, sparking due to the contact between the electrodes was observed.

The interpolations possible between the different plots related to the machining gap, were proven to be In agreement with each other (see for example the case of $\mathrm{ZrB}_{2}$ in $\mathrm{KNO}_{3}$ ). 


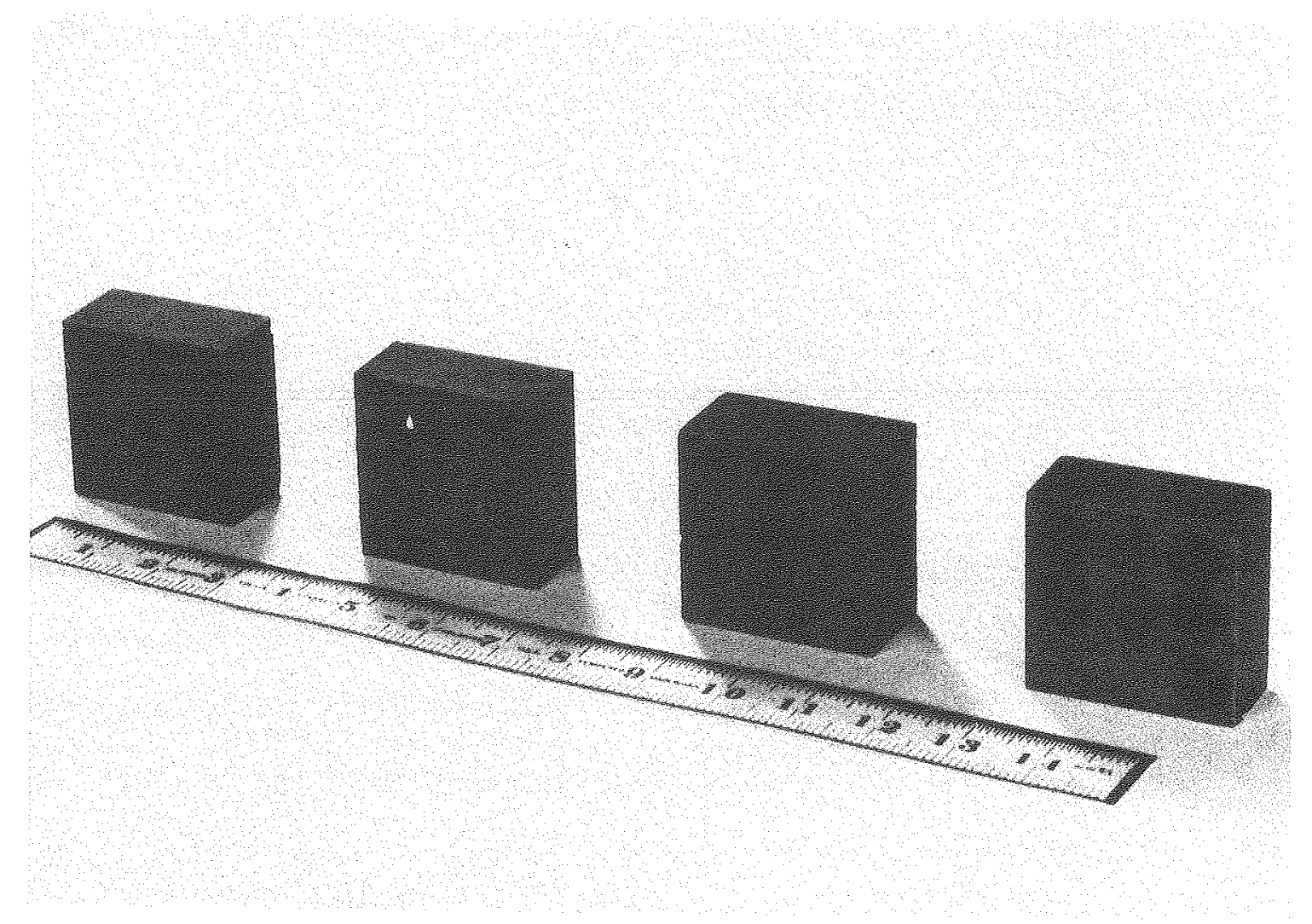

XBB $784-4796$

Figure 10. View of the holes drilled, from left to right: ZrC, TiC, $\mathrm{TiB}_{2}, \mathrm{ZrB}_{2}$ 。 


\section{B. Titanium Carbide}

B1. Apparent electrochemical equivalent and valence of dissolution

The machining rate $(F r)$ and the mass removal rate $(\triangle M)$ are plotted respectively versus the current density $i$ and the current $I$.

The two quantities are derived from two different experimental informations: the slope of the toolpiece advancement on the recording chart gives an instantaneous measure of the machining rate, whereas the weight loss measurements yields an averaged dissolution rate for the experiment. The experimental correlations (1abels [X] on Figs. 11 and 12), obtained for the two figures, clearly show that the same chemical reaction is involved in the process and that the process occurs with the same apparent valence of dissolution, regardless of the electrolyte and throughout the range of current density investigated.

The theoretical lines added to the figures are calculated from equations (10) and (5) and correspond to a dissolution process reaction occurring with a known apparent valence of dissolution: 4 electrons (label a), 6 electrons (label b) and 8 electrons (label c). The experimental correlation being between the 6 and the 8 electron processes.

$$
\begin{aligned}
& F x=(A / z) \frac{1}{F d} i \\
& \Delta M=(A / z) \frac{1}{F} I .
\end{aligned}
$$

The slope of the experimental correlation representing the machining rate versus the current density yields the electrochemical equivalent ( $A / z$ in gram/faraday) for the overall reaction of dissolution by the equation: 


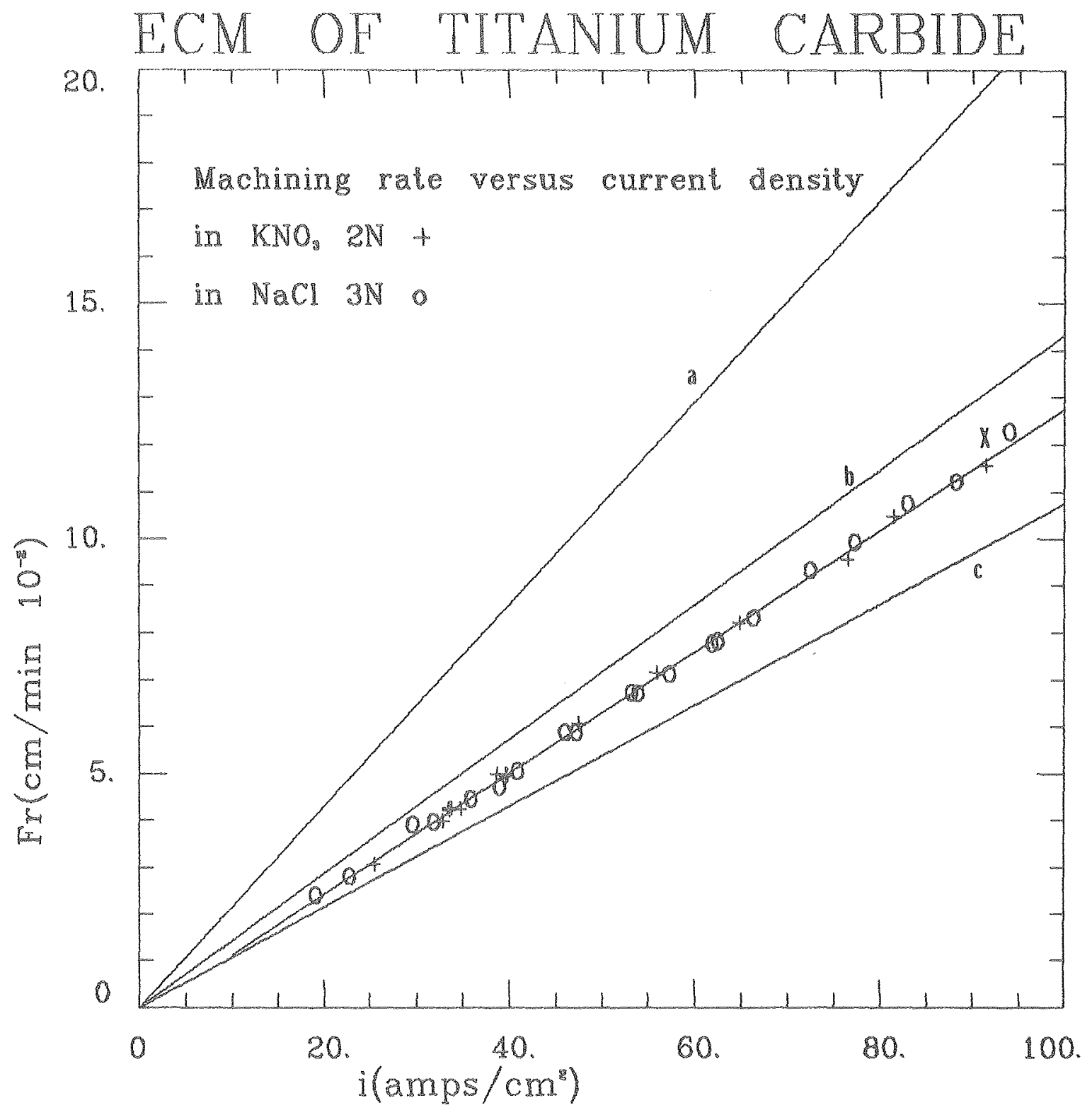

XBL $785-8621$

Figure 11. Machining rate versus current density for TiC. Experimental correlation, line $\mathrm{x}$.

Theoretical lines: a) 4 electron process

b) 6 electron process

c) 8 electron process 


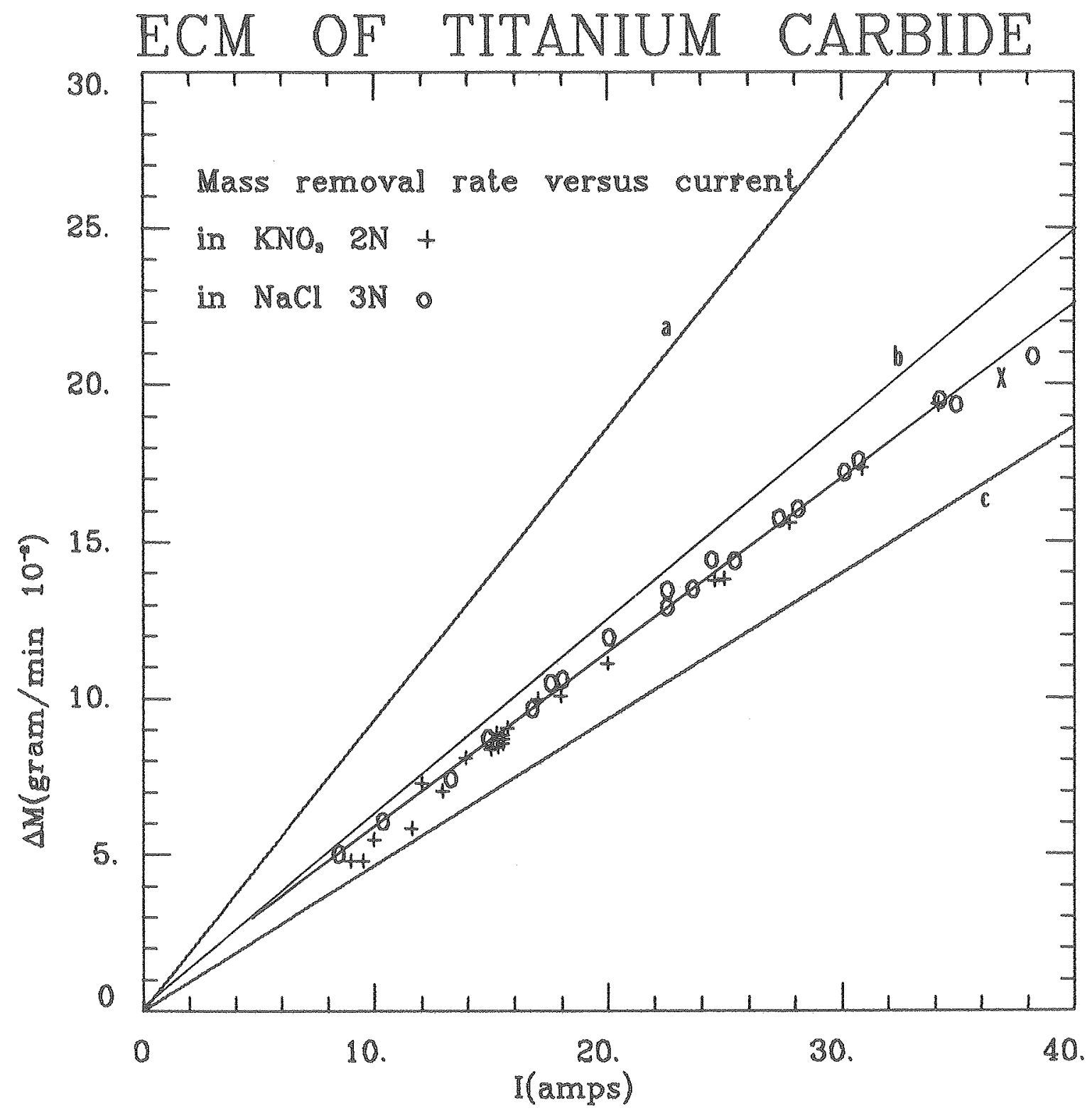

XBL 785-8622

Figure 12. Dissolution rate versus current for TiC. Theoretical and expeximental lines same as figure 11. (Note the runs 70 to 74 at 16 Amps and $8.510^{-2} \mathrm{gram} / \mathrm{min}$ corresponding to different flow rate.) 


$$
A / z=\left(\frac{E x}{i}\right) \frac{E^{\cdot d}}{60}
$$

d is the density of the material (in gram/cc), Fr the machining rate in $\mathrm{cm} / \mathrm{min} ; 60$ is used to convert the units from second to minute.

A similar result is obtained from the slope of the mass removal rate versus the current by the relation

$$
A / Z=\left(\frac{\Delta M}{I}\right) \frac{F}{60}
$$

The two different quantities on the right hand side of the relations (12) and (13) are measured by different experimental methods, and the two results are found to agree with each other within the

\begin{tabular}{|c|c|c|}
\hline TiC & Fr vs $i$ & $\Delta M$ vS I \\
\hline $\begin{array}{l}\text { slope of correlation } \\
\text { (1ines X on Figs. } 11 \& 12 \text { ) }\end{array}$ & $\begin{array}{l}0.12910^{-2} \\
\mathrm{~cm}^{3} / \text { Amps. min. }\end{array}$ & $\begin{array}{l}0.55710^{-2} \\
\text { gram/min. Amps. }\end{array}$ \\
\hline $\begin{array}{c}\mathrm{A} / \mathrm{z} \\
\text { In gram/Faraday } \\
\text { (experimental error) }\end{array}$ & $8.98 \pm 0.18$ & $8.95 \pm 0.17$ \\
\hline $\begin{array}{l}\text { apparent valence of } \\
\text { dissolution }\end{array}$ & $6.67 \pm 0.15$ & $6.69 \pm 0.14$ \\
\hline average on 2 methods & \multicolumn{2}{|c|}{$6.7 \pm 0.2$} \\
\hline
\end{tabular}
experimental error, as shown on the following table:

Table III. Observed apparent valence of dissolution for TiC in $\mathrm{KNO}_{3}$ and $\mathrm{NaCl}$. 


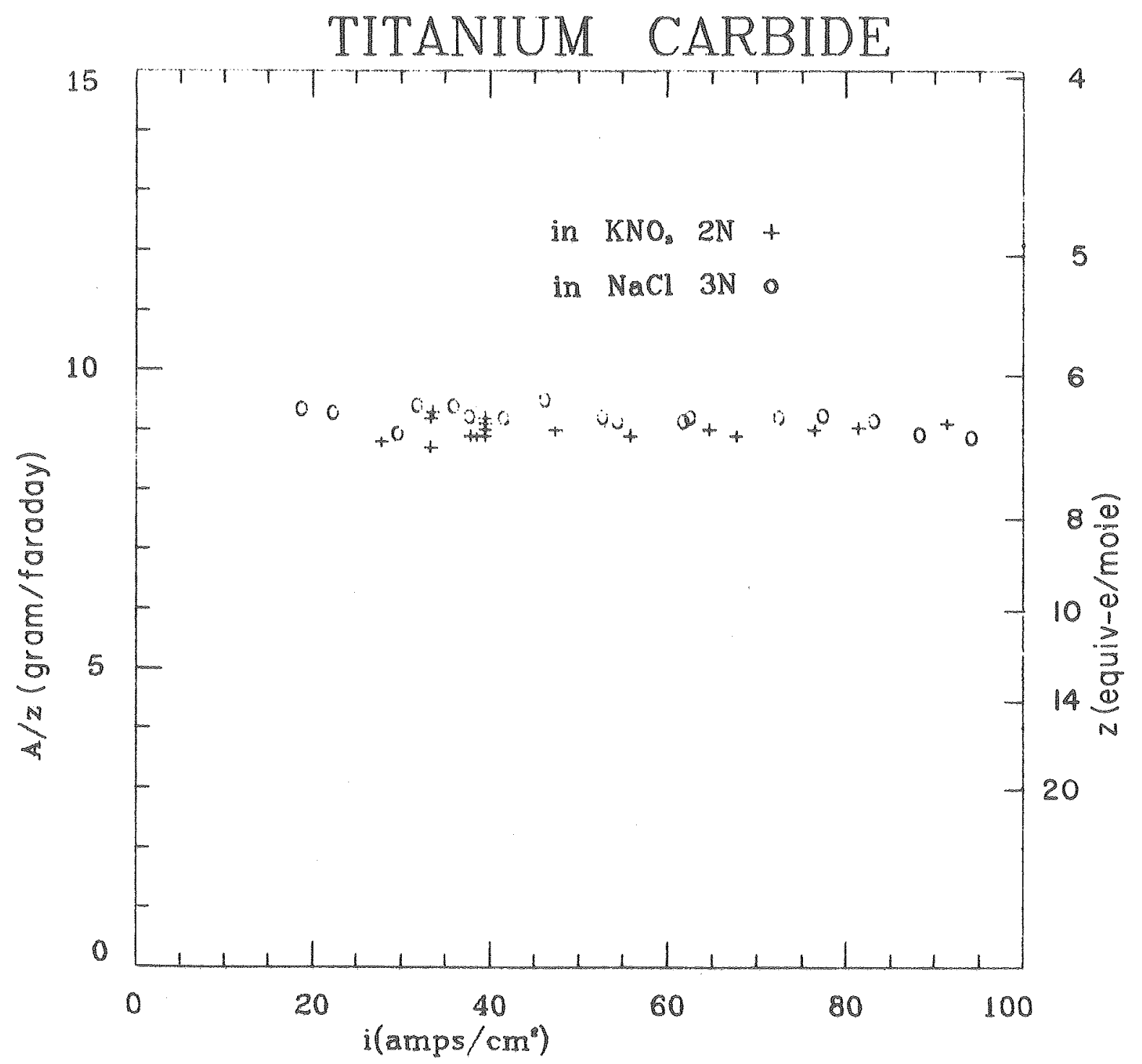

XBL. $785-8783$

Figure 13. Electrochemical equivalent $(\mathrm{A} / \mathrm{z})$ and apparent valence $(\mathrm{z})$ versus current density for TIC. 
The combined experimental exror on $(A / z)$ is in the range of $2 \%$ and the error on the apparent valence of dissolution is given by an. average on the two experimental results.

Figure 13 shows the electrochemical equivalent and the valence observed for the process versus the current density. It also indicates the independence of the electrochemical behavior of titanium carbide on the electrolyte. The apparent valence of dissolution is determined to be $6.7 \pm 0.2$, in $\mathrm{NaCl}$ as well as in $\mathrm{KNO}_{3}$.

\section{B2. Frontal gap of dissolution}

The machining gap is shown to be dependent on the current density for a given applied voltage (Fig. 15) and also on the ECM dxiving force (Fig. 14).

The grouping $\mathrm{k} \Delta \mathrm{V} / \mathrm{Fr}$ represents the driving force and is used to correlate the frontal gap of dissolution to the operating variables controlled during ECM operation. Thus, a large driving force corresponds to a high applied voltage or a low machining rate. The correlation on Fig. 14, 1inear for the two different electrolytes and within the range of the experimental exror, is independent of the electrolyte. The data are measured experimentally and include the vaxiations of conductivity with the observed temperature during the runs.

If $\mathrm{d}$ and $t_{1}$ are the initial density and temperature of the electrolyte in the main tank before the experiment and T the medium temperature of the electrolyte (measured at the outlet of the machining section and linearly averaged from the beginning to the end of the run), the electrolyte conductivity in the ECM gap is given by equation (14) 


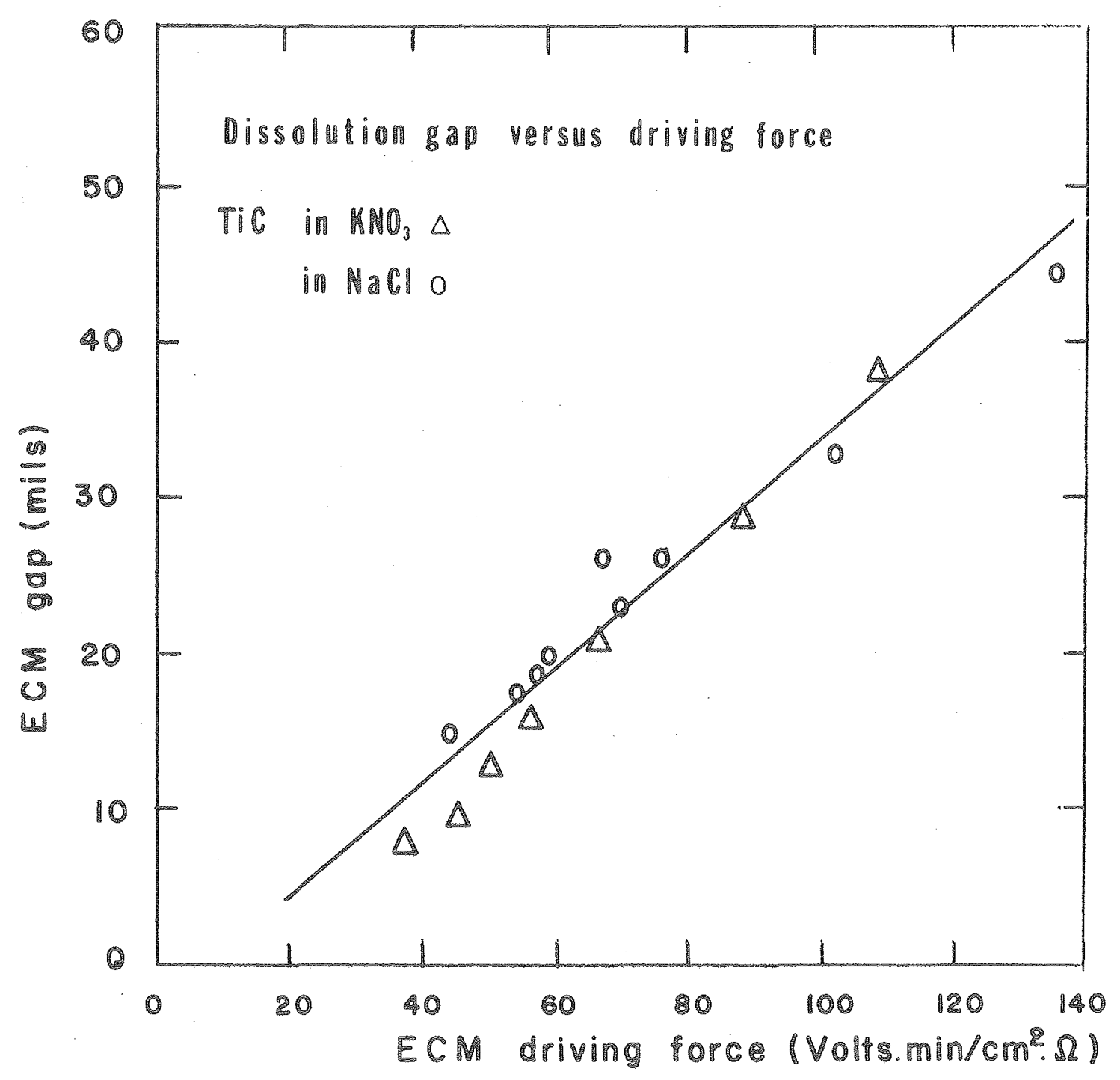

XBL 786-9264

Figure 14. Frontal gap of dissolution versus the ECM driving force. 


$$
k=\left[0.9981 \mathrm{a}\left(\mathrm{sp} \cdot \mathrm{gr} \cdot \mathrm{at} \mathrm{t}_{1}\right)-\mathrm{b}\right] \exp 0.025\left(\mathrm{~T}-20^{\circ} \mathrm{C}\right)
$$

where a (function of $t_{1}$ ) and $b$ (constant) are specific characteristics relating the density ( $\mathrm{sp} \cdot \mathrm{gr}$ 。) of the electrolyte to its conductivity (62).

The fact that the lineax correlation does not pass through the origin shows that the ECM driving force expression cannot be used below 10-15 mils "equilibrium" gap. Referring to the operating conditions, this indicates that there is an upper limit for the feed rate for this material, at a given applied voltage.

The same limiting effect is observed on the Fig. 15. The machining gap is plotted versus the current density (thereby the tool feed rate since these two variables are related) for different applied voltages. As deduced from this figure, the machining gap decreases with the current density and by extrapolation reaches a zero value, where ECM operation is practically impossible, at a given current density different for each value of the applied voltage.

In addition to the experimental correlations of Fig. 15, the theoretical gap values are represented by the broken lines; they are derived from equation 15 under the two following assumptions yielding equation 16:

1) The conductivity of the electrolyte remains constant during the experiment. (This assumption is justified for most of the experiments where the observed change of temperature is below $0.5^{\circ} \mathrm{C}$ except for runs at low flow rates.)

2) The sum $n$ of the electrodes potentials and overpotentials is a small fraction of the applied voltage $\Delta V$, and Ohm's law applies 


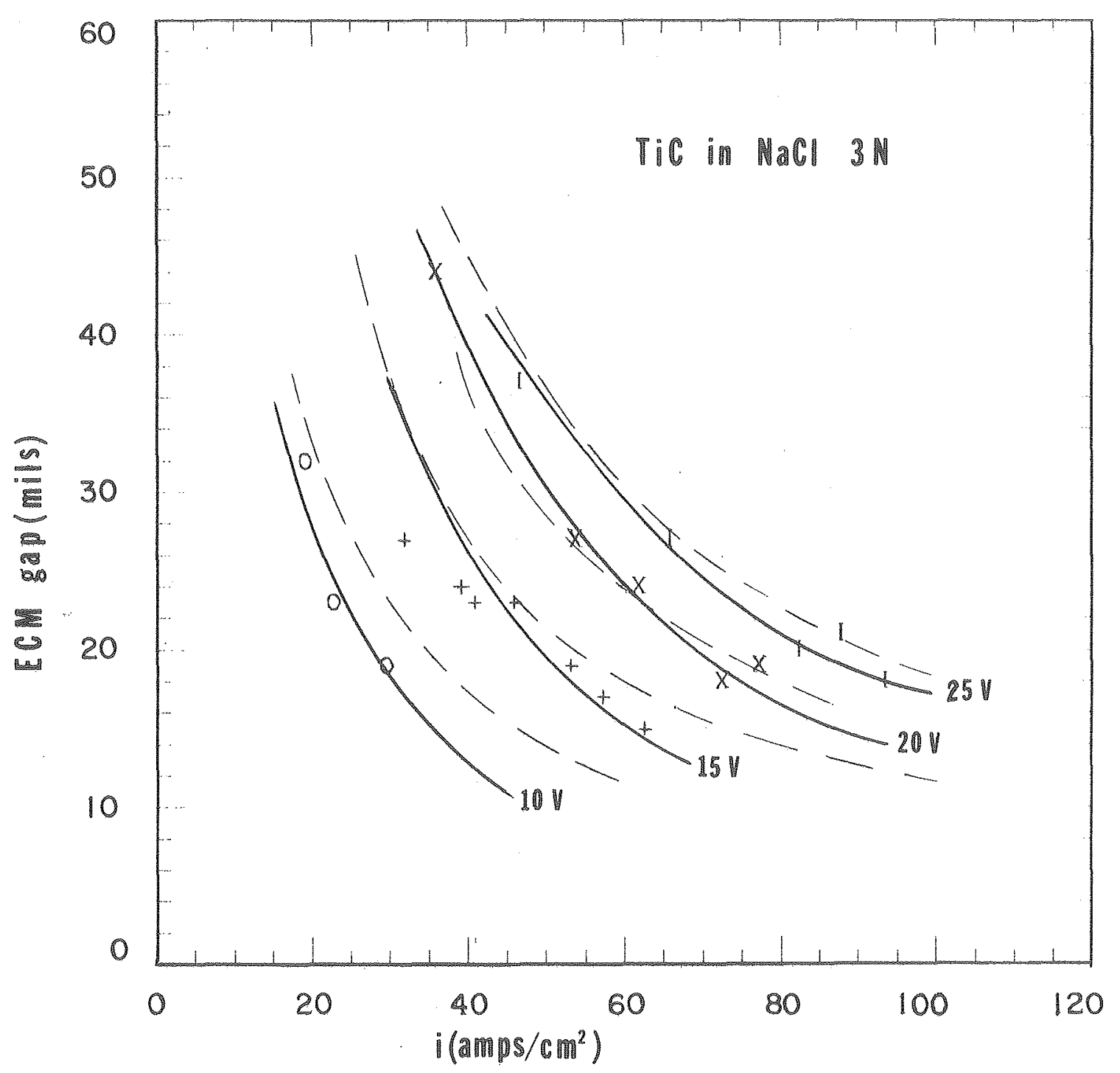

XBL $785-8623$

Figure 15. Frontal gap of dissolution for $\mathrm{TiC}$ in $3 \mathrm{~N}$ NaCl versus the current density for different applied voltages. Experimental data at 10 Volts $(0), 15$ Volts $(t), 20$ Volts $(X)$, and 25 Volts (I). The broken curves represent the theoretical correlations (equation 17). 
to the remaining voltage $(\Delta V-\eta)$.

Thus,

$$
(\Delta V-\eta)=\operatorname{IR}(I / S) \cdot\left(\frac{l}{k}\right)
$$

where $k$ represents the conductivity of the electrolyte, $s$ the anodic surface machined on the material. $l$, the front gap of dissolution or the distance between the toolpiece and the workpiece during ECM operation at steady state is then calculated by equation (16)

$$
\text { ECM gap }=k \frac{(\Delta V-\eta)}{i} .
$$

The accumulated exrors on the experimental results obtained by equation 11 are somewhat large ( \pm 1 mil) for small gaps.

$$
\mathrm{ECM} \text { gap }=h+\mathrm{S}_{0} \mathrm{G}_{0}-\delta .
$$

However, Fig. 15 shows a general behavior fairly close to the theoretical correlations (broken lines) using equation (16); except for the low applied voltages (10 Volts) where the assumption made by ignoring $\eta$ with respect to $\Delta V$ is less justified: since Tafel's law applies, the overvoltage associated with the activation energy of the reaction, proportional to the logarithm of the current density, cannot be considered as negligible with respect to the applied voltage in equation 16. 


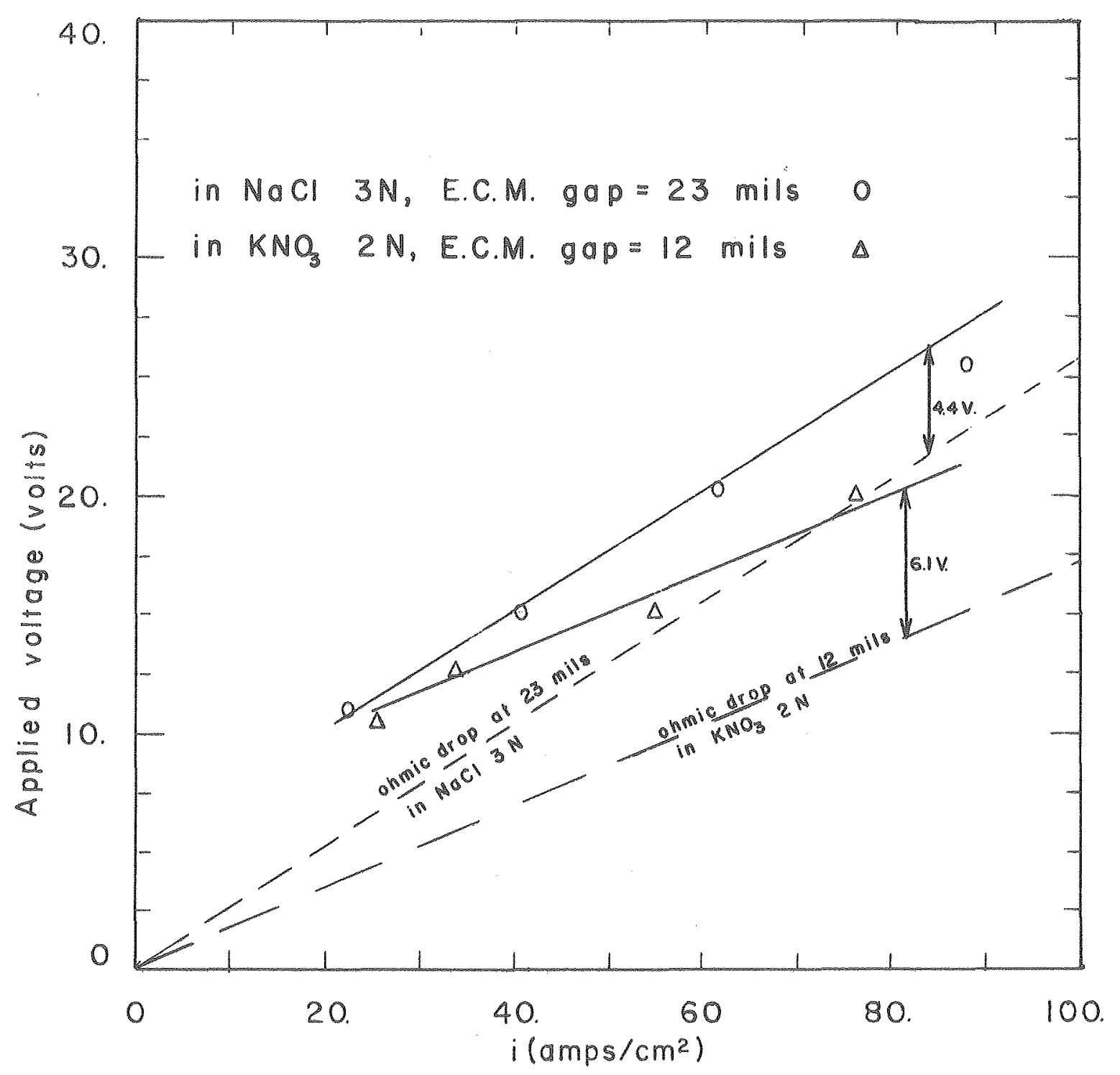

XBL 785-8734

Figure 16. Polarization curve for TiC in $\mathrm{KNO}_{3}(\Delta)$ and NaC1 (0) at different ECM gaps. 


\section{B3. Current-voltage relationship}

The relationship between the current density and the cell voltage is exploxed in the two electrolytes. The curves on Figs. 16 correspond to two different values of the frontal gap of dissolution, one for each electrolyte used, as listed in Table IV.

Since the machining gap is not a parameter controlled during the operation, the current-voltage curve is established after the experiments, by using equation 11 for each run. The collected data listed in Table IV thus correspond to a certain value of the ECM gap in the electrolyte used (for TiC, 12 mils in NaCl and 23 mils in $\left.\mathrm{KNO}_{3}\right)$.

\begin{tabular}{|c|c|c|c|c|c|}
\hline \multirow{2}{*}{$\begin{array}{l}\text { ECM gap }=23 \text { mils } \\
\text { in } \mathrm{KNO}_{3} 2 \mathrm{~N} \\
\Omega \mathrm{drop}=0.170 \mathrm{i}\end{array}$} & $\begin{array}{c}\Delta V \\
\text { (Volts) }\end{array}$ & 10.3 & 12.7 & 14.6 & 20.1 \\
\hline & $\begin{array}{c}i \\
\left(\mathrm{~A} / \mathrm{cm}^{2}\right)\end{array}$ & 25.4 & 33.5 & 55.9 & 76.5 \\
\hline \multirow{2}{*}{$\begin{array}{l}\text { ECM gap }=12 \text { mils } \\
\text { in NaC1 } 3 \mathrm{~N} \\
\Omega \text { drop }=0.254 i\end{array}$} & $\begin{array}{c}\Delta V \\
\text { (Vo1ts) }\end{array}$ & 11.0 & 15.0 & 20.1 & 25.1 \\
\hline & $\left(\mathrm{A} / \mathrm{Cm}^{2}\right)$ & 22.9 & 41.0 & 62.0 & 88.4 \\
\hline
\end{tabular}

Table IV: Experimental data for the current-voltage relationship of $\mathrm{TiC}$ in $\mathrm{KNO}_{3}$ and $\mathrm{NaCl}$.

Figure 16 indicates that the experimental line has a similar slope than the ohmic drop and that the sum of the overpotentials, (5-6 Volts: activation, surface, concentration, etc.) is almost constant for the dissolution reaction throughout the range of current densities 
in the two electrolytes investigated. It is noticed also that the overpotential of dissolution is largex in $\mathrm{KNO}_{3}$ than in $\mathrm{NaCl}$, (size of the arrows in Fig. 16), this difference is due to the electrolyte: NaCl is known (23) co have a stronger action than $\mathrm{KNO}_{3}$ on the oxide films formed; this is consistent with the present observations.

\section{B4. Surface roughness; effect of the flow conditions}

As the main concern in machining materials is not only which techniques are available to reproduce similar shapes, but also to meet specific characteristics such as dimensions, tolerances and appearance of the surface, the surface finish is thought to be an interesting parameter to investigate.

It is known that, using traditional machining techniques $(37,38)$, the surface of the material machined is altered and the residual stresses induced can significantly affect the mechanical properties of the material. Since ECM is achieved without contact between the tool and the workpiece, the properties of the materials are not altered.

For comparison, Kuhn (40) clains that surface finishes in the range of 0.4 to $1.5 \mu \mathrm{m}$ for forged or rolled steels and nickel chrome alloys, and 1 to 2 um for cast irons and cast nickel chrome alloys, are figures attainable.

In the investigation of ECM of tungsten carbides in nitratealkaline solutions, Petrov and Parshutin (41) showed that the more uniform the structure of the sintered carbide (or for the composites of low cobalt content), the better surface finish attainable. The same 
EFFECT OF FLOW RATE ON ECM PARAMETERS

TjC in $2 \mathrm{~N} \mathrm{KNO}_{3}$

\begin{tabular}{|c|c|c|c|c|c|c|}
\hline $\begin{array}{c}\text { Run } \\
\#\end{array}$ & $\begin{array}{c}\mathrm{V} \\
(\operatorname{volts})\end{array}$ & $\begin{array}{l}\text { Fr } \\
\left(10^{-2} \mathrm{~cm} / \mathrm{min}\right)\end{array}$ & $\begin{array}{l}\text { le } \phi \\
(\mathrm{cm})\end{array}$ & $\begin{array}{l}I \\
\text { (amps) }\end{array}$ & $\stackrel{i}{\left(\operatorname{amps} / \mathrm{cm}^{2}\right)}$ & $\begin{array}{c}\mathrm{M} \\
\left(10^{-2} \operatorname{gram} / \mathrm{min}\right)\end{array}$ \\
\hline 70 & 15.2 & 4.98 & 0.710 & 15.3 & 38.6 & 8.44 \\
\hline 7.1 & 15.1 & 4.98 & 0.7110 & 15.5 & 39.6 & 8.90 \\
\hline 72 & 15.2 & 4.99 & 0.710 & 15.5 & 39.6 & 8.81 \\
\hline 73 & 15.2 & 4.95 & 0.710 & 15.5 & 39.6 & 8.53 \\
\hline 74 & 15,1 & 4.96 & 0.710 & 15.7 & 39.7 & 8.62 \\
\hline
\end{tabular}

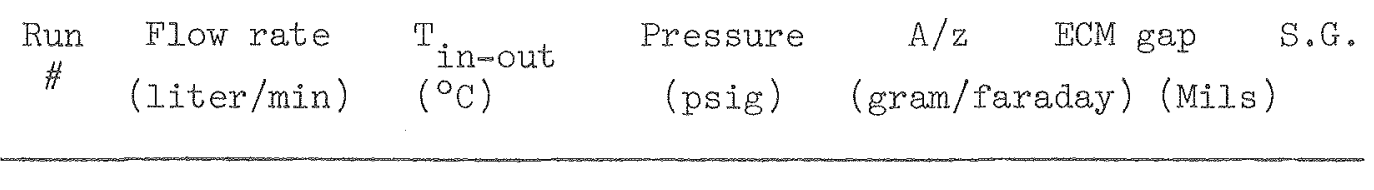

$\begin{array}{rrrrrrr}70 & 4.98 & .5^{\circ} \mathrm{C} & 84 & 8.9 & 14 & 12 \\ 71 & 4.62 & .5^{\circ} \mathrm{C} & 68 & 9.2 & 17 & 7 \\ 72 & 3.23 & .8^{\circ} \mathrm{C} & 46 & 9.1 & 17 & 7 \\ 73 & 2.70 & 1.0^{\circ} \mathrm{C} & 32 & 8.9 & 17 & 7 \\ 74 & 1.76 & 2.3^{\circ} \mathrm{C} & 15 & 8.8 & 17 & 12\end{array}$

Table V. ECM parameters for the runs 70 to 74 ; influence of the flow rate on the ECM of $\mathrm{TiC}$ in $2 \mathrm{~N} \mathrm{KNO}_{3}$. Toolpiece \# $\mathrm{B} 125$, outside diameter $=0.645 \mathrm{~cm}$ with $0.2 \mathrm{~mm}$ coating. 

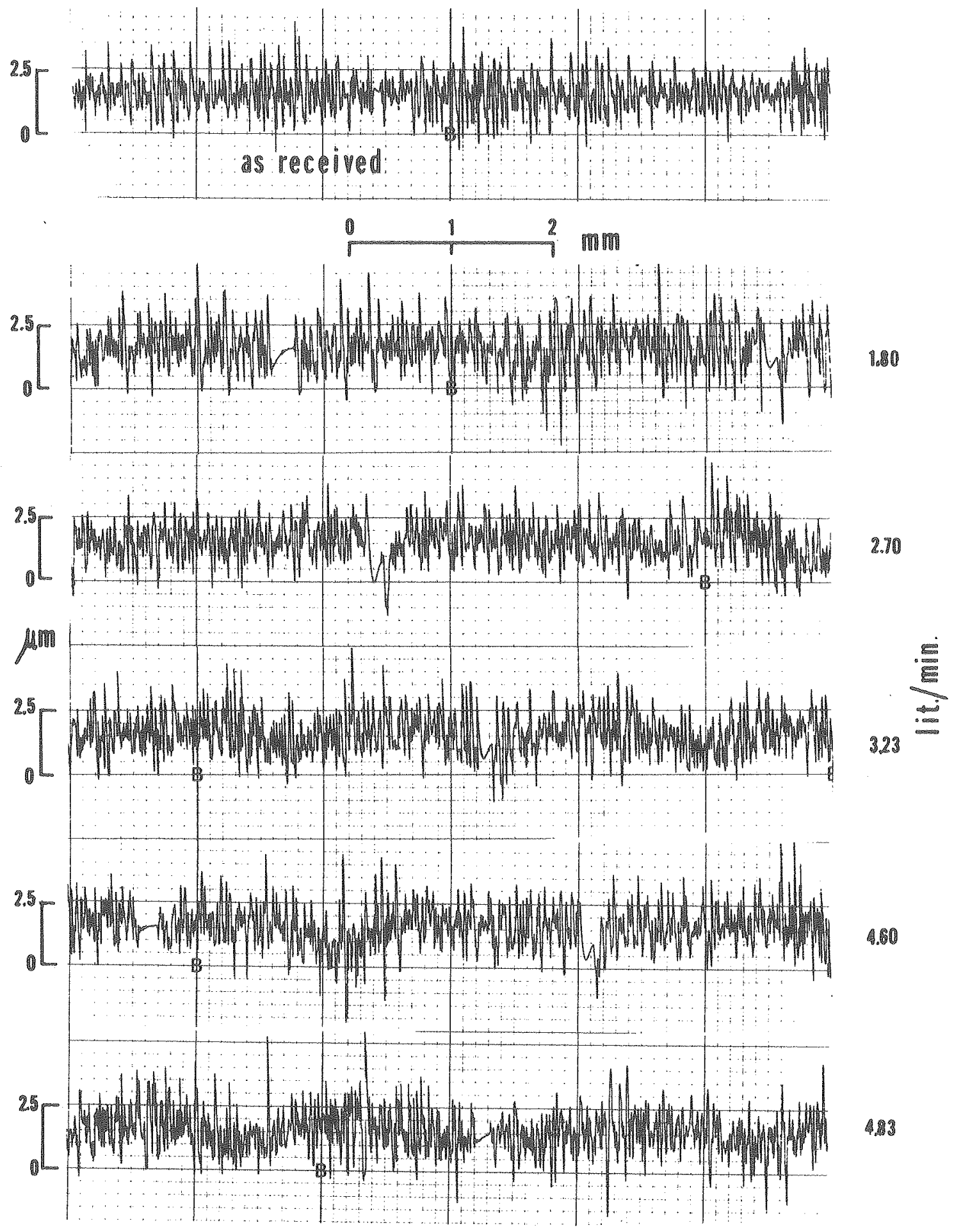

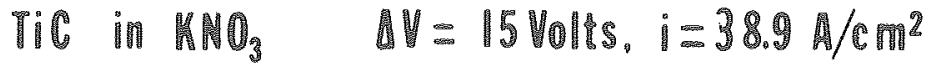

XBL 785-8876

Figure 17. Effect of the flow rate on the surface roughness of ECM"d parts: traces of the bottoms of the holes on TiC in $\mathrm{KNO}_{3}$. Toolpiece \#B 125. 
authors show that the choice of the electrolyte has a great influence on the surface finish, while other operating variables, such as current density or applied voltage, had less influence.

Figure 17 shows the effect of the flow conditions on the surface finish obtained on paxts of titanium carbide machined in $2 \mathrm{~N}$ potassium nitrate. The surface roughness obtained on TiC is within 3-4 $4 \mathrm{~m}$ in $\mathrm{KNO}_{3}$. All the operating conditions are maintained constant except the flow rate: 15 Volts and an inlet temperature of $25^{\circ} \mathrm{C}$ $\left(\mathrm{KNO}_{3} 2 \mathrm{~N} ; 0.145 \Omega^{-1} \mathrm{~cm}^{-1}\right)$, the tool feed rate is $4.4810^{-2} \mathrm{~cm} / \mathrm{min}$. The same toolpiece and the usual procedure (described in Chapter III) were used during these experiments.

The surface profile and roughness data were determined by a surface analyzer* ${ }^{*}$, using a special probe to be able to trace the surface of the bottoms of the holes drilled.

The result in Fig. 17, listed in Table $V$ clearly shows that the surface roughness is independent of the flow conditions. Furthermore, the difference relative to the findings of Bannard (42), showing that the dissolution efficiency of mild steel under ECM conditions in NaCl depends on the flow conditions is evident: it is supported by the observation of Figs. 11 and 12 where the expeximental data corresponding to the runs 70 to 75 are not scattered and lie within the range of the experimental error $\left(F r=4.4310^{-2} \mathrm{~cm} / \mathrm{min}, \Delta M=8.910^{-2} \mathrm{~g} / \mathrm{min}\right.$, $I=15$ Amps., $i=35 \mathrm{~A} / \mathrm{cm}^{2}$ ). These do not reflect the drop in efficiency

\footnotetext{
* Skidless surfanalyzer system, Model 21, Clevite Corporation.
} 
observed with mild steel in different electrolytes ( $\mathrm{NaCl}, \mathrm{NaNO}_{3}, \mathrm{NaClO}_{3}$ )。 The difference is explained by the fact that this drop in efficiency was mainly observed by Bannard (42) at current densities below $20 \mathrm{~A} / \mathrm{cm}^{2}$, while in this work, due to the technical limitations of the equipment, the lowest tool feed rate was $2.510^{-2} \mathrm{~cm} / \mathrm{min}$ corresponding to $25 \mathrm{~A} / \mathrm{cm}^{2}$ for TiC.

\section{B5. SEM microphotographs: effect of the current density}

Figure 18 shows the typical appearance of the areas of the bottom surface of the holes drilled in titanium carbide by ECM using potassium nitrate as electrolyte. The two series of microphotographs represent the same area at different magnification (from top to bottom) and at two different current densities $\left(21.7\right.$ and $68.1 \mathrm{~A} / \mathrm{cm}^{2}$ ) corresponding respectively to a toolpiece feed rate of 2.50 at 15 Volts and $8.5010^{-2}$ $\mathrm{cm} / \mathrm{min}$ at 25 Volts (from left to right). The surface as received is also included for comparison.

A careful examination of the pictures shows that the current density does not affect the appearance of the machined areas, and that there are two different structures left on the surface after ECM: one consisting of large grains with a pitted appearance (top of the lower left corner of the photograph at $2000 x$ magnification), the other, small sized grain structure accounting for the etching of the surface by the electrolyte. However, the appearance of the surface is shown to be independent of the current density as well as of the applied voltage. 


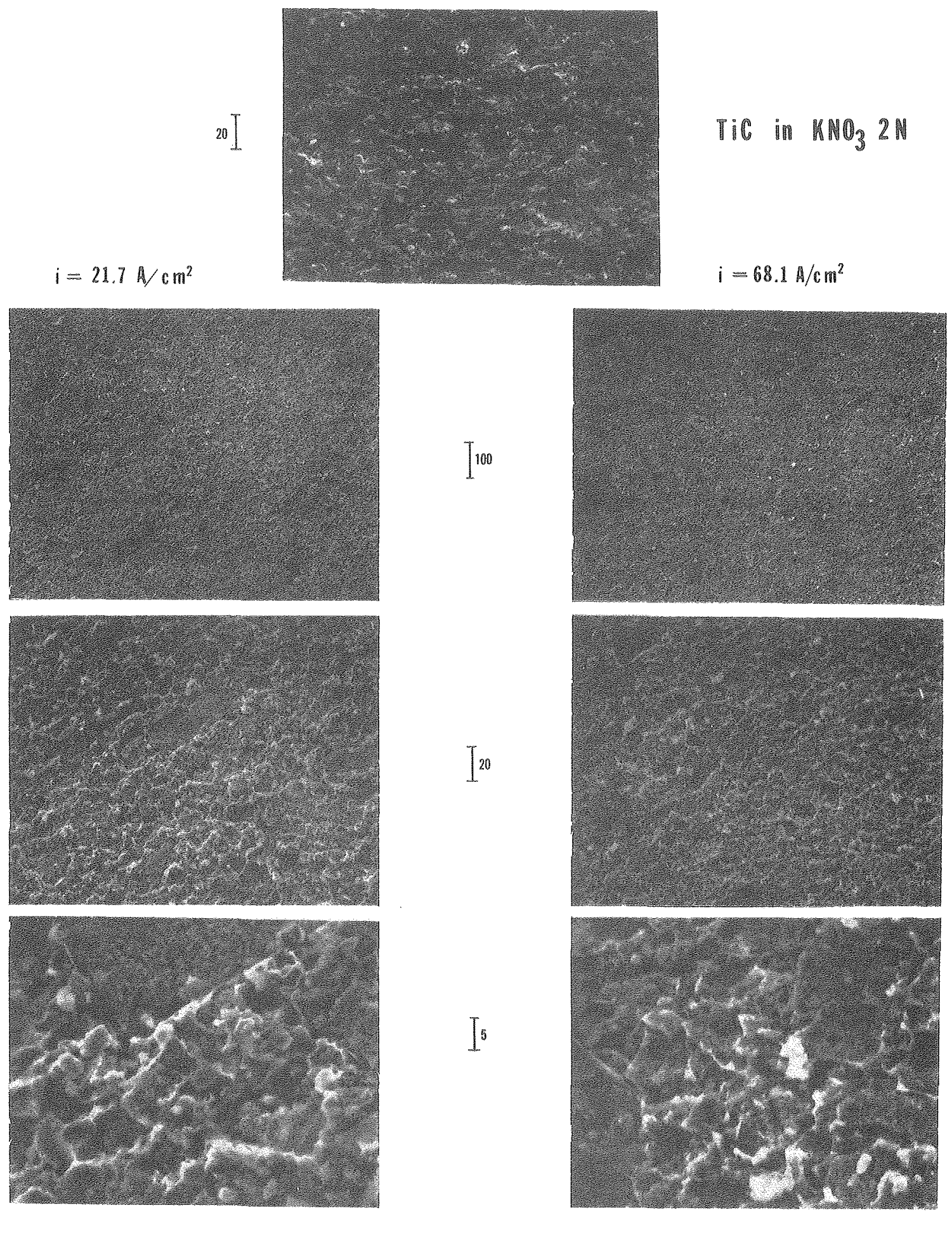

XBB $785-5627$

Figure 18. SEM microphotographs of the bottom of the holes drilled in TiC with $\mathrm{KNO}_{3}$, effect of current density. (scale in $\mu \mathrm{m}$ ) 
Table VI. Experimental data for the ECM of TiC in $3 \mathrm{~N} \mathrm{NaCl}$ and of $\mathrm{ZrC}$ in $2 \mathrm{~N} \mathrm{KNO} 3^{\circ}$ Flow rates in Iiter/min, $A / z$ in gram/Faraday.

\begin{tabular}{|c|c|c|c|c|c|c|c|c|c|c|c|c|c|c|c|c|}
\hline sui & $\begin{array}{l}\text { Press, } \\
\text { (psi })\end{array}$ & $\begin{array}{l}\text { Frow } \\
\text { rate }\end{array}$ & "wire & (volts) & $\begin{array}{c}I \\
\text { (amps) }\end{array}$ & 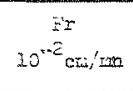 & $\begin{array}{l}\text { inole } \not \\
(\operatorname{css})\end{array}$ & $\stackrel{i}{i}\left(\mathrm{~A}^{\prime} \mathrm{cmi}^{2}\right)$ & $\begin{array}{c}0 \\
10^{-2} \mathrm{E} / \mathrm{mm}\end{array}$ & $\begin{array}{l}\mathrm{A} / \mathrm{z} \\
\mathrm{z} / \mathrm{CIb}\end{array}$ & density/t $t_{1}$ & $\begin{array}{l}\mathrm{k} \text { at } \\
\Omega^{-1} \mathrm{~cm}^{-1}\end{array}$ & $\begin{array}{l}5.6 . \\
\text { (mils) }\end{array}$ & $\begin{array}{l}\text { Mraxia dial } \\
\text { (mils) }\end{array}$ & $\begin{array}{l}\text { If hole } \\
\text { (cm) }\end{array}$ & $\begin{array}{l}E C M \quad g R P \\
(\text { wi2s })\end{array}$ \\
\hline 152 & 65 & 4.09 & $27.5^{\circ} \mathrm{C}$ & 11.0 & 10.4 & 2.77 & 0.760 & 22.9 & 6.03 & 9.3 & $112700 / 23^{\circ} \mathrm{C}$ & 0.227 & $\overline{12}$ & 170 & 0.460 & 23 \\
\hline 153 & 68 & $3.55^{\circ}$ & $25.5^{\circ} \mathrm{C}$ & 21.4 & 13.3 & 3.68 & 0.755 & 29.7 & 7.38 & 8.9 & $1.12900 / 20^{\circ} \mathrm{C}$ & 0.188 & 10 & 202 & 0.535 & 19 \\
\hline 155 & 55 & 4.35 & $27.5^{\circ} \mathrm{C}$ & 15.0 & 16.8 & 4.69 & $0.7 \% 0$ & 39.1 & 9.63 & 9.2 & $1.12600 ; 13.5^{\circ i}$ & $: 0.226$ & 10 & 207 & 0.560 & 24 \\
\hline 256 & 57 & 3.91 & $29.0^{\circ} \mathrm{C}$ & 15.0 & 28.1 & 5.02 & 0.750 & 41.0 & 30.57 & 9.2 & $1.12575 / 25^{\circ} \mathrm{C}$ & 0.235 & 9 & 222 & 0.600 & 23 \\
\hline 250 & 64 & 3.37 & $32^{\circ} \mathrm{C}$ & 14.9 & 22.6 & 6.70 & 0.740 & 53.3 & 32.89 & 9.2 & $1.12500 / 28^{\circ} \mathrm{C}$ & 0.854 & 9 & 232 & 0.615 & 19 \\
\hline 160 & 71 & 2.56 & $27.5^{\circ} \mathrm{C}$ & 15.2 & 25.5 & 7.80 & 0.720 & 62.6 & 14.37 & 9.1 & $3.12575 / 23^{\circ} \mathrm{C}$ & 0.225 & 10 & $24 I$ & 0.685 & 15 \\
\hline 261 & 60 & 4.27 & $28.5^{\circ} \mathrm{C}$ & 20.1 & 27.4 & 7.75 & 0.750 & 62.0 & 35.72 & 9.2 & $1.32525 / 24^{\circ} \mathrm{C}$ & 0.231 & 11 & 282 & 0.750 & 24 \\
\hline 163 & 40 & 2.65 & $31.0^{\circ} \mathrm{C}$ & 20.3 & 30.3 & 9.31 & 0.735 & 72.6 & 17.56 & 9.2 & $1.12375 / 26^{\circ} \mathrm{C}$ & 0.245 & 8 & 487 & 1.160 & 18 \\
\hline 164 & 23 & 4.27 & $31.0^{\circ} \mathrm{C}$ & 25.1 & 17.5 & 4.43 & 0.790 & 36.0 & 20.45 & 9.5 & $3.12375 / 26.5^{\circ} \mathrm{C}$ & 0.245 & 11 & 207 & 0.610 & 44 \\
\hline 165 & 42 & 3.82 & $32.0^{\circ} \mathrm{C}$ & 25.1 & $3^{h .3}$ & 10.73 & 0.725 & 83.1 & 19.49 & 9.1 & $1.12200 / 27^{\circ} \mathrm{C}$ & 0.250 & 9 & 440 & 1.145 & 20 \\
\hline 166 & 50 & 2.92 & $25.5^{\circ} \mathrm{C}$ & 25.1 & 35.0 & 11.20 & 0.710 & 88.4 & 19.34 & 3.9 & $1.124750 / 20.5^{\circ} 0$ & 0.212 & 9 & 435 & 1.135 & 21 \\
\hline 170 & 47 & 5.34 & $30.0^{\circ} \mathrm{C}$ & 10.2 & 8.5 & 2.37 & 0.750 & 19.2 & 4.99 & 9.4 & $1.12325 / 26.5^{\circ} \mathrm{C}$ & 0.239 & ב. & 158 & 0.455 & 32 \\
\hline 271 & 80 & 4.80 & $31.0^{\circ} \mathrm{C}$ & 25.0 & 38.3 & 12.27 & 0.720 & 94.1 & 20.86 & 8.7 & $1.12300 / 28^{\circ} \mathrm{C}$ & 0.245 & 12 & 446 & 1.150 & 28 \\
\hline 79 & 50 & 6.05 & $26.0^{\circ} \mathrm{C}$ & 10.2 & 6. & 3.14 & 0.750 & 14.0 & 6.83 & 27.7 & $1.12175 / 20.5^{\circ} \mathrm{C}$ & 0.169 & 7 & 213 & 0.590 & 26 \\
\hline 81 & 59 & 3.62 & $27.5^{\circ} \mathrm{C}$ & 20.1 & 7.8 & 4.33 & 0.715 & 19.4 & 9.36 & 19.3 & $1.12050 / 23.0^{\circ} \mathrm{C}$ & 0.175 & $T$ & 215 & 0.585 & 22 \\
\hline 82 & 33 & 5.16 & $29.0^{\circ} \mathrm{C}$ & 15.2 & 10.5 & 4.99 & 0.765 & 22.8 & 12.90 & 19.7 & $1.11950 / 24.0^{\circ} \mathrm{C}$ & 0.181 & 7 & 215 & 0.610 & 32 \\
\hline 33 & 20 & 3.55 & $30.5^{\circ} \mathrm{C}$ & 25.2 & 12.2 & 6.13 & 0.740 & 28.4 & 14.44 & 19.0 & $1.11875726 .5^{\circ} \mathrm{C}$ & 0.289 & 12 & 215 & 0.590 & 29 \\
\hline 84 & $4 I$ & 6.86 & $31.0^{\circ} \mathrm{C}$ & 15.3 & 14.2 & 7.69 & 0.725 & 34.4 & 26.97 & 19.2 & $1.13850 / 27^{\circ} \mathrm{C}$ & 0.191 & 12 & 227 & 0.605 & 23 \\
\hline 85 & 79 & 3.46 & $25.5^{\circ} \mathrm{C}$ & 35.1 & 13.7 & 3.35 & 0.695 & 36.1 & 16.08 & 28.8 & $1.42000 / 21^{\circ} \mathrm{C}$ & 0.167 & 12 & 245 & 0.645 & $2 I$ \\
\hline$\hat{6} 6$ & 60 & 6.25 & $27.0^{\circ} \mathrm{C}$ & 20.1 & 36.9 & $9.0 \%$ & 0.735 & 39.8 & 19.64 & 18.7 & $1.12000 / 23^{\circ} \mathrm{C}$ & 0.172 & 12 & 302 & 0.790 & 22 \\
\hline 37 & 52 & $5.3^{4}$ & $29.0^{\circ} \mathrm{C}$ & 20.2 & 19.5 & 10.72 & 0.725 & $4 ? .2$ & 23.57 & 17.8 & $1.12000 / 25^{\circ} \mathrm{C}$ & 0.184 & $I 7$ & 438 & 1.110 & 26 \\
\hline 33 & 58 & 4.26 & $27.0^{\circ} \mathrm{C}$ & 20.1 & 20.3 & \pm 1.47 & 0.720 & 49.9 & 23.07 & 18.3 & $1.12150 / 23^{\circ} \mathrm{C}$ & 0.174 & 12 & 246 & 0.635 & 16 \\
\hline 92 & 55 & 6.50 & $33.0^{\circ} \mathrm{C}$ & 25,0 & 23.1 & 12.55 & 0.745 & 53.0 & 27.31 & 19.0 & $1.13850 / 27.5^{\circ} \mathrm{C}$ & 0.202 & 9 & 4,524 & 2.295 & 25 \\
\hline 93 & 56 & 6.41 & 30.5 & 25.3 & 23.4 & 12.78 & 0.740 & 49.9 & 27.43 & 18.9 & $1.11375 / 26.0^{\circ} \mathrm{C}$ & $=0.182$ & 7 & 455 & 3.295 & 22 \\
\hline 94 & $T I$ & 6.77 & $32^{\circ} \mathrm{C}$ & 25.3 & 24.9 & 23.90 & 0.740 & 57.9 & 29.86 & 19.3 & $1.11400 / 28.0^{\circ} \mathrm{C}$ & 0.191 & 7 & 4,54 & 1.185 & 20 \\
\hline
\end{tabular}


Table VII. Experimental data for Z $\mathrm{XC}$ in $3 \mathrm{~N}$ NaCl and $\mathrm{TIC}$ in $2 \mathrm{~N} \mathrm{KNO}_{3}$.

\begin{tabular}{|c|c|c|c|c|c|c|c|c|c|c|c|c|}
\hline $\begin{array}{c}\text { BUN } \\
" 1\end{array}$ & $\begin{array}{l}\text { Press. } \\
\text { (psig) }\end{array}$ & $\begin{array}{l}\text { Flow } \\
\text { rattee }\end{array}$ & I' Are & $\begin{array}{c}\Delta^{V} \\
(\text { voltis })\end{array}$ & $\begin{array}{c}\text { I. } \\
\text { (wins) }\end{array}$ & $10^{-25} \mathrm{C}^{3 \mathrm{~m} / \mathrm{snn}}$ & $\begin{array}{l}\text { hole } \not f^{\prime} \\
(\mathrm{cm})\end{array}$ & $\begin{array}{c}\mathrm{i} \\
(\mathrm{N} / \mathrm{cm}\end{array}$ & $\begin{array}{c}\Delta M \\
10^{-2}\end{array}$ & tensity $/ t_{1}$ & 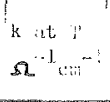 & $\begin{array}{l}1 / 2 \\
n / 21, k\end{array}$ \\
\hline 48 & 37 & 6.58 & $25.0^{\circ} \mathrm{C}$ & 15.1 & 8.1 & 2.99 & 0.855 & 24.2 & 9.33 & $1.11800 / 20.5^{\circ} \mathrm{C}$ & 0.203 & .28 .7 \\
\hline 50 & 83 & 6.40 & $20.5^{\circ} \mathrm{C}$ & 10.0 & 9.8 & 5.38 & 0.710 & 23.8 & 31.00 & $1.1 .1500 / 23.0^{\circ} \mathrm{C}$ & 0.210 & 19.0 \\
\hline 46 & 82 & 7.65 & $25.0^{\circ} \mathrm{C}$ & 25.2 & 10.3 & 4.72 & 0.770 & 22.1 & 10.25 & $1.12500 / 21.0^{\circ} \mathrm{C}$ & 0.210 & 16.0 \\
\hline 45 & 60 & 7.96 & $28.0^{\circ} \mathrm{C}$ & 24.2 & 10.3 & 3.23 & 0.935 & 15.0 & 12,70 & $1.12450 / 20.5^{\circ} \mathrm{C}$ & 0.226 & 19.8 \\
\hline 35 & 27 & 3.90 & $23.0^{\circ} \mathrm{C}$ & 14.8 & 13.4 & 5.59 & 0.735 & 27.1 & 13,50 & $1.12300 / 20.0^{\circ} \mathrm{C}$ & 0.197 & 1.8 .8 \\
\hline 43 & 77 & 9.00 & $25.0^{\circ} \mathrm{C}$ & 24,1 & 15.6 & 7.30 & 0.780 & 32.5 & 18.60 & $1.12400 / 20.5^{\circ} \mathrm{C}$ & 0.195 & 19.2 \\
\hline 47 & 84 & 6.40 & $23.0^{\circ} \mathrm{C}$ & 24.8 & 15.1 & 8.30 & 0.710 & 33.1 & 16.70 & $1.11750 / 18.5^{\circ} \mathrm{C}$ & 0.192 & 17.4 \\
\hline 41 & 30 & 3.71 & $28.0^{\circ} \mathrm{C}$ & 20.0 & 19.8 & 9.20 & 0.760 & 43.6 & 20.80 & $1.12400 / 21^{\circ} \mathrm{C}$ & 0.225 & 15.7 \\
\hline 51 & 83 & 9.26 & $30.0^{\circ} \mathrm{C}$ & 20,0 & 17.3 & 8.57 & 0.755 & 38.8 & 20.72 & $1.12750 / 18.5^{\circ} \mathrm{C}$ & $0 / 193$ & 19.0 \\
\hline 55 & 84 & 3.79 & $26.0^{\circ} \mathrm{C}$ & 14.8 & 29.5 & 10,03 & 0.705 & 49.9 & 20.64 & $1.11300 / 21.0^{\circ} \mathrm{C}$ & 0,203 & 17.0 \\
\hline 53 & 84 & 6.35 & $26.0^{\circ} \mathrm{C}$ & 20.0 & 22.4 & 1.1 .89 & 0.720 & 54.5 & 23.52 & $1.11600 / 22.0^{\circ} \mathrm{C}$ & 0,207 & 17.0 \\
\hline 54 & 84 & 5.97 & 27.5 & 24.3 & 27.3 & 14.14 & 0.725 & 66.2 & 28.86 & $1.11400 / 22.5^{\circ} \mathrm{C}$ & 0.213 & 17.0 \\
\hline 62 & 85 & 3.90 & $26.5^{\circ} \mathrm{C}$ & 10.3 & 9.5 & 3.05 & 0.690 & 25.4 & 4.79 & $1.1225 / 18.5^{\circ} \mathrm{C}$ & & 0.1 \\
\hline 64 & 84 & 2.83 & $29.0^{\circ} \mathrm{C}$ & 1.4 .8 & 38.0 & 6.06 & 0.695 & 4.7 .5 & 10.05 & $1.1210 / 22^{\circ} \mathrm{C}$ & & 9.0 \\
\hline 65 & 85 & 2.30 & $26.0^{\circ} \mathrm{C}$ & 14.6 & 20.0 & 7.15 & 0.675 & 55.9 & 12.09 & $1.1225 / 22.5^{\circ} \mathrm{C}$ & & 8.9 \\
\hline 66 & 84 & 3.73 & $29.0^{\circ} \mathrm{C}$ & 20.4 & 24.6 & 8.22 & 0.695 & 64.8 & 13.78 & $1.1215 / 22.5^{\circ} \mathrm{C}$ & & 0.0 \\
\hline 67 & 84 & 3.20 & $29.0^{\circ} \mathrm{C}$ & 20.1 & 27.8 & 9.55 & 0.680 & 76.5 & 15.59 & $1.2195 / 24.0^{\circ} \mathrm{C}$ & & 8.9 \\
\hline 68 & 83 & 3.37 & $27.0^{\circ} \mathrm{C}$ & 24.7 & 30.9 & 10.47 & 0.695 & 81.5 & 17.35 & $1.1205 / 21.0^{\circ} \mathrm{C}$ & & 0.0 \\
\hline 69 & 84 & 4.98 & $27.0^{\circ} \mathrm{C}$ & 15,2 & 15.3 & 4.98 & 0.710 & 38.6 & 8.44 & $1.1185 / 28.0^{\circ} \mathrm{C}$ & & 3.9 \\
\hline 70 & 82 & 3.37 & $29.0^{\circ} \mathrm{C}$ & 24.8 & 34.2 & 11.56 & 0.690 & 91.5 & 19.36 & $1.1195 / 23.0^{\circ} \mathrm{C}$ & & 9.1 \\
\hline 72 & 46 & 3.23 & $26.5^{\circ} \mathrm{C}$ & 25.2 & 3.5 .9 & 4.99 & 0.710 & 39.6 & 8.81 & $1.1200 / 23.5^{\circ} \mathrm{C}$ & & 9.1 \\
\hline 75 & 76 & 4.15 & $26.0^{\circ} \mathrm{C}$ & 12.7 & 12.9 & 4.26 & 0.700 & 33.5 & 7.02 & $1.1200 / 20.5^{\circ} \mathrm{C}$ & & 8.8 \\
\hline 76 & 62 & 5.52 & $28.0^{\circ} \mathrm{C}$ & 16.0 & 23.9 & 4.25 & 0.725 & 33.7 & 8.09 & $1.1275 / 25.5^{\circ} \mathrm{C}$ & & 9.4 \\
\hline 77 & 52 & 6.86 & $29.0^{\circ} \mathrm{C}$ & 20.6 & 15.2 & 4,22 & 0.760 & 33.5 & 8.85 & $2.1275 / 25^{\circ} \mathrm{C}$ & & 9.4 \\
\hline 78 & 48 & 7.18 & $30.0^{\circ} \mathrm{C}$ & 24.8 & 17.0 & 4.23 & 0.790 & 34.7 & 9.95 & $1.1280 / 26.5^{\circ} \mathrm{C}$ & & 9.4 \\
\hline
\end{tabular}




\section{Zirconium Carbide}

\section{C1. Electrochemical behavior}

The second carbide investigated in this work presents a similar behavior to that of titanium carbide. The machining rate and the dissolution rate are plotted versus the current density and the current in Figs. 19 and 20 .

The experimental Iinear correlations (labels $x$ on figures) show that the dissolution occurs also with a constant valence throughout the range of curtent densities investigated, regardless of the electrolyte used.

The theoretical lines added to the Figs. 19 and 20 are calculated from equations 5 and 10 and correspond to the dissolution reaction occurring with 4 electrons (label a), 6 electrons (label b) and 8 electrons (label c)

$$
F r=\left(\frac{A}{z}\right) \frac{60}{F d} i /(10) \quad \Delta M=\left(\frac{A}{z}\right) \frac{60}{F} I
$$

The following table lists the electrochemical equivalent and the apparent valence of dissolution for zirconium carbide from the relations 12 and $13:$ 


\begin{tabular}{|l|r|r|}
\hline \multicolumn{1}{|c|}{ ZrC } & Fr vs 1 & $\Delta M$ vs I \\
\hline $\begin{array}{l}\text { slope of experimenta1 } \\
\text { correlation (1ine X on Figs.19\&20) }\end{array}$ & $\begin{array}{l}0.23210^{-2} \\
\mathrm{~cm}^{3} / \text { Arps.min. }\end{array}$ & $\begin{array}{c}1.09410^{-2} \\
\text { gram/Amps.min. }\end{array}$ \\
\hline $\begin{array}{l}\text { A/z (gram/Faraday) } \\
\text { (experimental errox) }\end{array}$ & $18.50 \pm 0.55$ & $17.59 \pm 0.52$ \\
\hline $\begin{array}{l}\text { z: apparent valence of } \\
\text { dissolution } \\
\text { average on both methods }\end{array}$ & $5.58 \pm 0.17$ & $5.86 \pm 0.18$ \\
\hline
\end{tabular}

Table VIII. Observed apparent valence of $\mathrm{ZrC}$ in $\mathrm{KNO}_{3}$ and $\mathrm{NaCl}$

The error caused by the combined effect of the surface area and the weight loss measurements, for the apparent valence of dissolution results in a $3 \%$ uncertainty for zirconium carbide. It is somewhat larger than with the other materials investigated because of the porosity of the material received. As shown in Table $I$, the actual observed density of ZrC is $4.93 \mathrm{~g} / \mathrm{cc}$, instead of $6.09 \mathrm{~g} / \mathrm{cc}$, the Iiterature value $(33,35)$. This difference can lead to erroneous results when using equation 10 where the density appears. The high porosity of zirconium carbide is responsible for the scattering of the experimental data, especially in Fig. 20 representing the mass removal rate versus the current. The high pressures used during ECM allowed the electrolyte to fill the pores of the sample, which needed to be vacuum dried for at least 4 to 5 hours before the weight loss measurements. The following procedure was then used for experimental work with ZxC: 


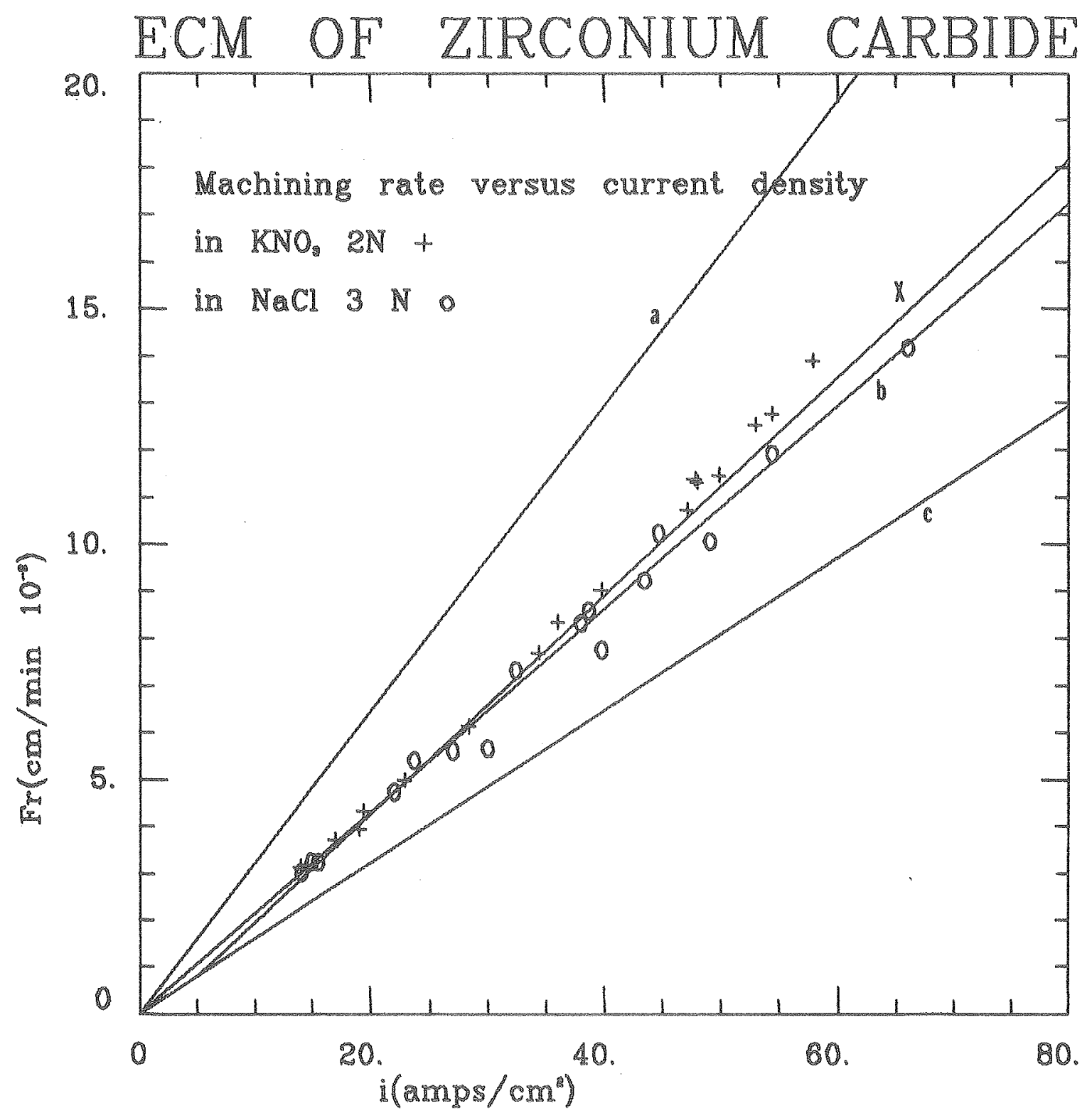

XBL $785-8624$

Figure 19. Machining rate versus current density for ZrC. Experimental correlation, line $\mathrm{x}$.

Theoretica1 Iines: a) 4 electron process

b) 6 electron process

c) 8 electron process 


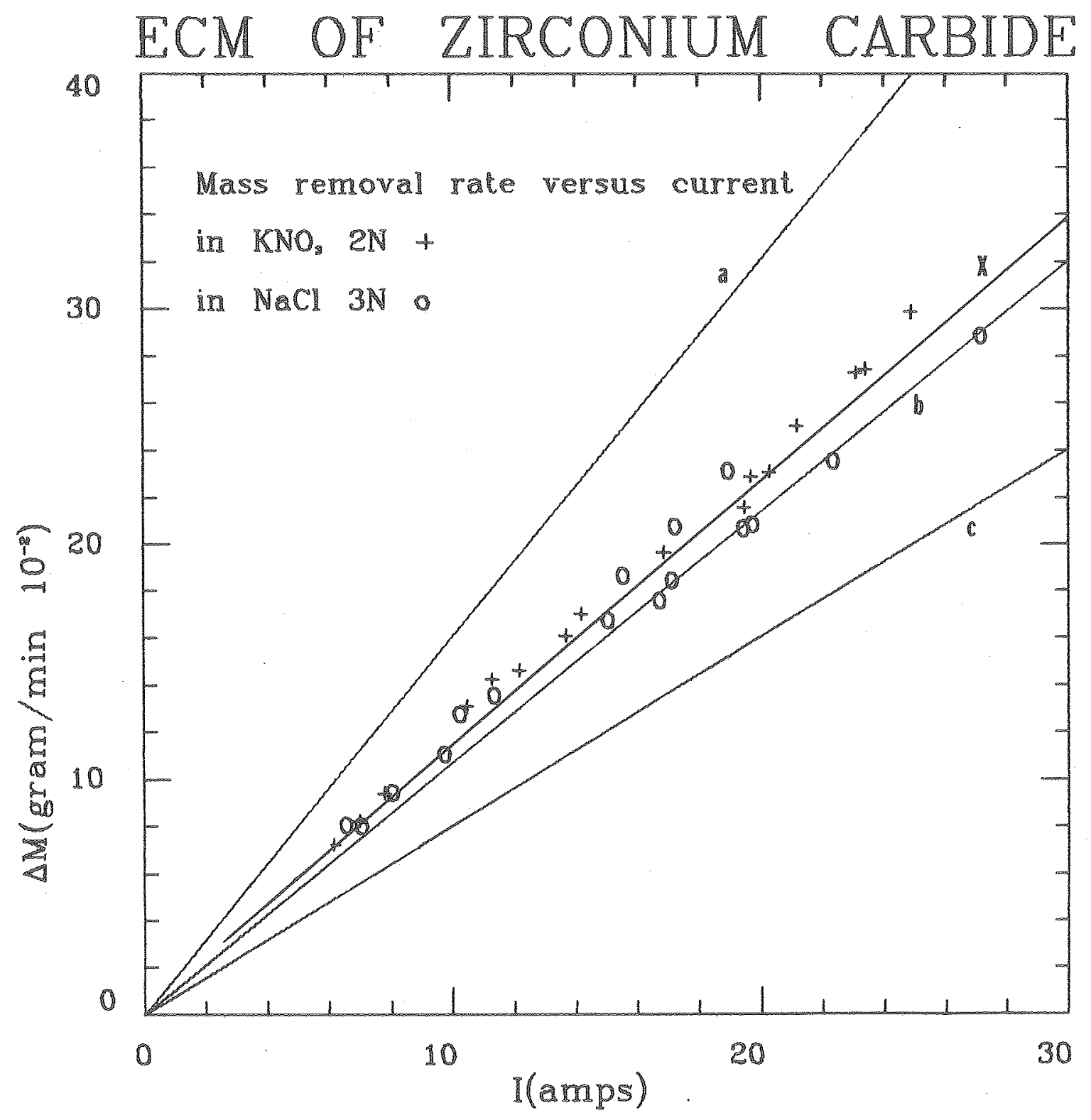

XBL $785-8781$

Figure 20. Dissolution rate versus current for ZrC. Theoretical and experimental lines same as in figure 19. 


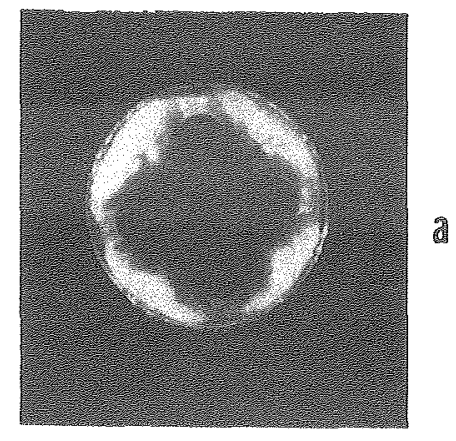

a
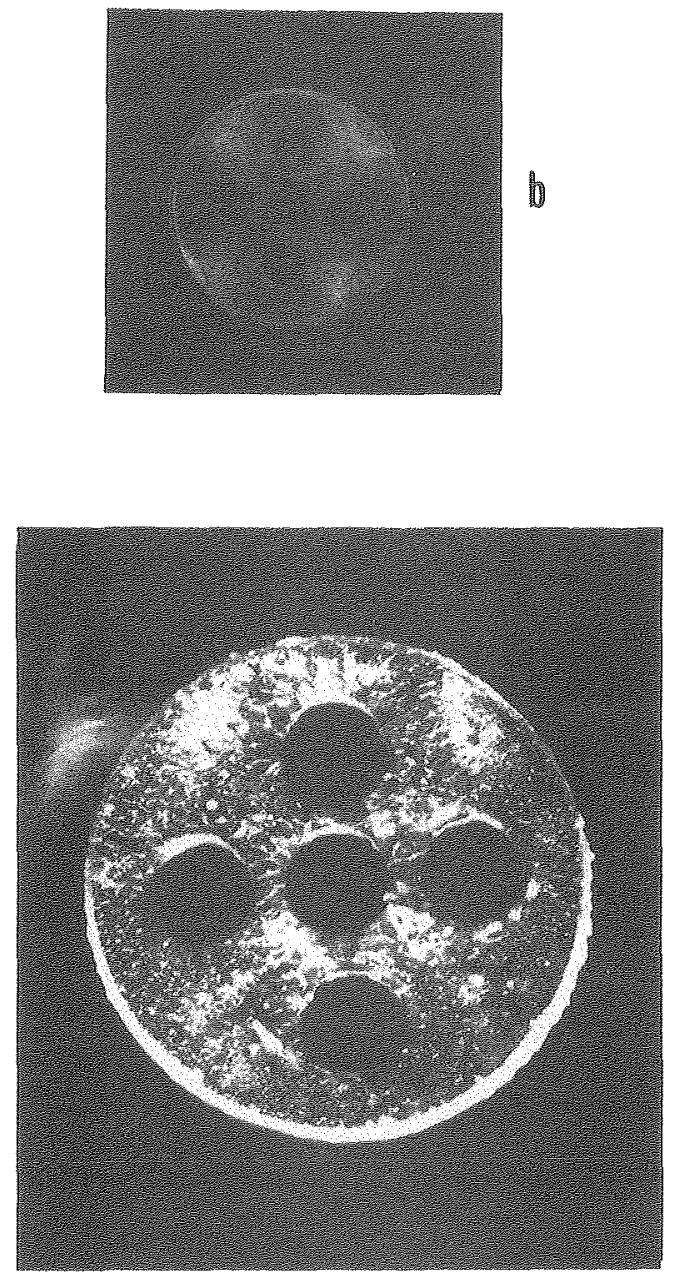

C

XBB $785-6124$

Figure 21. Cathodic deposition; appearance of the toolpiece after ECM in NaCl, a) and b) ECM of TiC, c) ECM of ZrC. 


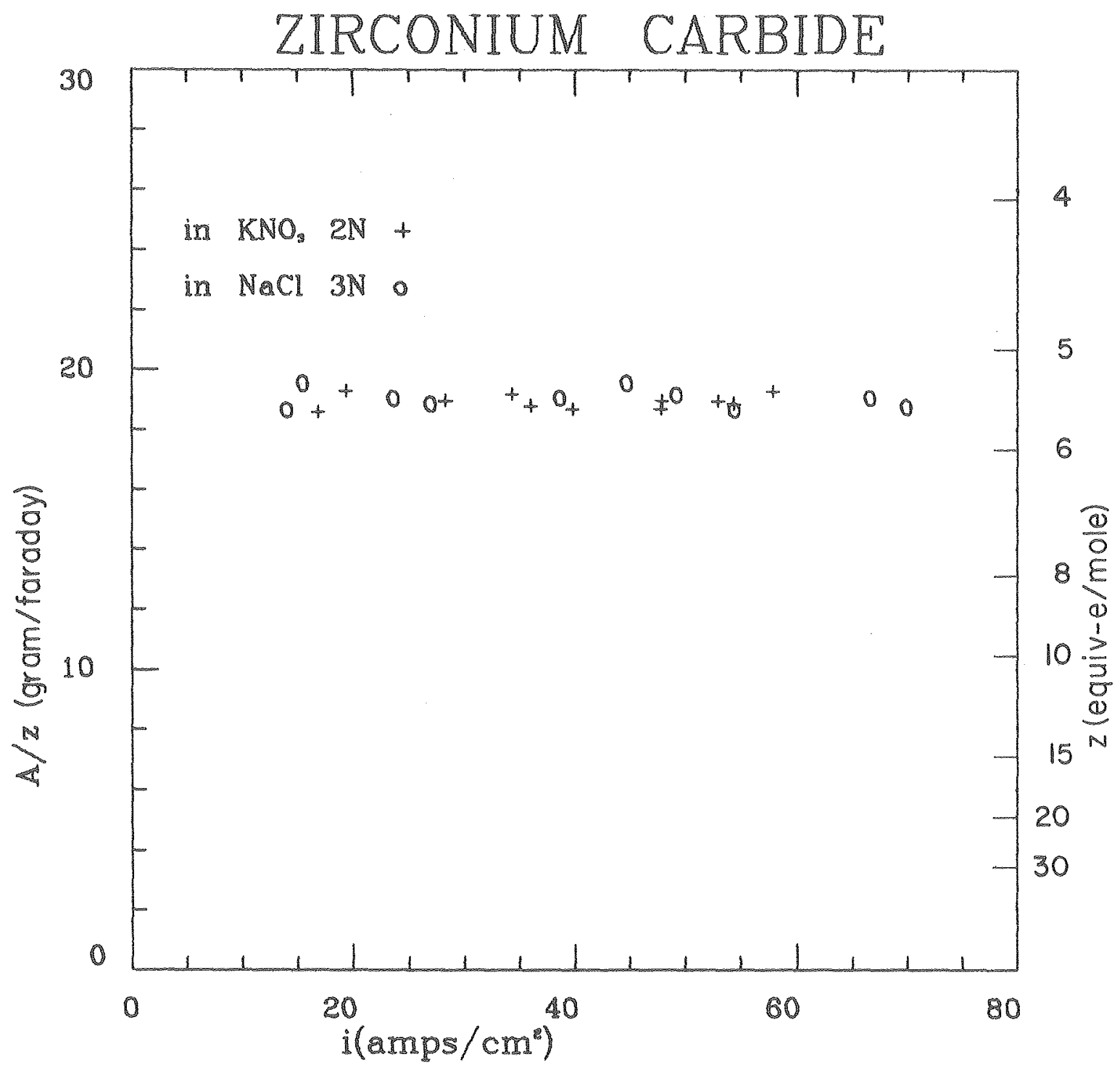

XBL $785-8780$

Figure 22. Electrochemical equivalent $(A / z)$ and apparent valence of dissolution for ZrC. 
- The sample was thoroughly cleaned and rinsed with hot water to dissolve most of the particles of electrolyte contained in its pores.

- Acetone was used to dry the sample in removing most of the water still present from the cleaning operation.

- The sample then dried under vaccum for as long as 5 hours after and before each run. The period of 5 hours was determined by comparison of the weight loss measurements with the dimensions measurements using the actual density as reference, so as to result in a experimental exrox below $1 \%$ by the two methods.

Another reason for the deviation of certain experiments from the correlation is cathodic deposition on the toolplece. plating is not observed with potassium nitrate but can be significant and visible with sodium chloride after a prolonged use of this electrolyte. The two top photographs of figure 21 represent the tip of the toolpiece after ECM of titanium carbide in $\mathrm{NaCl}$ and the bottom picture shows the same toolpiece after ECM of of ZrC in NaCl.

However, no further analysis of these black deposited particles on the top of the toolplece was made, because of the fluffiness and the scarcity of these deposits; attempts for Xray powder pattern analysis were unsuccessful.

Figure 22 shows the electrochemical equivalent and the apparent valence of dissolution for zirconium carbide:just as titanium carbide, its electrochemical behavior is independent of the nature of the electrolyte throughout the range of current densities investigated. 


\section{C2. Frontal gap of dissolution}

According to equation 16, and neglecting the overvoltages, the ECM gap is

$$
\mathrm{ECM} \text { gap }=k \frac{\Delta V}{i} .
$$

By combining equations 10 and 17 , the ECM gap can be expressed direct1y as a function of the ECM driving force:

$$
\begin{gathered}
F r=\frac{F d}{F r}\left(\frac{2}{A}\right) k \Delta V \\
\therefore \quad E C M g a p=\alpha\left(\frac{k \Delta V}{F r}\right)
\end{gathered}
$$

where $\alpha$ is dependent on the valence of dissolution, a constant $(z=5.7 \pm 0.3$ equiv-e $/$ mole $)$. Figure 23 represents the variations of the machining gap versus the driving force. Since the absolute error estimated of the machining gap is large and ignoring the overvoltages in equation 17 represents an oversimplification, the correlation (equation 19) should be considered only as a useful approximation. However, the general trend shows a linear correlation for the range of driving forces investigated. This range excludes low applied voltages and high machining rates. Again, as with TiC, the correlation is independent of the electrolyte used and is shown to be linear as expected. 


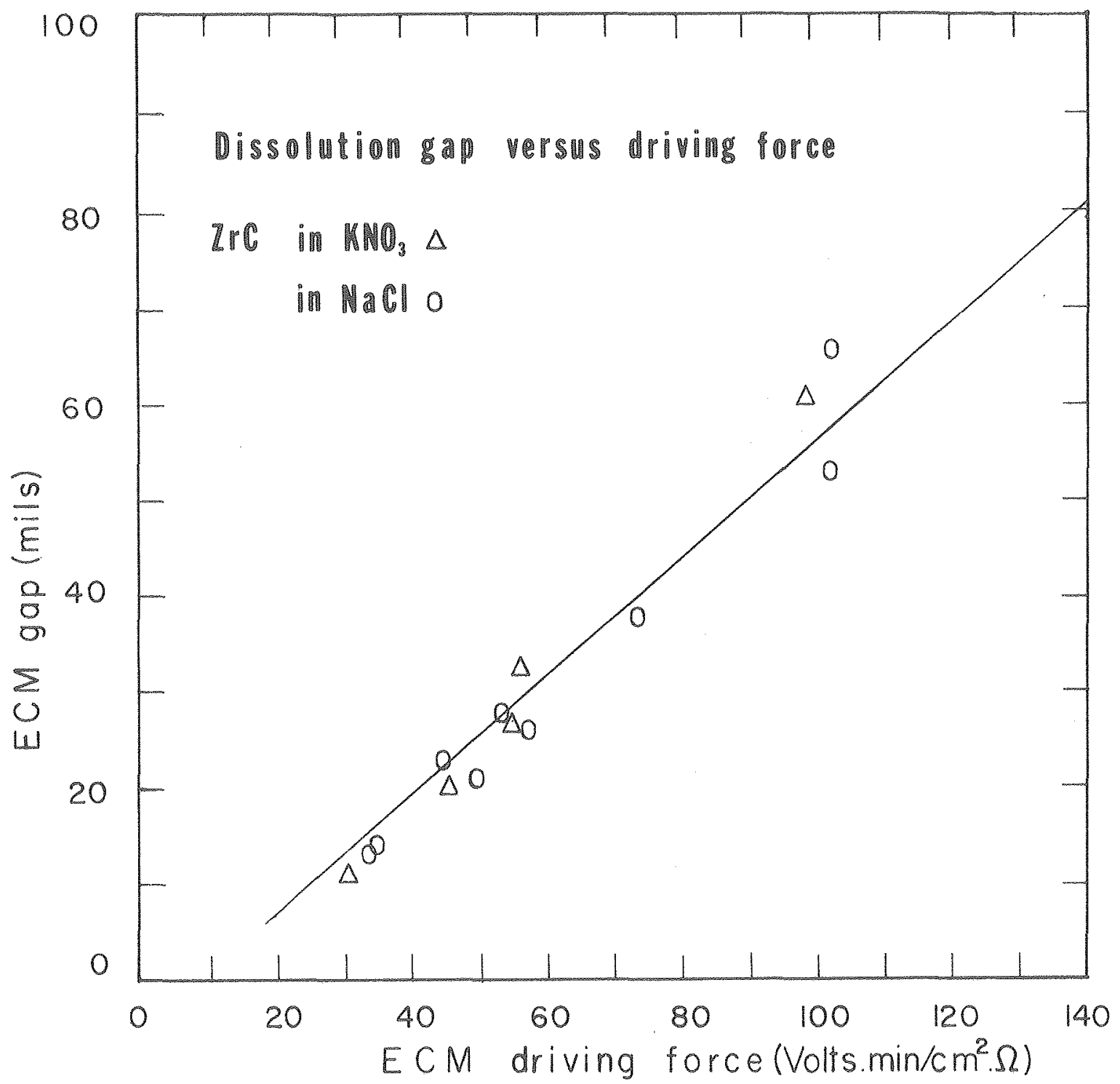

XBL $785-8627$

Figure 23. Frontal gap of dissolution versus the ECM driving force for ZxC in NaCl and $\mathrm{KNO}_{3}$. Data from runs 82 to 88 in $\mathrm{KNO}_{3}$ and from runs 41 to 50 in NaCl. 


\section{C3. Current voltage relation}

The current voltage relationship is determined for two configurations of the ECM ce11, in the two electrolytes the same experimental determination is used (eq. 11) as for $\mathrm{TiC}$ and the ohmic drop is measured under the assumption of a parallel plates geometry by equation 20 .

The behavior of zirconium carbide is qualitatively similar to that of titanium carbide. The Inear correlation obtained for the range of current densities shown does not allow the determination of the transition from the active to the transpassive regime of dissolution where ECM is believed to occur for most of the metals $(43,44,47)$. This transition would depend on the electrolyte and would require further study in a channel cell with a more accurate equipment to

explore the range of low current densities (below $20 \mathrm{~A} / \mathrm{cm}^{2}$ ) not available here.

However, the magnitude of the overvoltages associated with the high rate of anodic dissolution of ZxC can be determined. By extrapolation of the polarization curve to zero current density, a fairly good approsimation of the cell overvoltage is obtained for the process. This extrapolation is made by assuming constant current-independent overpotential and therefore it is not exactly representative of the low current density range. The sum of the overpotentials, including the electrodes potentials on both sides of the cell at a fixed current density, given by the difference between the experimental correlation (Fig. 24) and the ohmic drop is shown to be large and approximately constant $(8-9 \mathrm{~V})$ throughout the range of current densities investigated. 


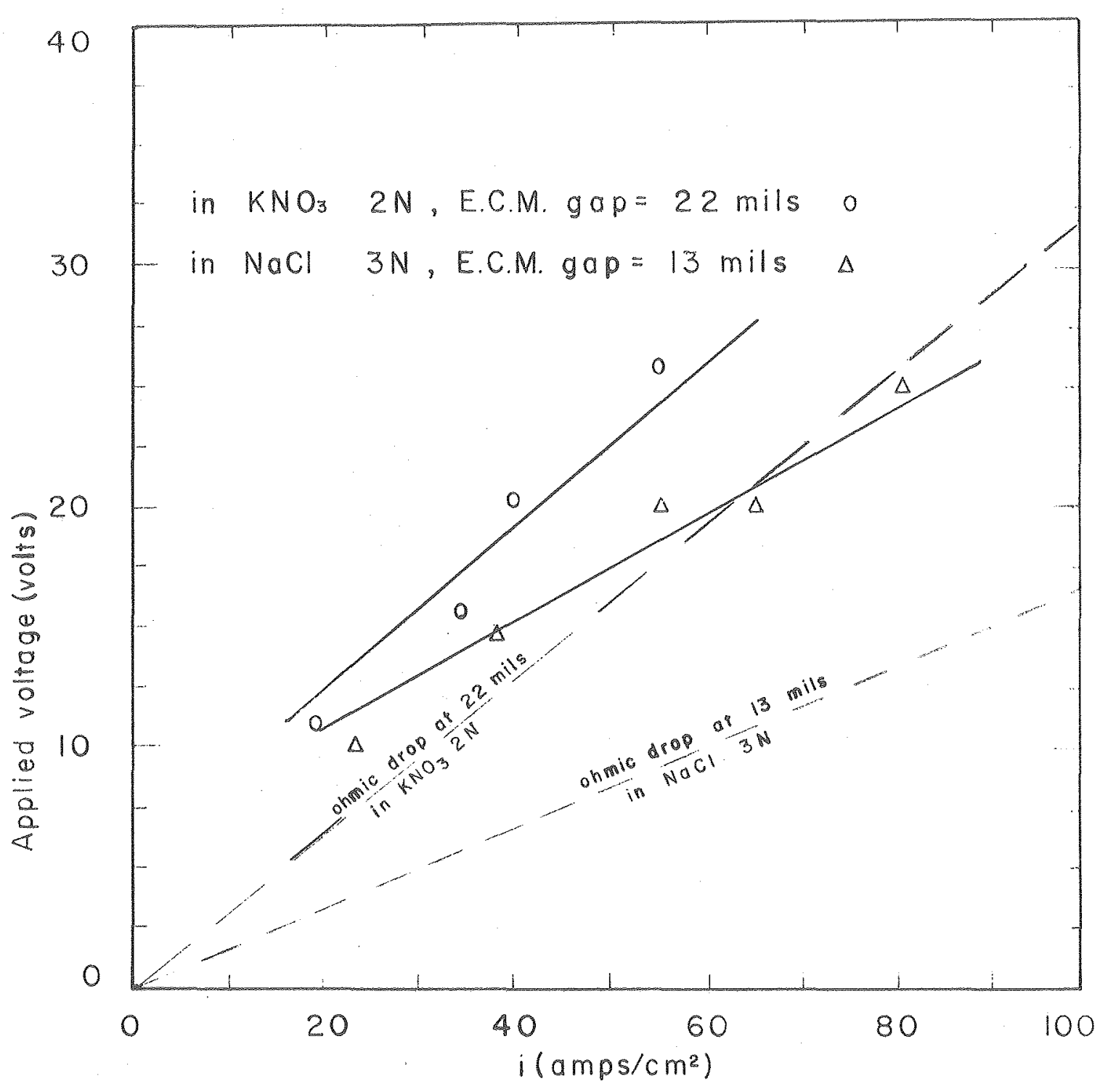

XBL 785-8735

Figure 24. Polarization curve for $\mathrm{ZrC}$ in $\mathrm{KNO}_{3}$ and in $\mathrm{NaCl}$ at different machining gaps. 


\section{C4. Surface roughness}

As the influence of the current density on the surface finish of electrochemically machined parts has not yet been discussed in the literature it was thought worthwhile to investigate this effect. The traces of the surfanalyzer (Figs. $25 \& 26$ ) used to determine the surface profiles and roughness ${ }^{*}$ of the bottoms of the holes where dissolution occurs show no dependence of the surface finish on the current density or on the applied voltage. The only factor influencing the surface roughness is the nature of the electrolyte as seen by comparing Figs. 25 and 26, corresponding respectively to $2 \mathrm{~N}$ potassium nitrate and $3 \mathrm{~N}$ sodium chlordie. For the same operating conditions, the surface roughness is within $5-6 \mu \mathrm{m}$ in $\mathrm{KNO}_{3}$ and within $8-10 \mu \mathrm{m}$ in NaCl.

The relationship between suxface finish, dimensional control and electrolyte has been investigated for metals. Hoare et Laboda $(43,44,46)$ related the dimensional control obtained in $\mathrm{NaClO}_{3}$ and NaCl to the transition from the active to the transpassive state, observed in the polaxization curve of different hardened steels in these two electrolytes. A more recent study by the same authors (45) on the electrochemical machining of high temperature alloys in $\mathrm{NaClO}_{3}$ shows that the surface finish attainable by ECM is also dependent on

\footnotetext{
The roughness of a surface is the profile of the surface itself where al1 irregularities with wavelengths greater than a specified value are filtered out and not traced. This allows the cutoff of the five small peaks provided they have larger "wavelength" than the specified value. Usually on all of the surfanalyzer traces reported in the present work, the width cutoff is $0.03 \mathrm{in}$.
} 


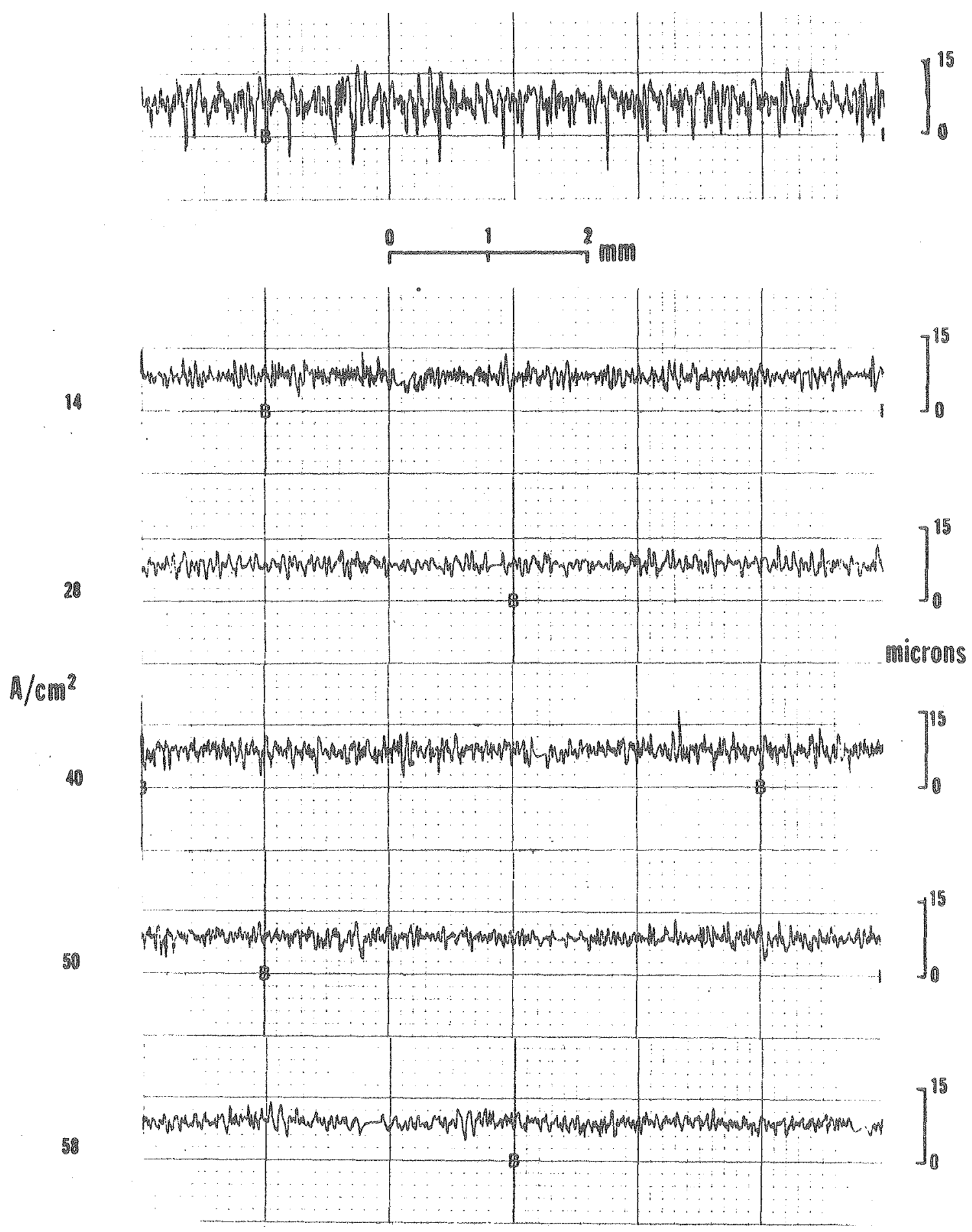

X8L $785-8614$

Figure 25. Traces of suranalyzex: effect of the current density on the surface roughness of ZrC in $\mathrm{KNO}_{3}$. Toolpiece $\|_{12} 26$ polished with 非600 abrasive paper before experiment. 


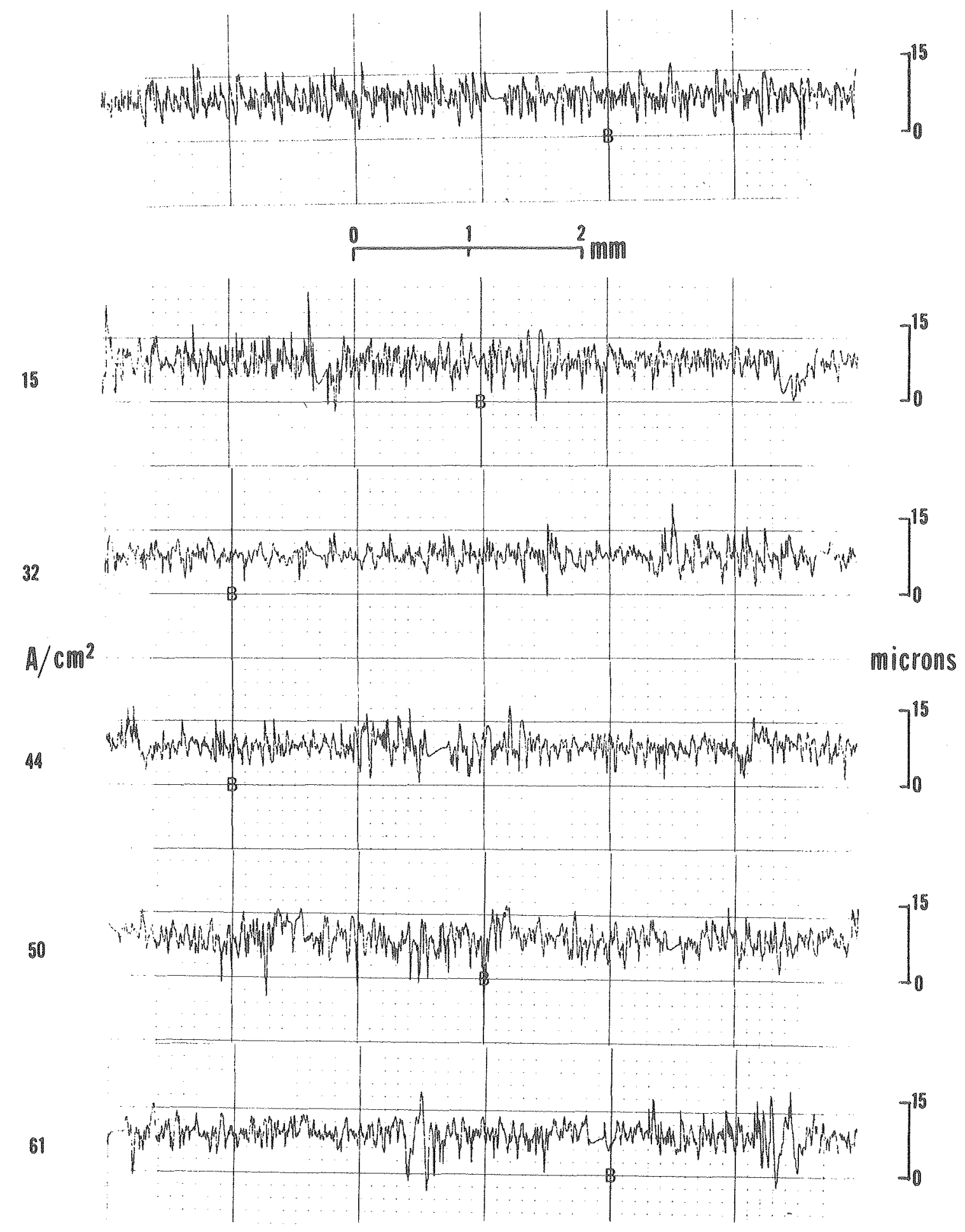

XBL 785-8619

Figure 26. Traces of surfanalyzer; ZrC in NaCl. Same as in figure 25. 
the contents of the matexials in alloying elements. High iron content alloys exhibit excellent values of surface roughness while the low iron content alloys, due to preferential phase attack, show comparatively poor values of surface roughness.

The same result is given by Petrov (41) showing that the content of cobalt, used to bind tungsten carbide, influences the suxface Finish of electrochemically machined parts; the more cobalt is present in the sintered carbide, the less smooth a finish is attainable in the same electrolyte under the same operating conditions.

These results are in agreement with the findings of this work where it is shown in Figs. 17, 25 and 26 that the surface roughness after ECM is dependent on the electrolyte as well as the material itself.

C5. SEM analysis: effect of the electrolyte and the current density

a) Figure 27 presents photographs of the same area on the anodic surface at the bottoms of the hole. The SEM pictures reveal that the appearance of the surface morphology, just as the surface roughness, does not depend on current density.

The surface appears to be dull and reveals the grain structure due to the porosity of the samples of zirconium carbide received (26\%; see Table 1). The comparison with the surfaces as received shows no large difference before and after machining except for the sharpness of the large grains noticeable, which would be presumably due to the attack of the surface oxides by the electrolyte anions during ECM, 

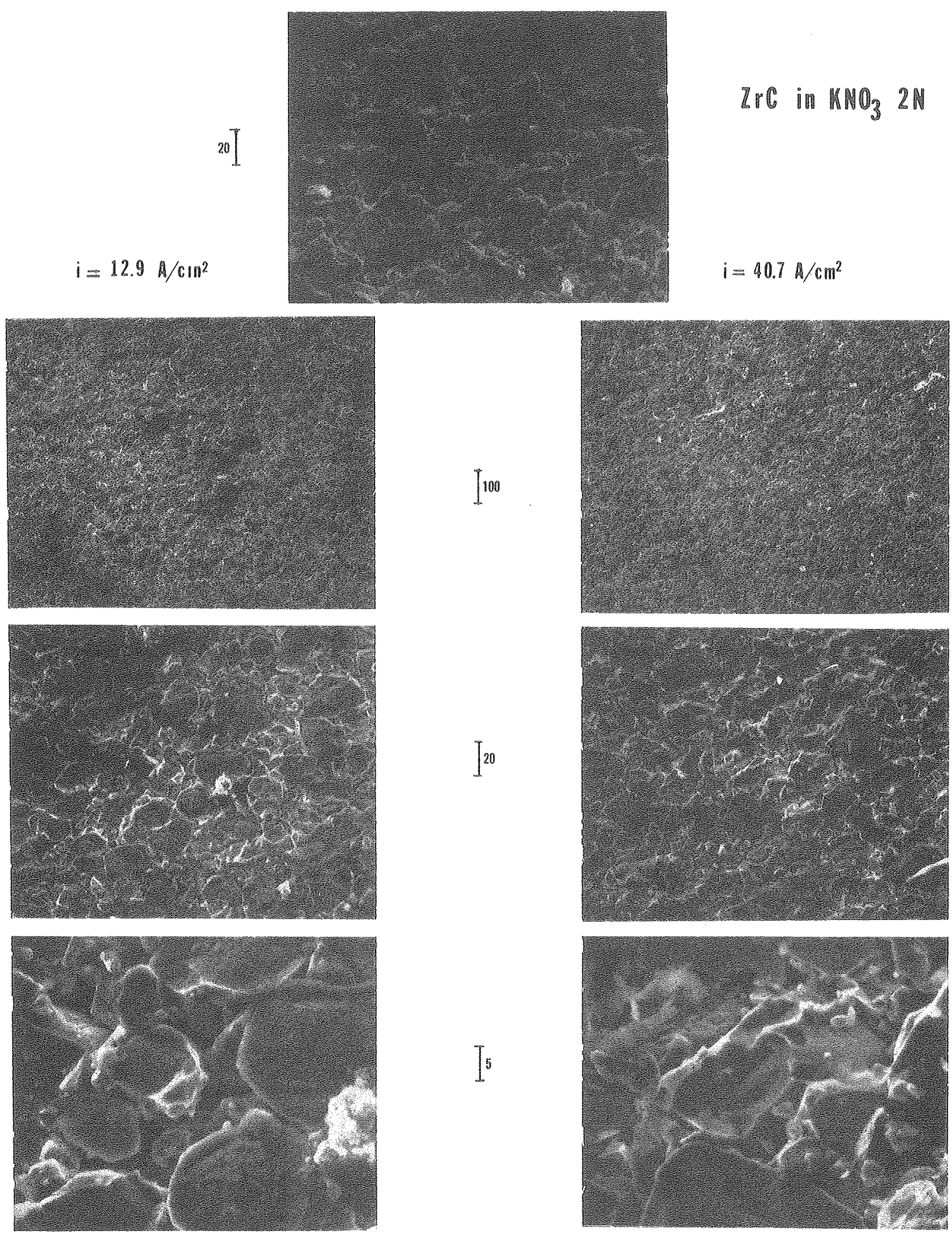

XBB $785-5629$

Figure 27. SEM microphotographs of the bottom of the holes drilled in $\mathrm{ZrC}$ with $\mathrm{KNO}_{3}$; effect of the current density. (scale in $\mu \mathrm{m}$ ) 


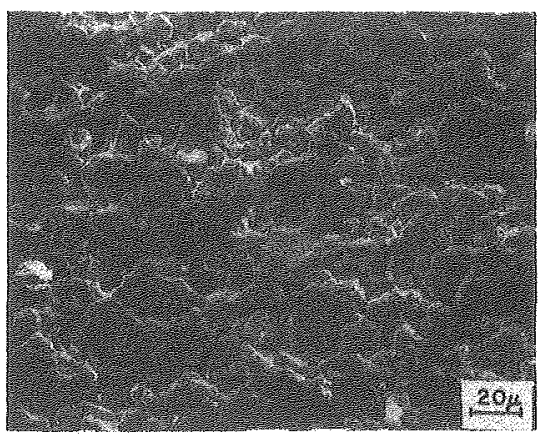

\section{Zircomium carbide}
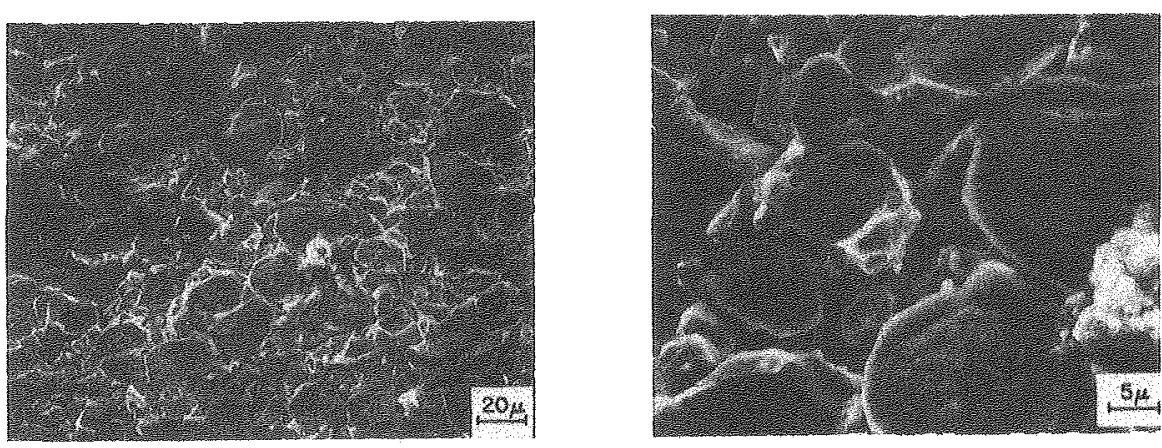

in $\mathrm{NNO}_{3}$

$i=27.1 \mathrm{~A} / \mathrm{cm}^{2}$

$\Delta V=14.8$ Volis

flow: $3.90 \mathrm{lpm}$.
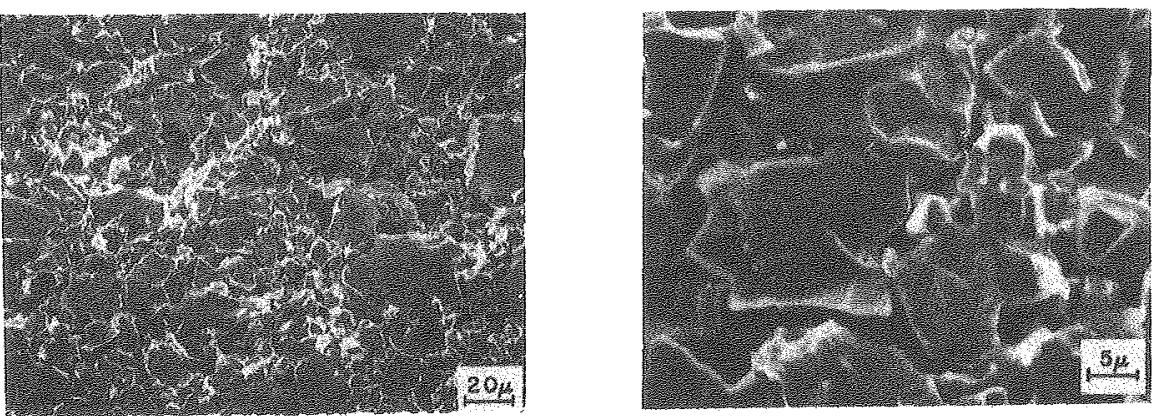

in $\mathrm{NaCl}$

$i=12.9 \mathrm{~A} / \mathrm{cm}^{2}$

$\Delta V=15.6 \mathrm{Volts}$

flow: 7.46 l.p.m.

$X B B \quad 785-6471$

Figure 28. SEM microphotographs of the bottom of the holes drilled in this work; effect of the electrolyte. (scale in $\mu \mathrm{m}$ ) 
b) The results in Fig. 28 present the appearance of zirconium carbide after $\mathrm{ECM}$ in $\mathrm{KNO}_{3}$ (top) and $\mathrm{NaCl}$ (bottom). The conclusion drawn from the examination of the SEM pictures parallel the conclusion drawn from the surface roughness: the grains have a somewhat smaller size after machining in $\mathrm{NaCl}$ than in $\mathrm{KNO}_{3}$. This would suggest there is an attack of the surface stronger with C1- than with $\mathrm{NO}_{3}^{-}$anion. It is to be noticed that, in contrast with titanium carbide, the larger grain structure is prominent, but the small grain structure is still in evidence, although very faintly between the large grains. This would suggest a less effective protective action of the oxide film formed on zirconium carbide.

\section{Titanium Diboride}

DI. Electrochemical behavior

As shown in the Table I listing the physical characteristics, titanium diboride is known to have the highest haxdness of the four materials investigated in this work.

The figures representing the machining rate (Fr) and the dissolution rate ( $\triangle M$ ) are plotted as the two previous carbides (Figs. 29 and 30). They show comparable behavior for the dissolution of titanium diboride in $2 \mathrm{~N}$ potassium nitrate over current densities from $15 \mathrm{~A} / \mathrm{cm}^{2}$ to $120 \mathrm{~A} / \mathrm{cm}^{2}$. The theoretical 1ines [a), b), c)] on Figures 29 and 30 have been calculated by use of equations (5) and (10) for six, eight and twelve electron processes, respectively. The experimental correlation (1ine $X$ on Figs. 29 and 30) indicates the number of electrons 


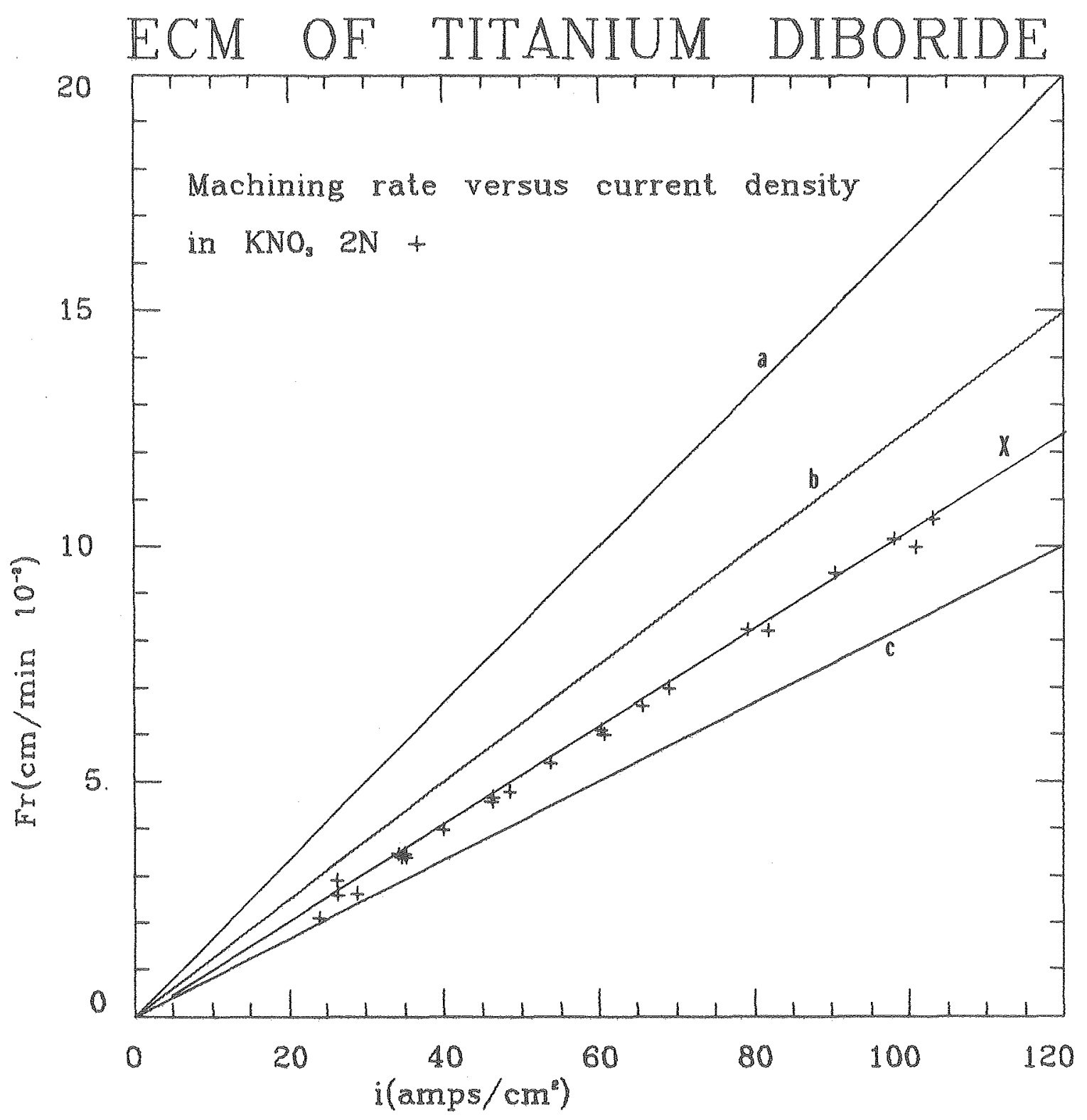

XBL 785-8782

Figure 29. Machining rate versus current density for $\mathrm{TiB}_{2}$ in $\mathrm{KNO}_{3}$. Experimental correlation, line $X$. Theoretical lines: a) 6 electron process

b) 8 electron process

c) 12 electron process 


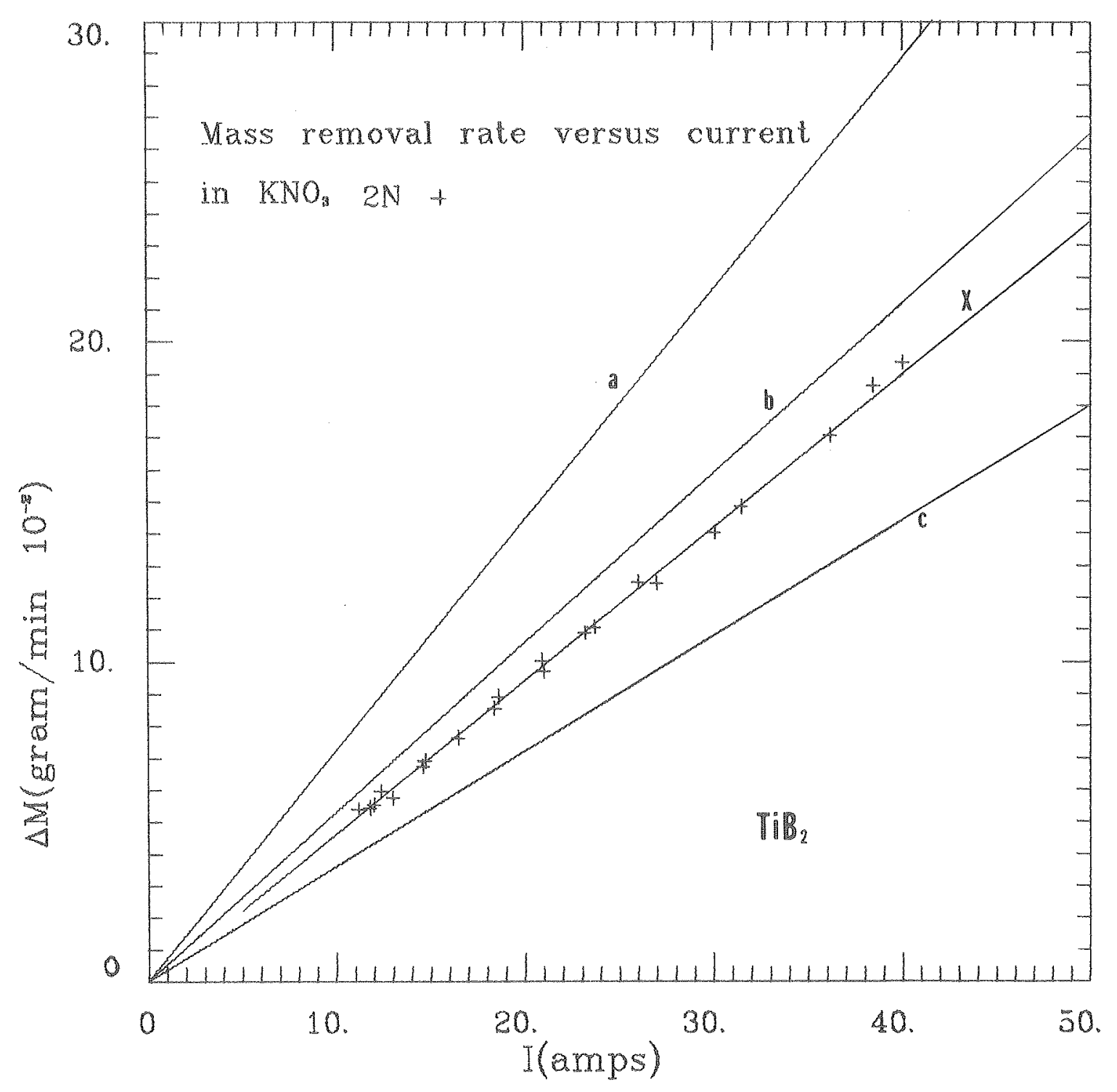

XBL 785-8629

Figure 30. Dissolution rate versus current for $\mathrm{TiB}_{2}$ in $\mathrm{KNO}_{3}$. Experimenta1 and theoretical lines same as in figure 29. 
(9.3 equiv-e $/$ mole) involved in the anodic dissolution of titanium diboride (overall reaction) which is more than 6.7 used for titanium carbide under the same conditions. For example if a tool feed rate of $0.1 \mathrm{~cm} / \mathrm{min}$ is chosen, the current density requixed to machine a piece of titanium diboride is $97.9 \mathrm{~A} / \mathrm{cm}^{2}$ while the same cut is realized on a piece of titanium carbide with $78.9 \mathrm{~A} / \mathrm{cm}^{2}$ (the latter being $81 \%$ of the first current density). This is evidenced by the results listed in the following table for the electrochemical equivalent $(A / z)$ of titanium diboride, where, for comparison, the apparent valence of titanium carbide is also indicated:

\begin{tabular}{|c|c|c|}
\hline $\begin{array}{l}\text { titanium diboride } \\
\text { in } \mathrm{KNO}_{3} 2 \mathrm{~N}\end{array}$ & Fr vs i & $\Delta M$ vS $I$ \\
\hline $\begin{array}{l}\text { slope of } \\
\text { correlation (1ine X) }\end{array}$ & $\begin{array}{l}0.104310^{-2} \\
\mathrm{~cm}^{3} / \text { Amps . min. }\end{array}$ & $\begin{array}{c}0.47810^{-2} \\
\text { gram } / \mathrm{min} \text {. Amps. }\end{array}$ \\
\hline $\begin{array}{l}A / z \\
\text { (experimental exror) }\end{array}$ & $7.43 \pm 0.15$ & $7.68 \pm 0.16$ \\
\hline averaged result & \multicolumn{2}{|c|}{$7.5 \pm 0.2$ grams/Taraday } \\
\hline $\begin{array}{l}\text { apparent valence of } \\
\text { dissolution } z\end{array}$ & \multicolumn{2}{|c|}{$9.3 \pm 0.2$ equiv-e mole } \\
\hline$z$ for TiC & \multicolumn{2}{|c|}{$6.7 \pm 0.2$ equiv-e $/$ mole } \\
\hline
\end{tabular}

Table IX. Observed apparent valence of dissolution for $\mathrm{TiB}_{2}$ in $\mathrm{KNO}_{3}$.

The total number of electrons involved in the observed reaction of dissolution is given by equation (4), as defined in the introduction. These flgures, shown on Table IX, are valid for the overall process, including the possible anodic side reactions which could be: 


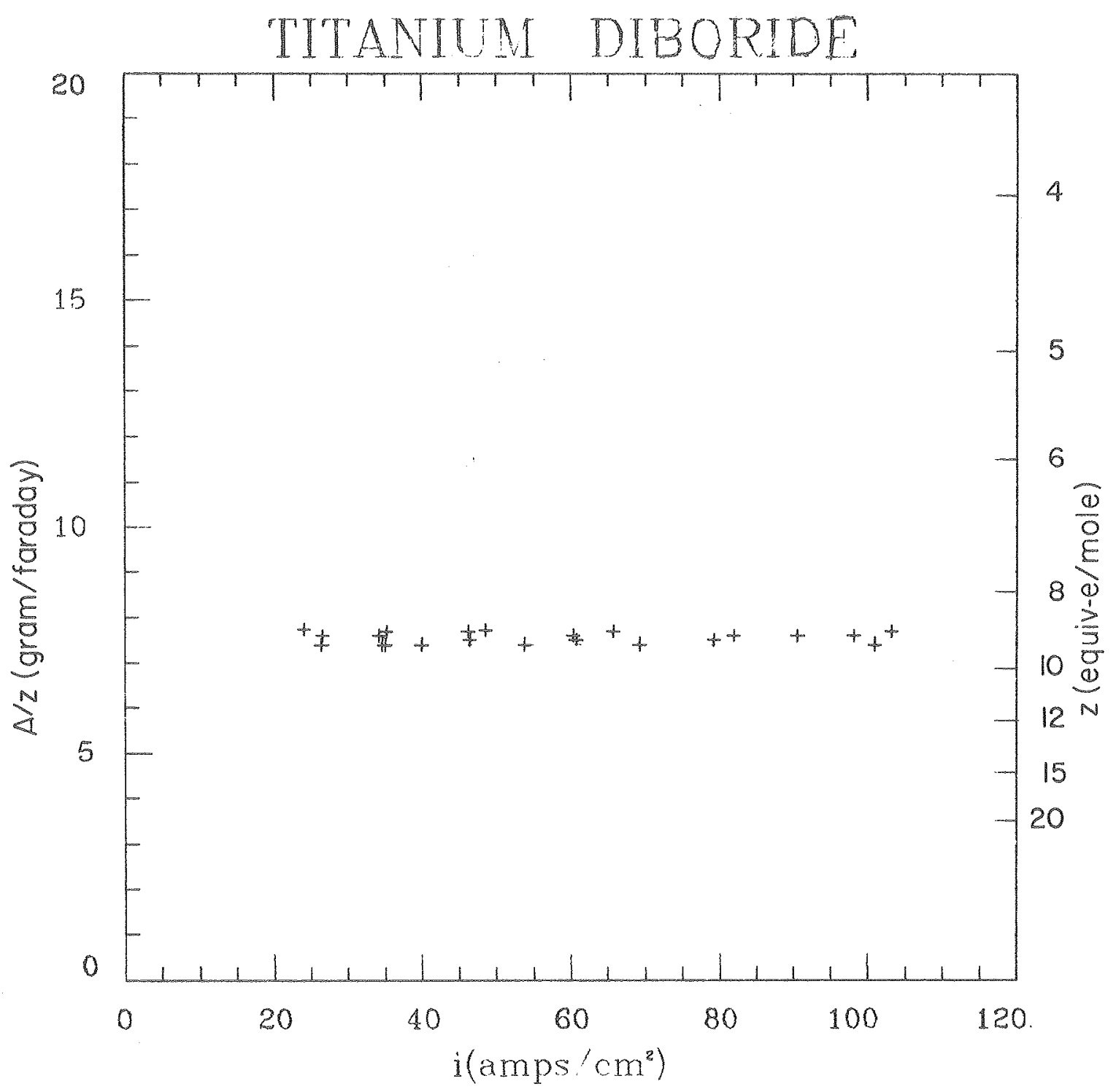

XBL $785-8630$

Figure 31. Electrochemical equivalent $(\mathrm{A} / \mathrm{z})$ and apparent valence of dissolution (z) for $\mathrm{TiB}_{2}$ in $\mathrm{KNO}_{3}$. 
1) Oxygen evolution, which cannot be determined by visual observation of the electrolyte at the outlet of the machining gap (see Fig. 7B), because the hydrogen evolved at the cathode is also present in the flow of electrolyte.

2) Differential dissolution of the material due to the presence of more than one structural phase or more than one element, as observed during ECM of composite materials and multiphase alloys $(20,50)$. The exact chemical analysis of all the reaction products could ascertain this last reaction but was not done.

Figure 31 shows the electrochemical equivalent and the apparent valence of the reaction versus the current density according to equations (12) and (13). The behavior of titanium diboride is constant through the whole range of current density investigated, indicating that the reaction of dissolution occurs with the same apparent valence of dissolution ( 9.3 as determined).

\section{D2. Analysis of the reaction products}

Chemical analysis of the dissolved reaction products has not been attempted during this work because the dilution of these species is very high. It was calculated that, during one experimental run, if the mass dissolved averaged 1 gram, and assuming that a11 the reaction products are soluble, one molecule of dissolved species would. be present in $450 n 00$ molecules of water and electrolyte (2 ppm).

Solid reaction products have been recovered and analyzed After ECM operation, the edges, or walls, of the holes drilled were 

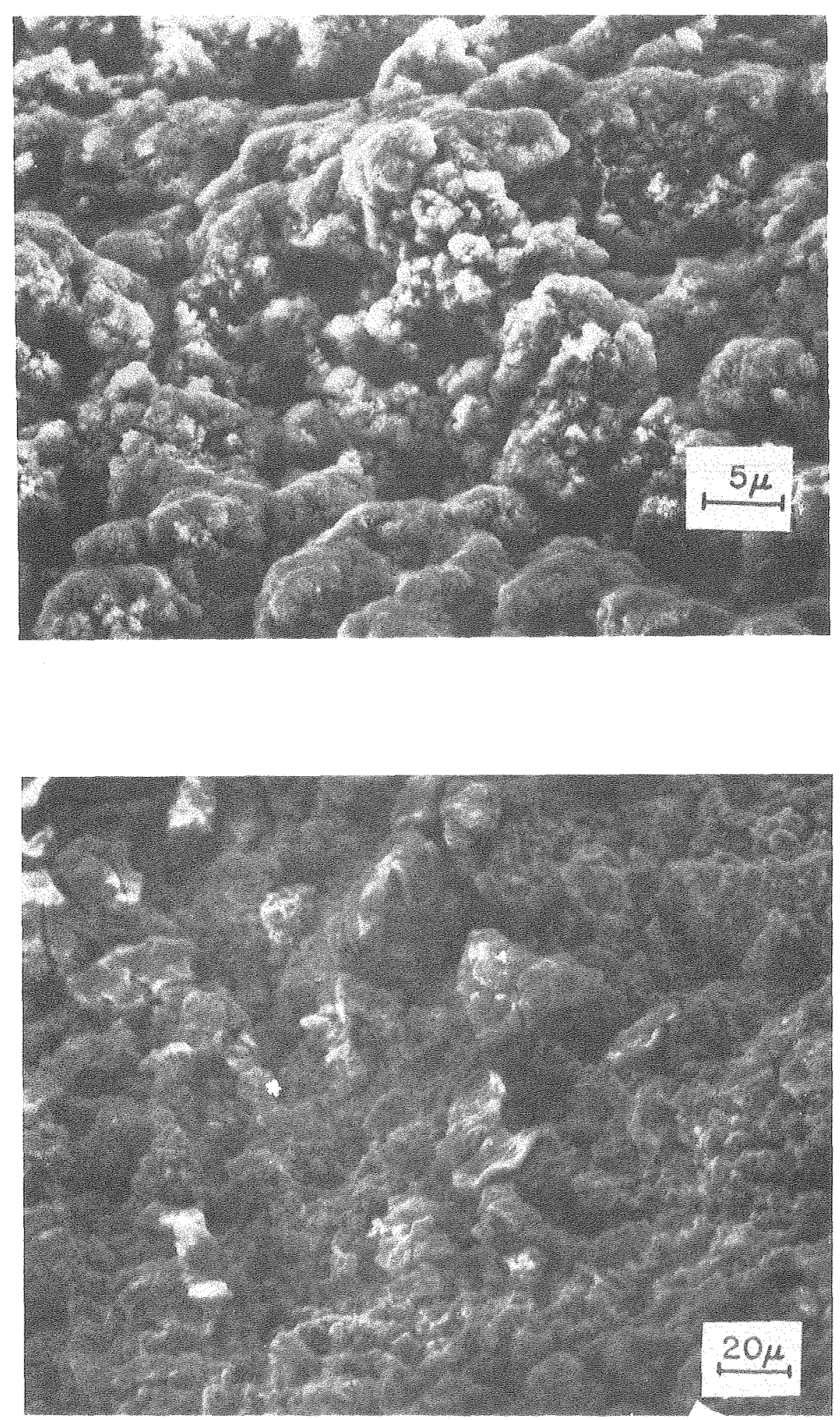

XBB $785-6121$

Figure 32. SeM microphotographs of the white powder recovered on the walls of the holes after ECM of $\mathrm{TIB}_{2}$ in $\mathrm{INO}_{3}$ (top) and of TiC in NaCl (bottom). (scale in $\mu \mathrm{m}$ ) 
covered by a white powder downstream of the feed holes of the cathode. This white powder was present on the walls of the holes after machining $\mathrm{TiB}_{2}$ as well as TiC (Fig. 32). No such material was observed $\mathrm{ZrC}$ or $\mathrm{ZrB} 2$ The powder was recovered carefully and analyzed by $\mathrm{X}$-ray. As only very small amounts (below $1 \mathrm{mg}$ ) were scraped off the walls after each run, 25-30 runs were necessary to fill the capillary used for the analysis. The capillary was placed in a $5.73 \mathrm{~cm}$ diameter Debye Sherrex camera mounted on an X-ray diffraction unit using the Ni filtered Cu radiation at $35 \mathrm{kV}$ and $15 \mathrm{~mA}$. The exposure time to the X-ray beam varied from 4 to 8 hours to obtain visible $X$-ray lines on the film* The films were then processed with $\mathrm{H}-19$ developer for $6^{\circ}$ at $25^{\circ} \mathrm{C}$. The diffraction lines were then measured and compared with the diffraction lines of reference compounds (49).

The results of the $X$-ray analysis are shown on Fig. 33. The diffraction pattern of titanium dioxide $\left(\mathrm{TiO}_{2}\right)$, found as a reference (49), is drawn between the two diffraction patterns of the powder recovered on $\mathrm{TIC}$ (top) and $\mathrm{TiB}_{2}$ (bottom) after machining. The very top and bottom diffraction patterns represent the diffraction patterns of sodium chloride (NaCI) and potassium nitrate $\left(\mathrm{KNO}_{3}\right)$, the electrolytes used to machine $\mathrm{TiC}$ and $\mathrm{T}^{\mathrm{B} B}{ }_{2}$, respectively.

Figure 33 shows that $\mathrm{TiO}_{2}$ is part of the reaction products after anodic dissolution of $\mathrm{TiC}$ and $\mathrm{TiB}_{2} \cdot$ Regardless of the electrolyte used. The other diffraction lines were proven to be caused by the

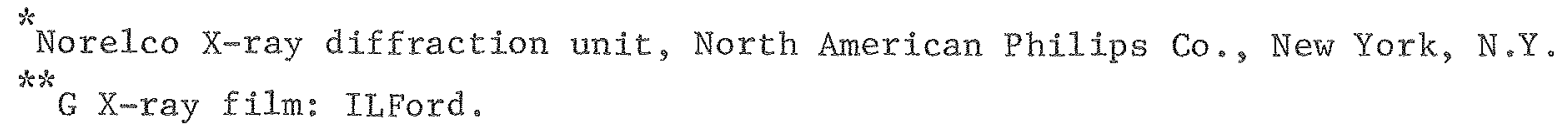




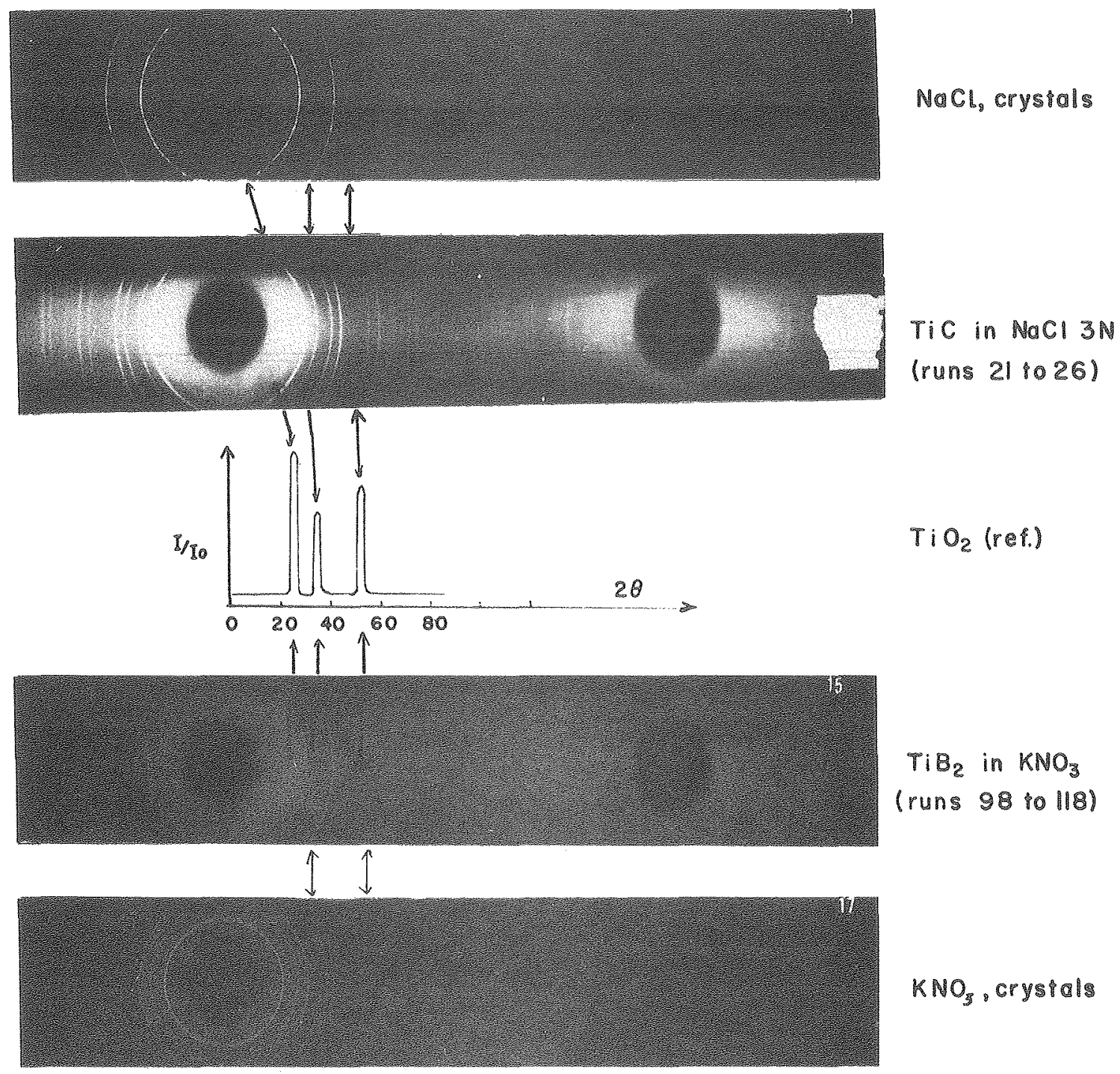

XBB $\quad 785-6497$

Figure 33. X-ray analysis of the solid reaction products after ECM of $\mathrm{TiC}$ (top) and $\mathrm{TiB}_{2}$ (bottom). The X-ray diffraction pattern of the electrolytes used are shown as references. The diffraction lines of $\mathrm{TiO}_{2}$ are also indicated (ref. 49). 
electrolyte; the lines at large diffraction angles axe not identified. The other oxides of titanium: Tio[Ti(t2)], Ti $\mathrm{O}_{3}[\mathrm{Ti}(+3)]$ and $\mathrm{Ti}_{3} \mathrm{O}_{5}[\mathrm{Ti}(3.33)]$ as well as the titanates: $\mathrm{NaTiO}_{2}[\mathrm{TI}(+3)]$ and $\mathrm{Na}_{2} \mathrm{TiO}_{4} \mathrm{H}_{2} \mathrm{O}$ $[\mathrm{Ti}(+6)]$ have been ruled out as possible solid products because they should show diffraction lines at very low angles which were not observed (49).

Although the reaction mechanism cannot be derived from the present experiments, the following overal1 reaction can be proposed on the basis of the experimentally determined apparent valence and of one of the reaction products $\left(\mathrm{T}_{2} \mathrm{O}_{2}\right)$. The overall reaction is written for titanium as:

$$
\mathrm{Ti} \rightarrow \mathrm{Ti}^{4+}+4 \mathrm{e}^{-} \rightarrow \mathrm{TiO}_{2}
$$

Current efficiencies for the ECM of titanium alloys (below $10 \%$ of alloying elements such as $\mathrm{Cu}, \mathrm{A} 1, \mathrm{Mo}$, and $\mathrm{Si}$ ) determined by Bannard (50) supported the following mechanism of reaction proposed before by chen et a1. (51):

$$
\begin{gathered}
\mathrm{Ti}+\mathrm{H}_{2} \mathrm{O} \rightarrow \mathrm{TiO}+2 \mathrm{H}^{+}+2 \mathrm{e}^{-} \\
\mathrm{TiO}+1 / 2 \mathrm{H}_{2} \mathrm{O} \rightarrow 1 / 2 \mathrm{Ti}_{2} \mathrm{O}_{3}+\mathrm{H}^{+}+\mathrm{e}^{-} \\
1 / 2 \mathrm{Ti}_{2} \mathrm{O}_{3}+1 / 2 \mathrm{H}_{2} \mathrm{O} \rightarrow \mathrm{TiO}_{2}+\mathrm{H}^{+}+\mathrm{e}^{-}
\end{gathered}
$$

The sum of these three reactions yields equation 21 representing the overall reaction for titanium. The valence th found here for titanium is consistent with that result and the same equation 21 represent 
the dissolution of titanium in $\mathrm{TiC}$ and $\mathrm{TiB} 2^{\circ}$

$$
\mathrm{Ti}+2 \mathrm{H}_{2} \mathrm{O} \rightarrow \mathrm{TiO}_{2}+4 \mathrm{H}^{+}+4 \mathrm{e}^{-}
$$

Unfortunately, no experimental data for the electrochemical reaction of carbon and boron have been obtained. If gaseous anodic products are formed, they would be difficult to observe in the presence of large amounts of cathodic hydrogen evolved. As proposed by Cowling and Hintermann (52) the anodic oxidation of TiC produce Ti[IV] ions, $\mathrm{CO}$ and $\mathrm{CO}_{2}$; the apparent valence of the reaction of dissolution of TiC has been determined as being +7 in pure sulfuric acid on a rotating disc electrode; this is in agreement with the findings of this work $(z=6.7 \pm 0.2)$. Furthermore, the Pourbaix diagrams (53) indicate that the oxidation of carbon and/or boron produces only gaseous or dissolved species which could not be analyzed in the present work.

The experimental determination of the valence of dissolution for TiC and $\mathrm{TiB}_{2}$ yields 6.7 and 9.3 respectively; assuming that titanium is dissolving in the +4 state, this suggests that 2.7 electrons are used for the oxidation of carbon and 2.8 for boron.

$$
\text { If } z_{x} \text { represents the valence of dissolution of titanium, } z_{y}
$$

the valence of caxbon or boron (depending on the material), $a$ and $b$ are the stoichiometry of the material $(a=b=1$ for $\mathrm{TiC}, \mathrm{a}=1$, $b=2$ for $\left.T i B_{2}\right)$, then the electrochemical equivalent for the compound can be expressed by equation $4:$

$$
\left(\frac{A}{z}\right)_{\text {observed }}=\frac{\bar{A}}{a z_{x}+b z_{y}} .
$$


The valence for each element in the compound cannot be assigned positively; also the observed electrochemical equivalent is affected by the current efficiency for the dissolution process. Although the reproductibility of the overall valence is $2-3 \%$, errors in valence for carbon and boron axe 1ikely to be higher $(6-7 \%)$. Thus, assuming Ti to be oxidized to $T i(+4)$, valences for $C$ and $B$ are found to be:

$$
\begin{aligned}
& z(C)=2.7 \pm 0.2 \\
& z(B)=2.8 \pm 0.2 .
\end{aligned}
$$

The present result for boron $(z \approx 3)$ is in agreement with the Pourbaix diagram; the only stable state of oxidation between B[0] solid and a gaseous or other dissolved species is $B[+3]$.

The average valence of carbon (2.7) could be assigned among $\mathrm{CO}$ and $\mathrm{CO}_{2}$ by the use of a mixing rule, where most of the carbon is oxidized to $C O$ in the +2 state.

The following overall reactions are consistent with the experimental observations:

$$
\begin{aligned}
& \text { for } \mathrm{TiC}: \mathrm{TiC}+3 \mathrm{H}_{2} \mathrm{O} \rightarrow \mathrm{TiO}_{2}+\mathrm{CO}+6 \mathrm{H}^{+}+6 \mathrm{e}^{-} \\
& \text {for } \mathrm{TiB}_{2}: \mathrm{TiB}_{2}+5 \mathrm{H}_{2} \mathrm{O} \rightarrow \mathrm{TiO}_{2}+\mathrm{B}_{2} \mathrm{O}_{3}+10 \mathrm{H}^{+}+10 \mathrm{e}^{-}
\end{aligned}
$$

D3. Frontal gap of dissolution

As for titanium carbide (see Fig. 13) the frontal gap of dissolution is determined by the same experimental procedure according to equations (11) and (16) 
Table X. Experimental data for figure 34. ECM gap versus current density for $\mathrm{TiB}_{2}$ in $\mathrm{KNO}_{3}$.

\begin{tabular}{|c|c|c|c|c|c|c|c|}
\hline $\begin{array}{c}\text { RUN } \\
\forall\end{array}$ & $\begin{array}{l}\mathrm{S} . \mathrm{G} . \\
\mathrm{mils}\end{array}$ & $\begin{array}{c}\text { H hole } \\
\mathrm{cm} .\end{array}$ & & $\begin{array}{l}\text { ram dial } \\
\text { mils }\end{array}$ & $\begin{array}{c}\text { ECM gap } \\
\text { mils }\end{array}$ & $\stackrel{i}{\mathrm{~A} / \mathrm{cm}^{2}}$ & $\begin{array}{l}\text { aV } \\
\text { Volts }\end{array}$ \\
\hline & APPLIED & VOITAGE & $=20$ & Volts & & & \\
\hline 95 & 12 & 0.880 & & 333 & 25 & 29.1 & 20.8 \\
\hline 105 & 12 & 1.060 & & 402 & 27 & 26.4 & 20.0 \\
\hline 109 & 12 & 1.035 & & 396 & 23 & 34.6 & 21.0 \\
\hline 96 & 12 & 1.055 & & 405 & 22 & 40.0 & 20.5 \\
\hline 97 & 18 & 1.050 & & 4.15 & 16 & 46.5 & 20.6 \\
\hline 98 & 17 & 1.060 & & 420 & 14 & 53.8 & 20.5 \\
\hline 99 & 12 & 1.070 & & 420 & 13 & 60.3 & 20.6 \\
\hline & APPLIED & VOLTAGE & $=25$ & Volts & & & \\
\hline 112 & 12 & 0.625 & & 216 & 42 & 24.1 & 25.1 \\
\hline 113 & 27 & 0.900 & & 340 & 25 & 34.2 & 25.1 \\
\hline 114 & 12 & 0.955 & & 364 & 24 & 46.3 & 25.0 \\
\hline 100 & 12 & 1.080 & & 420 & 17 & 60.7 & 24.3 \\
\hline 101 & 12 & 1.065 & & 416 & 15 & 69.2 & 24.5 \\
\hline 103 & 12 & 0.830 & & 324 & 14 & 81.8 & 24.3 \\
\hline 102 & 12 & 1.045 & & 4.11 & 12 & 79.3 & 24.4 \\
\hline
\end{tabular}

APPLIED VOLTAGE $=30$ Volts

$\begin{array}{lllllll}118 & 17 & 0.515 & 170 & 52 & 26.6 & 29.5 \\ 115 & 12 & 1.045 & 393 & 26 & 48.6 & 29.4 \\ 108 & 12 & 1.085 & 422 & 17 & 65.7 & 29.4 \\ 106 & 12 & 0.670 & 258 & 14 & 101.0 & 28.4 \\ 116 & 7 & 1.080 & 420 & 12 & 98.2 & 29.1 \\ 117 & 7 & 1.150 & 446 & 14 & 103.3 & 31.2\end{array}$




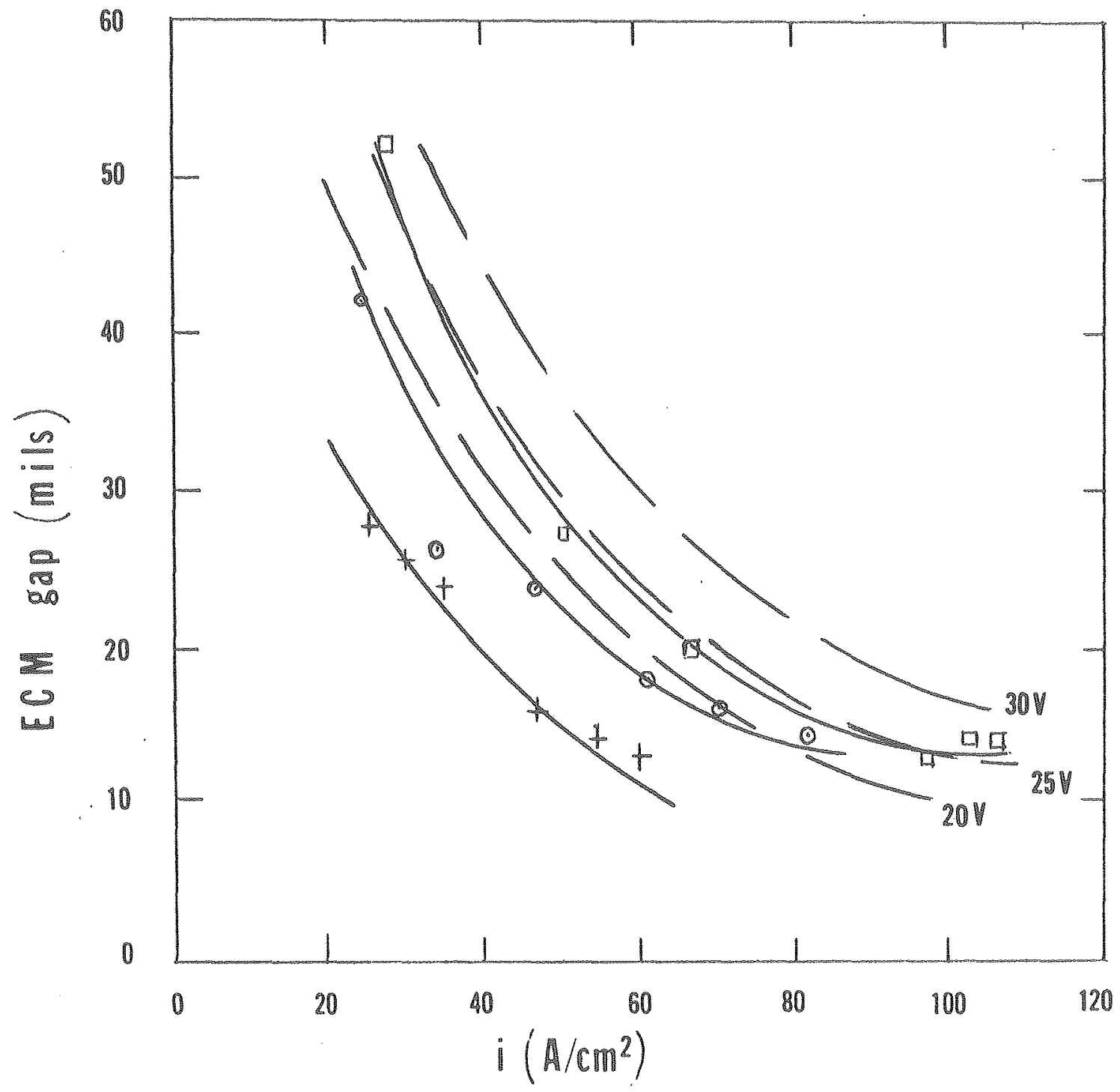

XBL 786-9262

Figure 34. Frontal gap of dissolution for $\mathrm{TiB}_{2}$ in $2 \mathrm{~N}^{2} \mathrm{KNO}_{3}$; the broken lines represent the theoretical correlations (equation 17). Experimental data: 20 Volts $(+), 25$ Volts (0) and 30 Volts (0). 


$$
\begin{aligned}
& \text { ECM gap }=\frac{k(\Delta V-n)}{i} \\
& \text { ECM gap }=h+S \cdot G_{0}-\delta
\end{aligned}
$$

where $k$ is the conductivity of the electrolyte during the xun,

$\Delta V$, the applied voltage between the cathodic toolpiece and the anodic workpiece

$n$, the sum of the overvoltages and the electrodes potentials

SG, the starting gap set before ECM operation

$\delta$, the total movement of the toolpiece

$h$, the depth of the hole.

No direct measurement of the overvoltage in equation (16) can be made so that it is neglected with respect to the overall applied voltage for the theoretical correlations (broken lines on Fig. 34). The assumption is certainly not justified for the low voltages but the trend assumed by the experimental correlations show a similar behavior to that expected; the offset between theoretical and experimental correlations possibly giving a relatively good idea for the value of the overvoltage for different operating current densities. The theoretical correlations are calculated assuming a temperature of $25^{\circ} \mathrm{C}$ and a conductivity of $0.145 \Omega^{-1} \mathrm{~cm}^{-1}$ for $\mathrm{KNO}_{3} 2 \mathrm{~N}$ in equation (17). Below 15 Volts, because of the passive state of $\mathrm{TiB}_{2}$, and the consequent high voltage losses through the surface oxide, the obtainable current density is too low to accommodate even the lowest tool advancement rate $\left(2.510^{-2} \mathrm{~cm} / \mathrm{min}\right)$ available on our ECM equipment. For this reason, instead of achieving an "equilibrium" machining condition, the cathodic tool would eventually come into physical contact with the workpiece, causing an electrically short circuit. 


\section{D4. Current voltage relationship}

Figure 35 shows the relation between the applied voltage and the current density for the dissolution of titanium diboride under ECM conditions in $2 \mathrm{~N}$ potassium nitrate at two different gaps (14 and 25 mils). The extrapolation to zero current density of the experimental Iineax correlation shows that the overvoltage associated with the dissolution of titanium diboride (11-12 Volts) is larger than that of the dissolution of titanium carbide ( $5-6$ Volts). The same large values of overvoltages are obtained at constant current density by the difference between the experimental line and the ohmic drop in the electrolyte. It is therefore concluded that the presence of boron in the material affects its chemical behavior in a different manner than the presence of carbon.

The high overvoltages might also explain the fact that no ECM is possible below 15 Volts at low current densities, where the IR drop in the electrolyte is of the same order of magnitude as seen on Fig. 35 .

D5. SEM analysis: effect of the current density

The surface appears etched as shown on the photographs of Fig. 36 representing the surface of the bottoms of the holes drilled in $\mathrm{KNO}_{3}$. This etching appears on the SEM micrographs (Fig. 36) at three different magnifications. The appearance of the surface is independent of the current density as shown in the two series of expeximental runs shown here at two different feed rates $\left(2.510^{-2}\right.$ and $8.510^{-2} \mathrm{~cm} / \mathrm{min}$ ) respectively for the left and the right side of $\mathrm{Fig} .36$. 


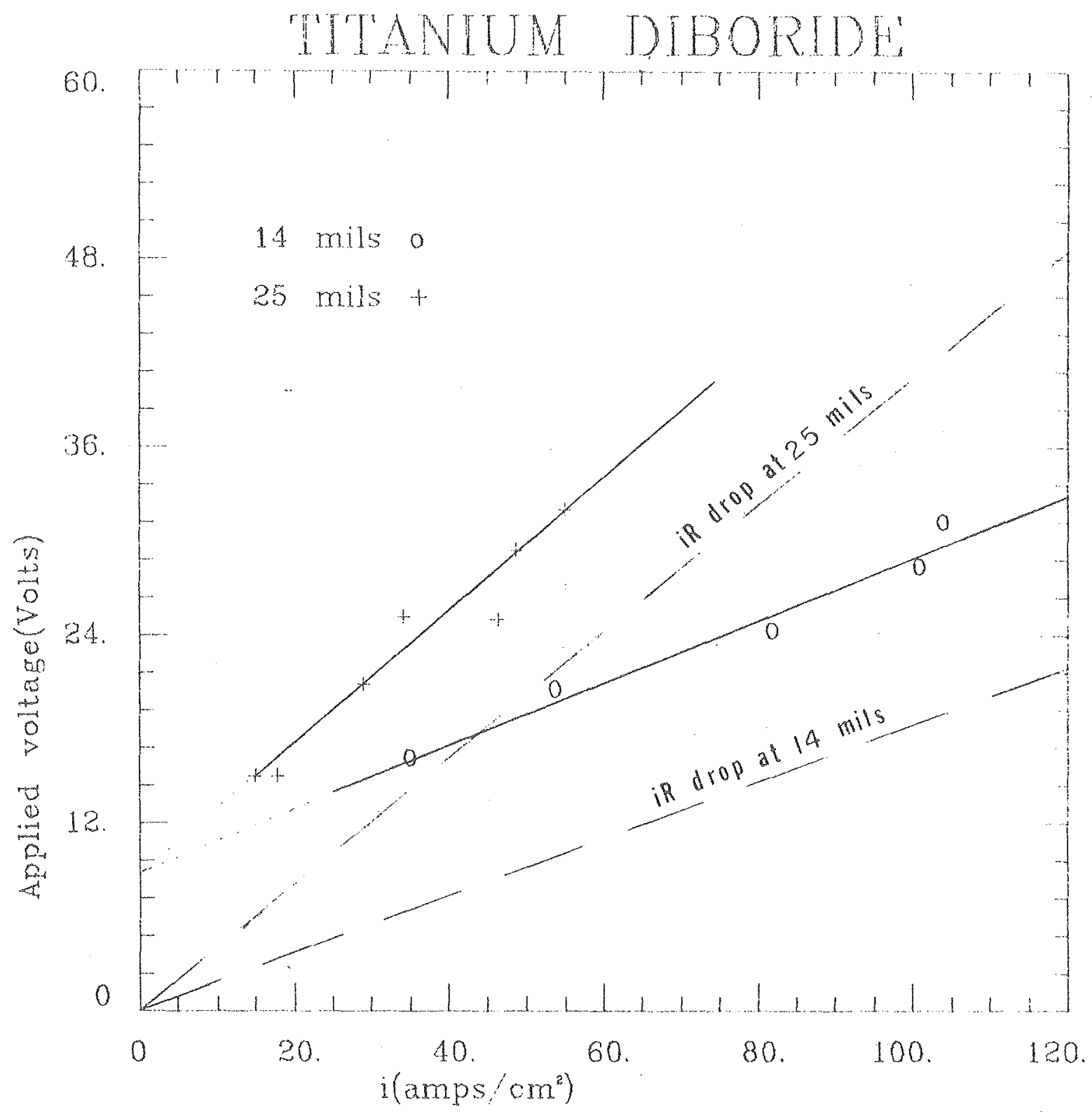

XBL 785-8639

Figure 35. Polarization curve for $\mathrm{TiB}_{2}$ in $2 \mathrm{~N}$ potassium nitrate at two ECM gaps. 

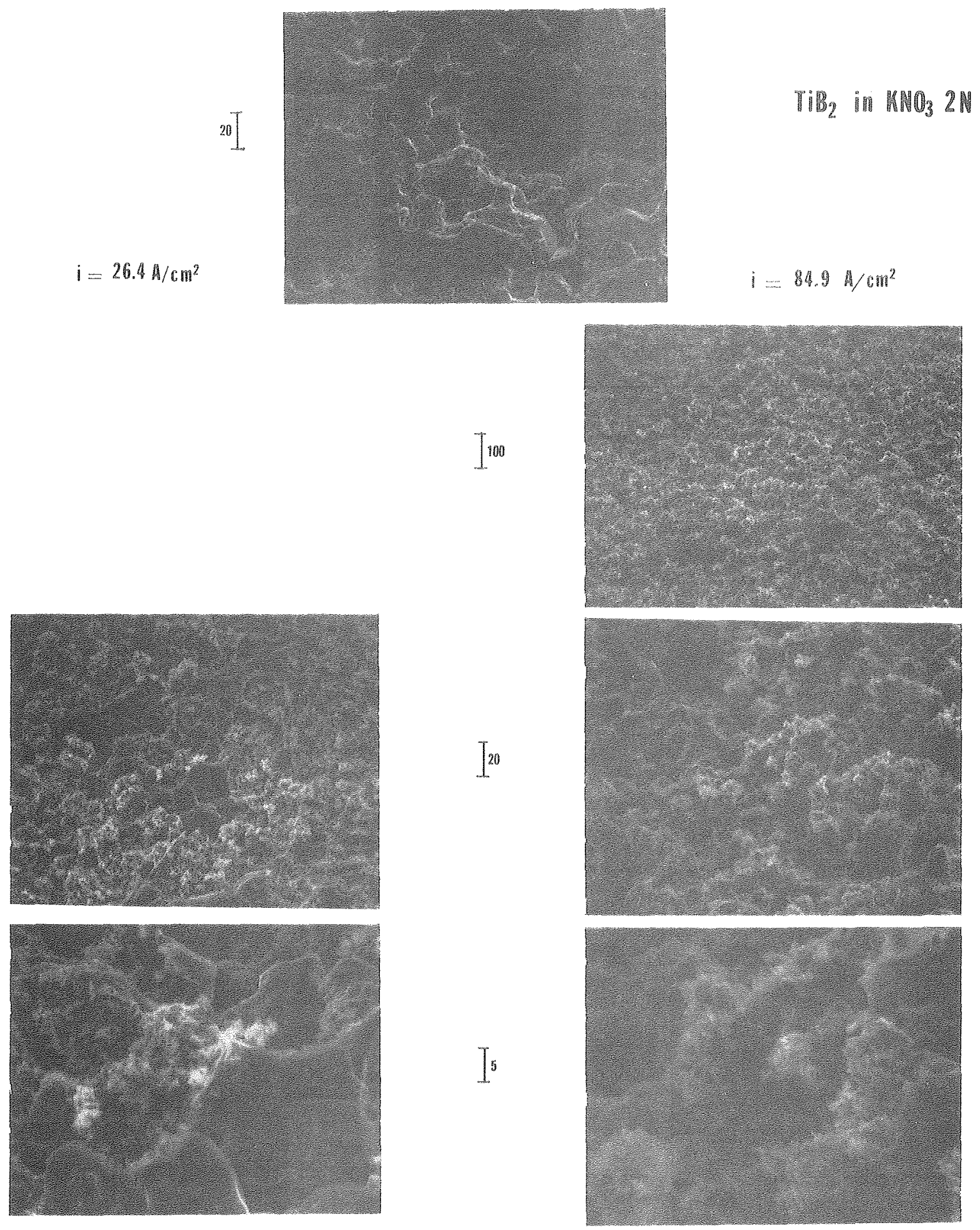

XBB $785-5628$

Figure 36. SEM microphotographs; appearance of the machined areas on ${ }^{\mathrm{T} i \mathrm{~B}} 2^{\circ}$. Effect of the current density in $\mathrm{KNO}_{3}{ }^{\circ}$ (scale in $\mathrm{\mu m}$ ) 
Table XI. Experimental data for $\mathrm{TiB}_{2}$ in $2 \mathrm{~N} \mathrm{KNO}_{3} \cdot$ Flow rates in liter/min, A/z in gram/Faraday.

\begin{tabular}{|c|c|c|c|c|c|c|c|c|c|c|c|c|}
\hline $\begin{array}{l}\text { RUN } \\
\#\end{array}$ & $\begin{array}{l}\text { Press. } \\
\text { (psig) }\end{array}$ & $\begin{array}{l}\text { Flow } \\
\text { rate }\end{array}$ & $\begin{array}{l}\text { T'ure } \\
\left({ }^{\circ} \mathrm{C}\right)\end{array}$ & $\begin{array}{l}\text { AV } \\
\text { (rolts) }\end{array}$ & $\begin{array}{c}I \\
\text { (amps) }\end{array}$ & $\begin{array}{c}\operatorname{Fr} \\
10^{-2} \mathrm{~cm} / \mathrm{mm}\end{array}$ & $\begin{array}{l}\text { hole } \not \\
(\mathrm{cm} .)\end{array}$ & $\left(\mathrm{A} / \mathrm{cm}^{2}\right)$ & $\begin{array}{c}M^{0} \\
10^{-2} \mathrm{~g} / \mathrm{mn} .\end{array}$ & density/t & $\begin{array}{c}k \text { at } \\
\Omega^{-1} \mathrm{~cm}^{-1}\end{array}$ & $\begin{array}{l}A / z \\
(g / c \mid b)\end{array}$ \\
\hline 112 & 75 & 8.03 & $29^{\circ} \mathrm{C}$ & 25.1 & 31.2 & 2.10 & 0.770 & 24.1 & 5.39 & $1.12650 / 24^{\circ} \mathrm{C}$ & 0.189 & 7.74 \\
\hline 110 & 83 & 3.51 & $28.5^{\circ} \mathrm{C}$ & 17.8 & 12.4 & 3.40 & 0.670 & 35.2 & 5.96 & $1.12350 / 28.5^{\circ} \mathrm{d}$ & 0.186 & 7.1 \\
\hline 95 & 72 & 5.75 & $29^{\circ} \mathrm{C}$ & 20.8 & 13.0 & 2.61 & 0.755 & 29.0 & 5.76 & $1.12000 / 20^{\circ} \mathrm{C}$ & 0.180 & 7.7 \\
\hline 96 & 74 & 5.25 & $31^{\circ} \mathrm{C}$ & 20.5 & 16.5 & 3.97 & 0.725 & 40.0 & 7.64 & $1.12250 / 27.5^{\circ} \mathrm{d}$ & 0.196 & 7.4 \\
\hline 134 & 25 & 3.16 & $33.5^{\circ} \mathrm{C}$ & 25.0 & 18.6 & 4.57 & 0.715 & 46.3 & 8.91 & $1.12450 / 30.5^{\circ} \mathrm{d}$ & 0.213 & 7.7 \\
\hline 125 & 44 & 4.80 & $29.5^{\circ} \mathrm{C}$ & 29.4 & 20.9 & 4.78 & 0.740 & 48.6 & 10.04 & $1.12500 / 31^{\circ} \mathrm{C}$ & 0.194 & 7.7 \\
\hline 98 & 70 & 4.08 & $34^{\circ} \mathrm{C}$ & 20.5 & 21.0 & 5.38 & 0.705 & 53.8 & 9.71 & $1.12175 / 30^{\circ} \mathrm{C}$ & 0.212 & 7.4 \\
\hline 99 & 82 & 3.91 & $30^{\circ} \mathrm{C}$ & 20.6 & 23.2 & 6.10 & 0.700 & 60.3 & 10.91 & $1.12050 / 32^{\circ} \mathrm{C}$ & 0.187 & 7.6 \\
\hline 101 & 77 & 3.99 & $31^{\circ} \mathrm{C}$ & 24.5 & 27.0 & 7.00 & 0.705 & 69.2 & 12.47 & $1.12450 / 24^{\circ} \mathrm{C}$ & 0.197 & 7.4 \\
\hline 102 & 73 & 3.28 & $30^{\circ} \mathrm{C}$ & 24.3 & 30.1 & 8.23 & 0.695 & 79.3 & 14.05 & $1.12400 / 26^{\circ} \mathrm{C}$ & 0.192 & 7.5 \\
\hline 107 & 82 & 4.06 & $32^{\circ} \mathrm{C}$ & 29.4 & 40.0 & 9.43 & 0.725 & 90.6 & 19.38 & $1.12600 / 28^{\circ} \mathrm{C}$ & 0.205 & 7.6 \\
\hline 106 & 86 & 3.19 & $30^{\circ} \mathrm{C}$ & 28.4 & 40.0 & 9.99 & 0.710 & 101.0 & 18.39 & $1.12600 / 28^{\circ} \mathrm{C}$ & 0.196 & 7.4 \\
\hline 117 & 83 & 3.25 & $25.5^{\circ} \mathrm{C}$ & 31.2 & 38.5 & 10.60 & 0.690 & 103.3 & 18.65 & 1. $12950 / 22^{\circ} \mathrm{C}$ & 0.175 & 7.7 \\
\hline
\end{tabular}


E. Zirconium Diboride

E1. Electrochemical behavior

Zirconium diboride is a matexial with excellent high temperatures properties, high melting point, excellent oxidation resistance and good high temperature strength (see Table I, Chapter II). It is often used in applications where resistance to corrosion is needed.

Some little cracks were visible on the edges of the samples received, presumably due to the manufacturing process, but were proven not to interfere much during the anodic dissolution. These cracks were not large and, if small variations were observed in the operating parameters (current or pressure drop) due to an abrupt increase in the machining gap because of the presence of a crack, they were not large to affect the ECM.

Figures 37 and 38 represent the characteristic curves of dissolution. It is to be noticed, by contrast to the previous materials investigated in this work, that the behavior of zirconium diboride is not constant over the range of current density used. The dissolution process seems to be different at low current densities than at high current density. The experimental correlations shown on these figures do not pretend to be quantitative at low current density: because of the lack of data available in this region, the investigation of the dissolution at low machining rates was not possible because the equipment used did not allow tool advancement rates below $2.510^{-2} \mathrm{~cm} / \mathrm{min}$.

Thus, the experimental correlation on the Figs, 37 and 38 , corresponding to the low current densities, represent only a qualitative behavior for the anodic dissolution of zirconium diboride in $\mathrm{KNO}_{3}$. 


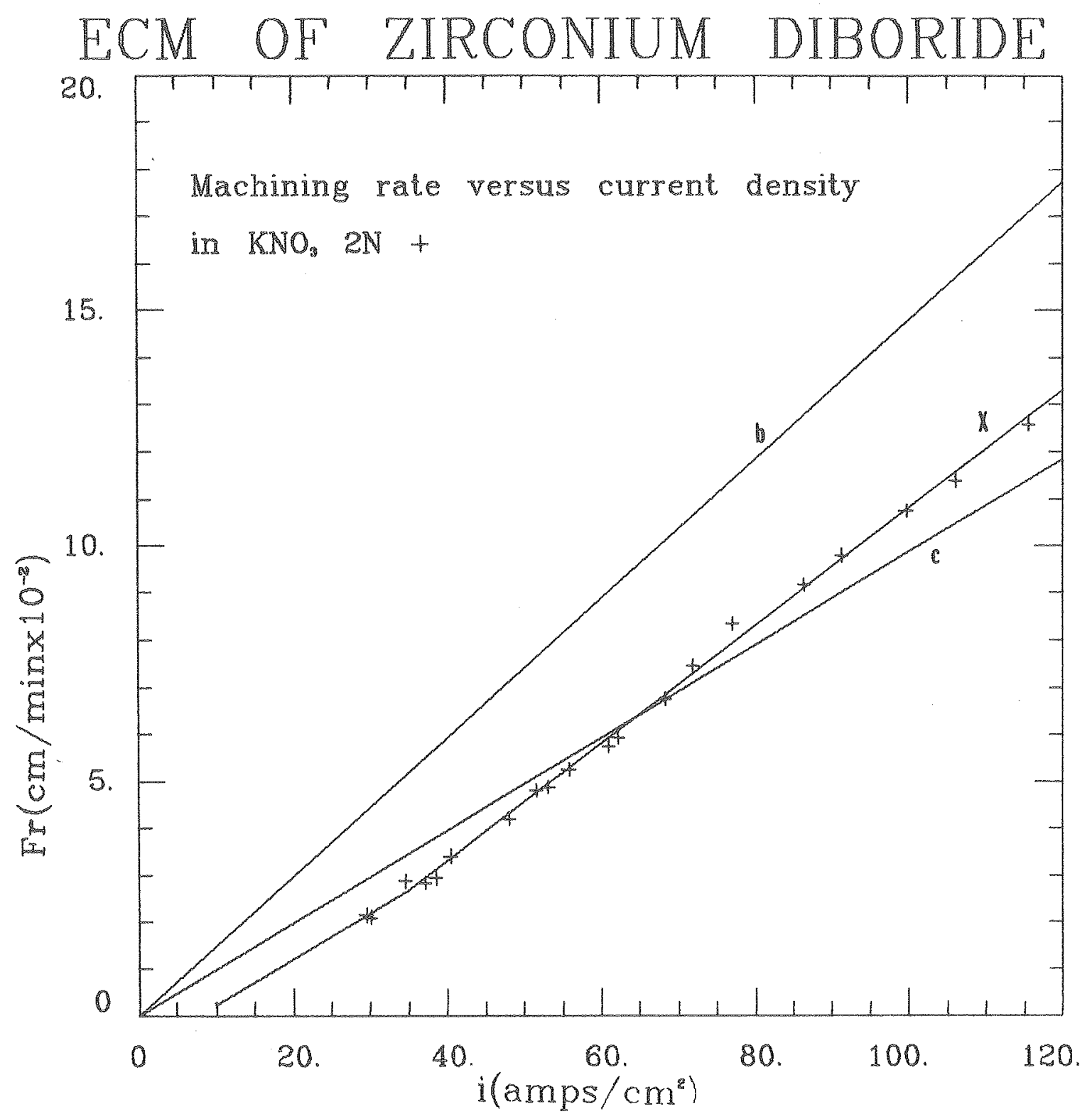

XBL $785-8634$

Figure 37. Machining rate versus current density for $\mathrm{ZrB}_{2}$ in $\mathrm{kNO}_{3}$. Experimental correlation, line $X$.

Theoretical lines: b) 8 electron process

c) 12 electron process 


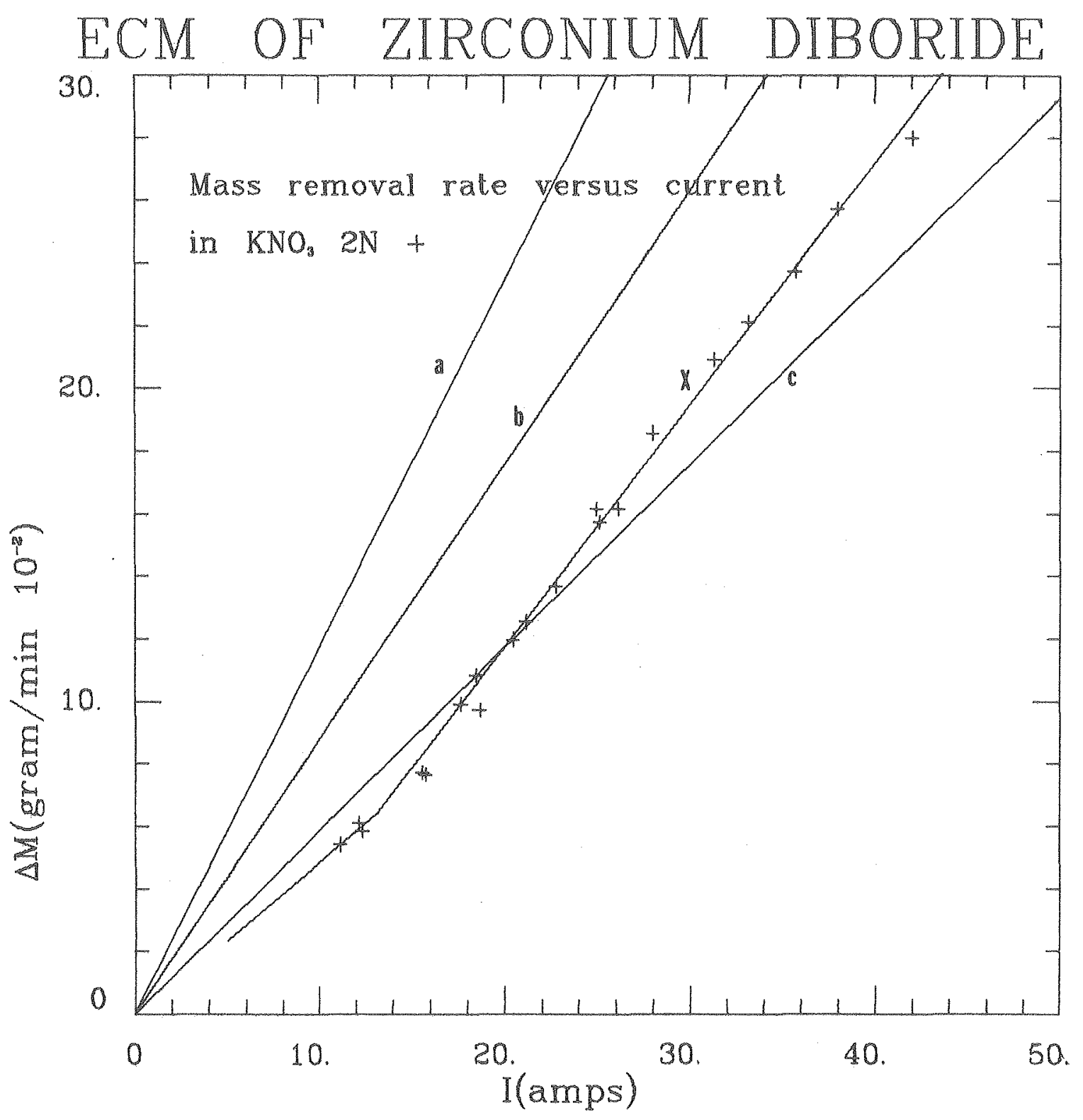

XBL $785-8635$

Figure 38. Dissolution rate versus current for $\mathrm{ZrB}_{2}$ in $\mathrm{KNO}_{3}$. Expeximental and theoretical lines same as in figure 37 . 
This surprising behavior could be ascribed to a transpassive dissolution with a low apparent valence occurxing at the higher current densities.

The theoretical lines included in the figures are calculated from equations 5 and 10 and represent two dissolution processes occurring with eight (Iine b) and twelve (line c) electrons.

The following table lists the values of the electrochemical equivalents and the apparent valences for the dissolution of zirconium diboride in $2 \mathrm{~N}$ potassium nitrate measured experimentally in the two different modes.

\begin{tabular}{|c|c|c|c|}
\hline $\mathrm{ZrB} 2$ & $\begin{array}{l}\text { current } \\
\text { density }\end{array}$ & Fr vs $i$ & $\Delta M$ vs $I$ \\
\hline $\begin{array}{l}\text { slope of } \\
\text { correlation } \\
\text { (1ine X on Figs. } \\
37 \& 38)\end{array}$ & $\begin{array}{l}\text { low } \\
\text { high }\end{array}$ & $\begin{array}{l}9.7510^{-2} \\
0.12010^{-2} \\
\mathrm{~cm}^{3} / \mathrm{Amin} .\end{array}$ & $\begin{array}{l}0.50210^{-2} \\
0.75010^{-2} \\
\text { gram/A min. }\end{array}$ \\
\hline $\begin{array}{l}\mathrm{A} / \mathrm{z} \\
\text { exp. correlation }\end{array}$ & $\begin{array}{l}\text { low } \\
\text { high }\end{array}$ & $\begin{array}{l}9.1 \\
11.2 \pm 0.2\end{array}$ & $\begin{array}{l}8.1 \\
11.9 \pm 0.2\end{array}$ \\
\hline $\begin{array}{l}\mathrm{A} / \mathrm{z} \\
\text { averaged on } \\
\text { both measures }\end{array}$ & $\begin{array}{l}\text { low } \\
\text { high }\end{array}$ & \multicolumn{2}{|c|}{$\begin{array}{c}8 \pm 1 \\
11.5 \pm 0.4\end{array}$} \\
\hline $\begin{array}{l}\text { apparent valence } \\
\text { of dissolution } \\
\text { (equation } 5 \text { ) }\end{array}$ & $\begin{array}{l}\text { Low } \\
\text { high }\end{array}$ & \multicolumn{2}{|c|}{$\begin{array}{c}14 \pm 1 \\
9.8 \pm 0.3\end{array}$} \\
\hline
\end{tabular}

Table XI. Observed apparent valence of $\mathrm{ZrB}_{2}$ in $\mathrm{KNO}_{3}$.

Because the error associated with the determination of the electrochemical equivalent at low current densities is large due to the small number of experimental runs in this region. A quantitative correlation is not attempted here. 


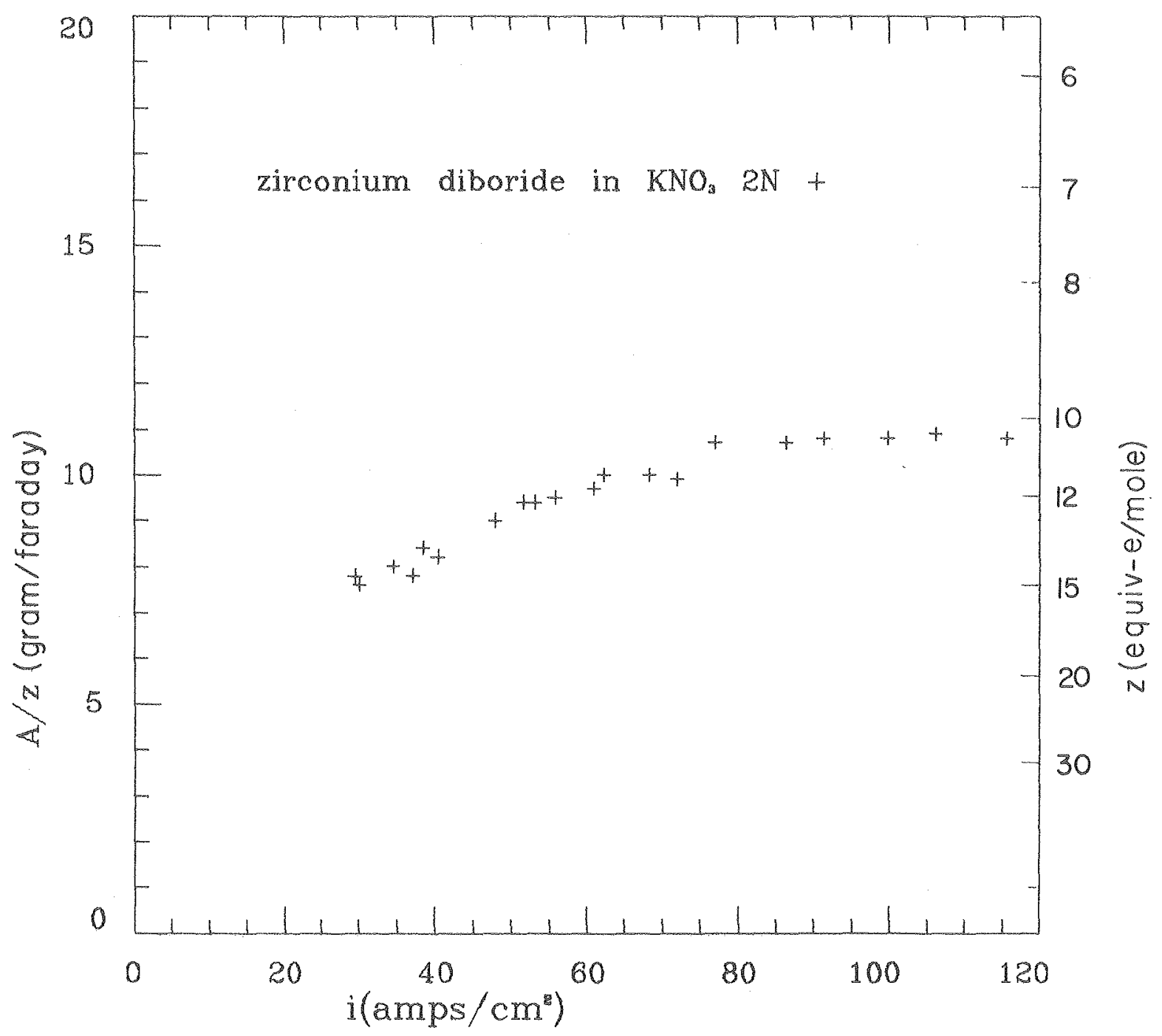

XBL. $785-8779$

Figure 39. Electrochemical equivalent $(A / z)$ and apparent valence $(z)$ of dissolution for $\mathrm{ZrB} 2$ in $2 \mathrm{~N}_{2} \mathrm{KNO}_{3}$. 
Further evidence of this transpassive behavior is shown on Fig. 39, by plotting the electrochemical equivalent and the apparent valence of dissolution versus the current density for each experimental run. The small value of $\mathrm{A} / \mathrm{z}$ at low current density reflects a high valence of dissolution in that region, as would be expected for a passivation phenomenon where side reactions are likely to occur on the anodic side.

The gradual change observed in the apparent valence of the dissolution reaction suggests that the overal1 process varies with the current density and reaches a steady state above $50 \mathrm{~A} / \mathrm{cm}^{2}$.

\section{E2. Frontal gap of dissolution}

Using the same equations 11 and 16 as for titanium carbide and titanium diboride, the frontal gap of dissolution is determined for the ECM of zirconium diboride in $\mathrm{KNO}_{3}$.

The same effect is observed: the general trend assumed by the experimental curves, being parallel to the theoretical calculations, (equation 16) represents the expected one.

The important parameters used in Fig. 40 are listed in Table XIII. Unlike titanium diboride, ECM of zirconium diboride is possible below 15 Volts because of its ability to dissolve in the passive state, probably due to the large porosity of the anodic film formed during passivation which does not prevent complete dissolution of the covered surface.

In the experimental correlation the curves at 15 and 20 volts are closer together than those at $20-25 \mathrm{~V}$ and at $25-30 \mathrm{~V}$. This could 
Table XIII. Experimental parameters for figure 40: ECM gap versus current.

\begin{tabular}{|c|c|c|c|c|c|c|c|}
\hline $\begin{array}{c}\text { RUNY } \\
\#\end{array}$ & $\begin{array}{l}\text { av } \\
\text { volts }\end{array}$ & $\begin{array}{l}\text { I hole } \\
\mathrm{cm}\end{array}$ & & $\begin{array}{l}S . G \\
m i I\end{array}$ & $d_{\text {mils }}$ & $\begin{array}{l}\text { gap } \\
\text { mils }\end{array}$ & $\stackrel{i}{\mathrm{~A} / \mathrm{cm}}$ \\
\hline \multicolumn{3}{|c|}{ APPLIED VOLTAGE } & $=$ & \multicolumn{2}{|c|}{5 Volts } & & \\
\hline 120 & 14.8 & 0.565 & & 11 & 206 & 27 & 29.5 \\
\hline 121 & 15.4 & 0.620 & & 12 & 236 & 20 & 34.6 \\
\hline \multicolumn{4}{|c|}{ APPLIED VOLTAGE $=$} & \multicolumn{2}{|c|}{20 Volts } & & \\
\hline 123 & 20.0 & 0.610 & & 10 & 212 & 40 & 30.0 \\
\hline 119 & 20.0 & 0.555 & & 12 & 210 & 20 & 40.5 \\
\hline 125 & 20.2 & 0.585 & & 9 & 223 & 16 & 51.7 \\
\hline
\end{tabular}

APPLIED VOLTAGE $=25$ VOItS

$\begin{array}{lllllll}122 & 25.1 & 0.625 & 14 & 222 & 38 & 37.2\end{array}$

$\begin{array}{lllllll}126 & 24.8 & 0.645 & 9 & 240 & 23 & 53.3\end{array}$

$\begin{array}{lllllll}128 & 25.2 & 0.580 & 10 & 217 & 21 & 61.0\end{array}$

$\begin{array}{lllllll}129 & 25.1 & 0.990 & 9 & 380 & 19 & 68.4\end{array}$

$\begin{array}{lllllll}131 & 25.4 & 0.955 & 10 & 365 & 15 & 77.1\end{array}$

APPLIED VOLTAGE $=30$ Volts

$\begin{array}{lllllll}138 & 30.0 & 0.505 & 14 & 165 & 48 & 38.6\end{array}$

$\begin{array}{lllllll}132 & 30.2 & 0.950 & 10 & 365 & 19 & 86.5\end{array}$

$\begin{array}{lllllll}133 & 29.9 & 1.010 & 9 & 390 & 17 & 91.4\end{array}$

$\begin{array}{lllllll}134 & 30.0 & 1.025 & 10 & 396 & 17 & 99.8\end{array}$

$\begin{array}{lllllll}136 & 31.0 & 1.030 & 10 & 400 & 16 & 115.7\end{array}$ 


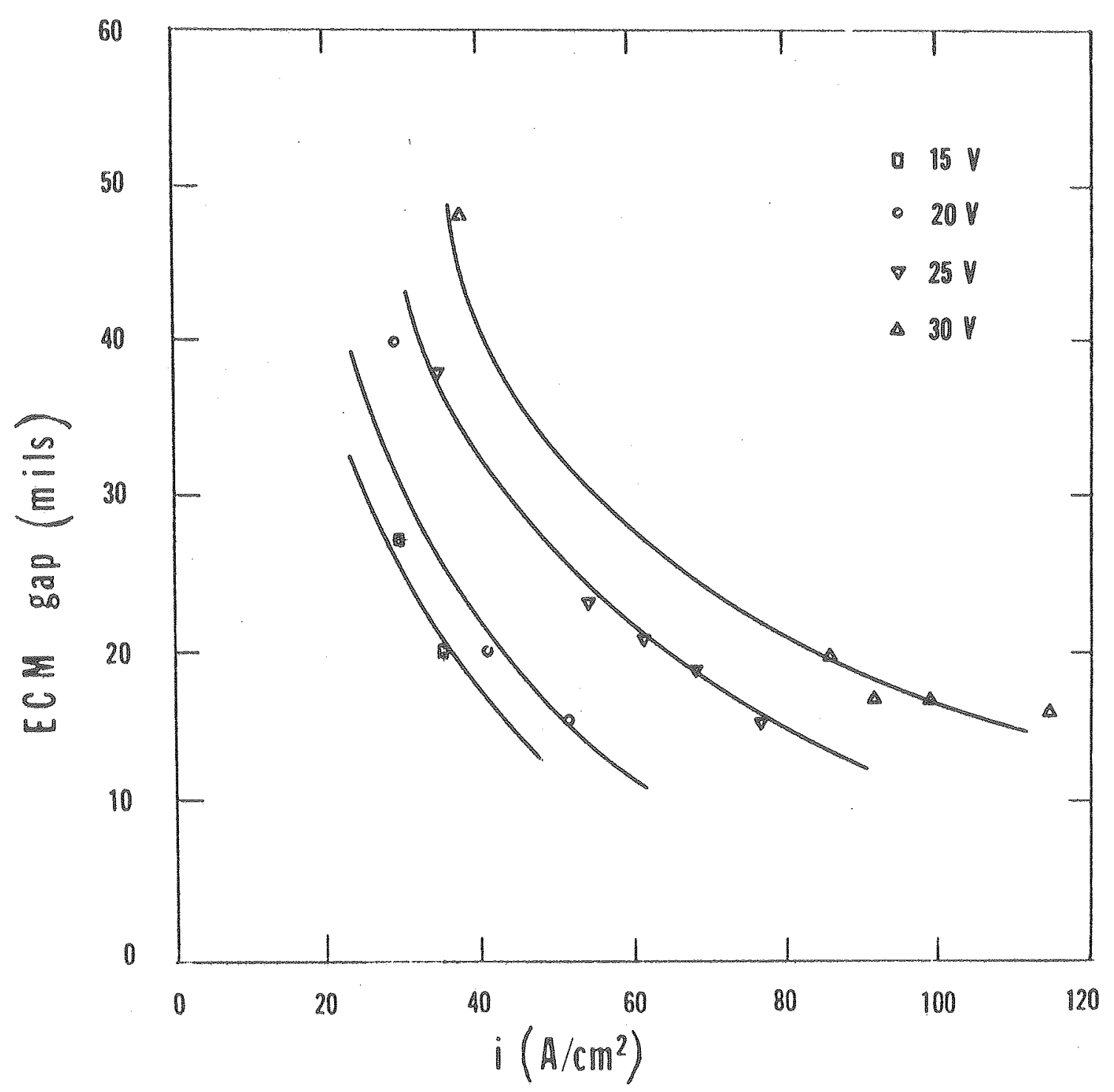

XBL $786-9263$

Figure 40. Frontal gap of dissolution at different applied voltages for the ECM of $\mathrm{ZXB}_{2}$ in $\mathrm{KNO}_{3}$. 
be due to the passivation of the surface which decreases the current density (at constant voltage) by comparison to the value it would have if dissolution of the material was the only anodic reaction. As shown in Fig. 40, a shift of the curve towards the higher values of gap for the same current density results. (The frontal gap is inversely proportional to the feed rate ox the current density.)

\section{E3. Current-voltage relationship in $\mathrm{KNO}_{3}$}

Since zirconium diboride is the only material investigated to present this particular behavior, the phenomenon has been further explored. The experiments carxied out in this work permit only the control of the applied voltage and since the current is determined by the machining rate, the polarization curve has been derived from measurements with a constant frontal gap of dissolution representing the third element necessary to the establishment of the polarization.

As mentioned earlier, the machining gap is not directly available by visual observation, but an approximate value can be obtained from the measurements with the use of equation (11):

$$
E C M \text { gap }=h+S, G,-\delta \text {. }
$$

Table XIV lists the useful parameters for three different machining gaps, representing a constant cell geometry; Fig. 41 plots the final results. This represents a further evidence of the observed phenomenon. Due to the exrors in the experimental determination of the gap, the polarization curve so determined is not precise, but the trend assumed indicates that a different dissolution reaction seems to occur at low current density. 
Table XIV. Experimental data for figure 41: polarization curve of $\mathrm{Z} \times \mathrm{B}_{2}$ in $\mathrm{KNO}_{3}$.

$$
\text { RUN \# }
$$

E.C.M.gap $=20 \mathrm{mils} / 0.508 \mathrm{~mm}$.

$\begin{array}{lll}121 & 15.4 & 34.6 \\ 119 & 20.0 & 40.5 \\ 128 & 25.2 & 61.0 \\ 132 & 30.0 & 86.5\end{array}$

E.C.M.gap $=16 \mathrm{mils} / 0.406 \mathrm{~mm}$.

$\begin{array}{lll}125 & 20.2 & 51.7 \\ 131 & 25.4 & 77.1 \\ 135 & 30.3 & 106.2 \\ 126 & 15.0 & 41.0\end{array}$

E.C.M. gap $=30 \mathrm{mils} / 0.762 \mathrm{~mm}$.

$\begin{array}{lll} & 15.0 & 27.1 \\ \text { from fig. } & 20.0 & 32.0 \\ (36) & 25.0 & 45.2 \\ & 30.0 & 61.1\end{array}$




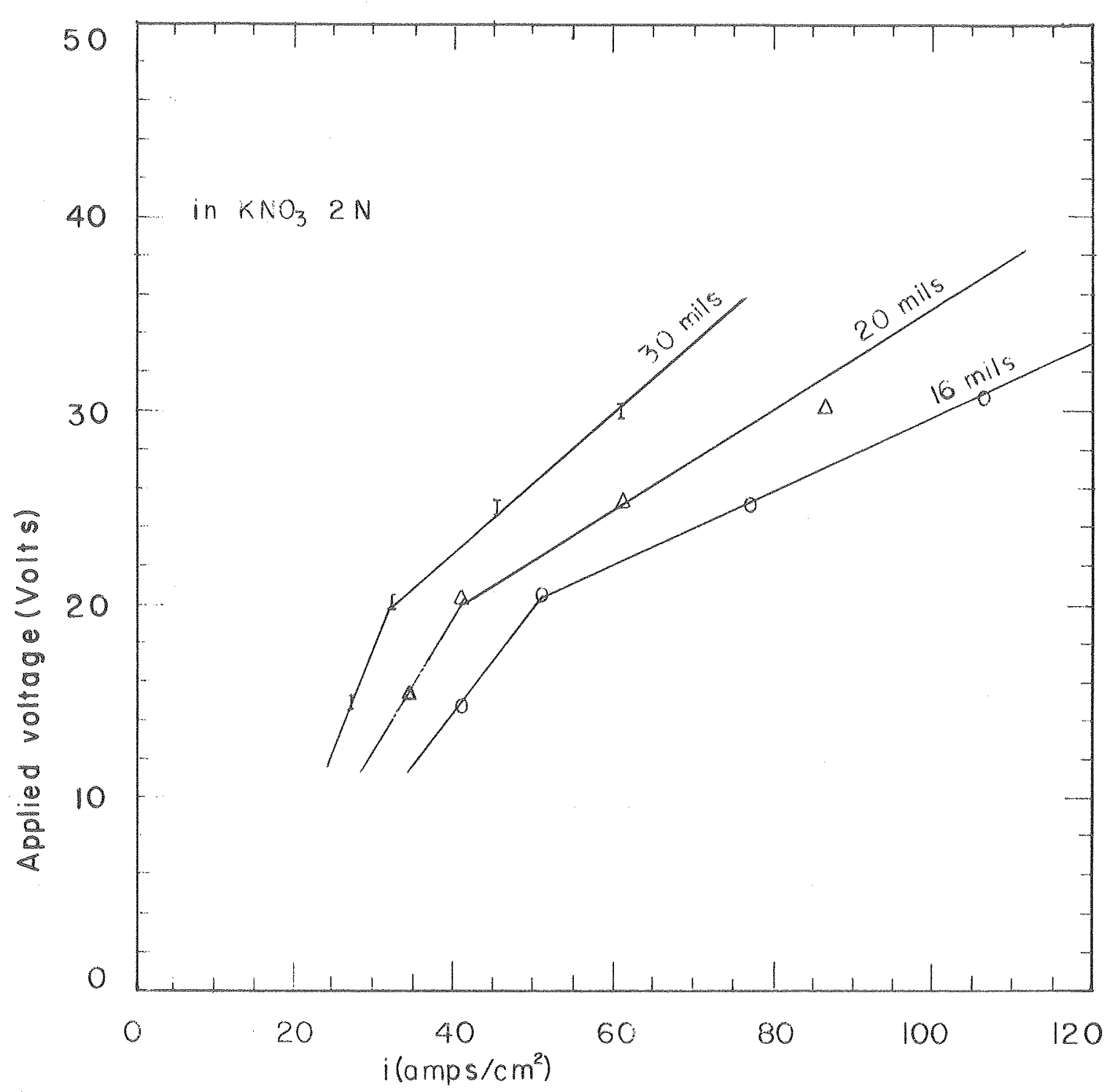

XBL $785-8637$

Figure 41. Polarization curve of $\mathrm{ZrB}_{2}$ in $2 \mathrm{~N} \mathrm{KNO}_{3}$. 
It is to be noticed that, for comparison, the data on the Fig. 41 corresponding to a ECM gap of $30 \mathrm{mils}$, have been deduced from fig. 40 representing the variations of the gap versus the current density. The same trend obtained by this interpolation suggests that the experimental determination of the machining gap used in the procedure yields valid approximations.

\section{E4. SEM analysis: effect of the current density}

The difference between the low current densities and the high current densities was a1so explored by SEM. The appearance of the surfaces lead to the same conclusion: on Fig. 42, microphotographs are showing the surfaces of the bottoms of the holes dxilled in zirconium diboride. The slight difference of appearance between the EC machined surfaces at low current density (1ert column) and at high current density (right column) could be due to an anodic film, more strongly adherent at low current density, and on which a possible side reaction at low current density, like oxygen evolution, could occur:

$$
\mathrm{H}_{2} \mathrm{O}=\mathrm{O}_{2}+2 \mathrm{H}^{+}+2 \mathrm{e}^{-} \text {. }
$$

This side reaction could accout for the high apparent overall valence of the dissolution reaction at low current densities (14 equiv e-/ mole versus 9.8 at high current densities).

Thus, if the 1 ight material visible on the pictures of the left column represent the anodic passivation film, it is shown to cover partially the anode surface and gradually disappear or to reach a steady 
as received
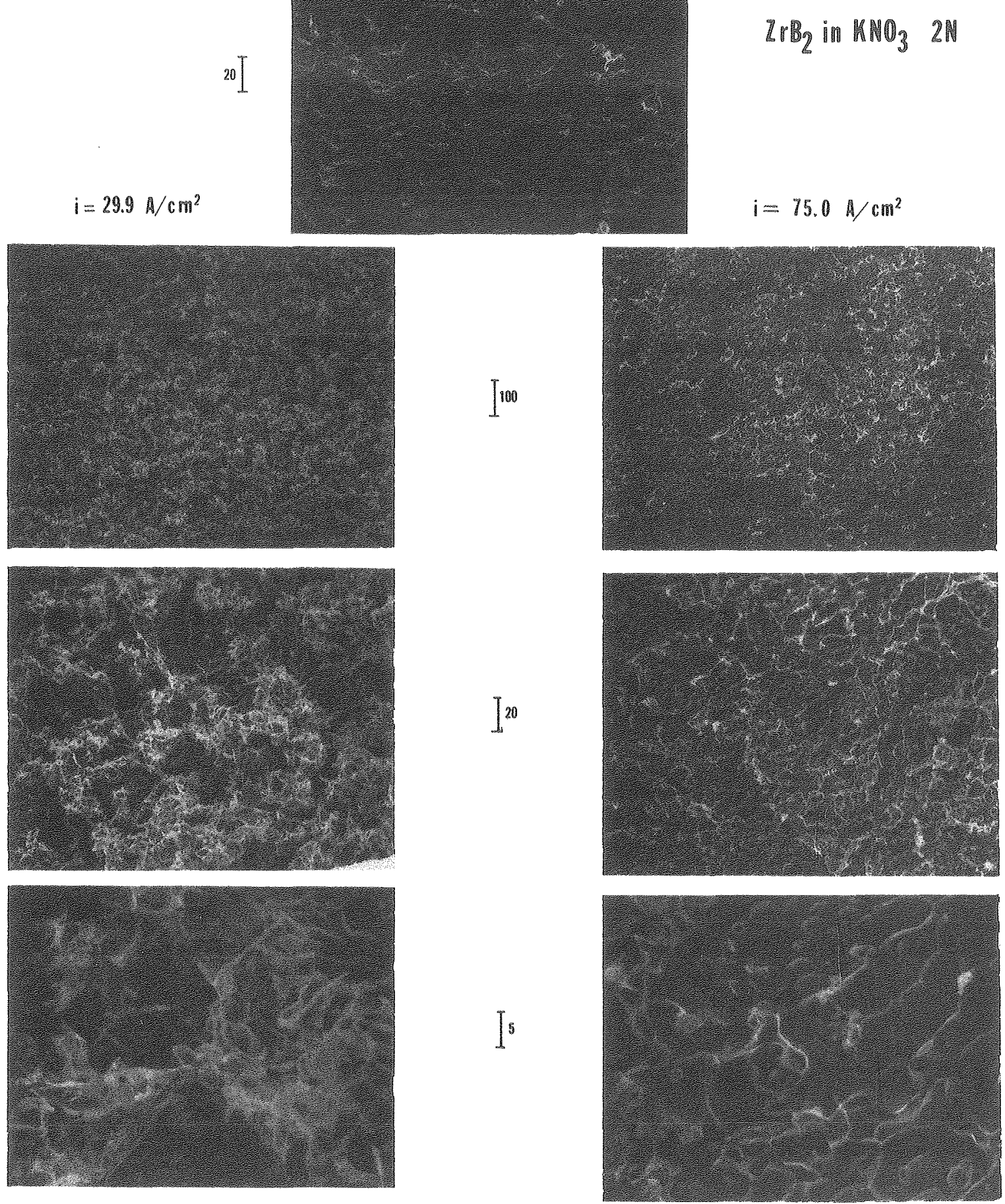

XBB $785-5626$

Figure 42. SEM microphotographs; effect of the current density on ECM of $\mathrm{ZrB}_{2}$. (scale in $\mu \mathrm{m}$ ) 
state coverage, as the current density increases, until stable conditions are observed (the lower limit for reaching this steady state is observed to be about $\left.50 \mathrm{~A} / \mathrm{cm}^{2}\right)$.

As seen on Fig. 42, the coverage of the surface at high current density is much less than the one at low current density. This supports the electrochemical behavior observed previously, indicating that a side reaction such as oxygen evolution could be responsible for the high apparent valence of dissolution at low current density. 
Table XV. Experimental data for $\mathrm{ZrB}_{2}$ in $\mathrm{KNO}_{3}$. Flow rates in liter/min, $\mathrm{A} / \mathrm{z}$ in gram/Faraday.

\begin{tabular}{|c|c|c|c|c|c|c|c|c|c|c|c|c|}
\hline RUN & $\begin{array}{l}\text { Press. } \\
\text { (big) }\end{array}$ & $\begin{array}{l}\text { Flow } \\
\text { rate }\end{array}$ & mores & $\begin{array}{l}\text { (volts }) \\
\text { (v) }\end{array}$ & $\begin{array}{l}I \\
(\operatorname{amps})\end{array}$ & $10^{-2} \mathrm{~cm} / \mathrm{mm}$ & $\begin{array}{l}\text { nole } p \\
(\mathrm{~cm})\end{array}$ & $\begin{array}{c}i \\
\left(A / c m^{2}\right)\end{array}$ & $\begin{array}{c}0 \\
10^{-2} \mathrm{~g} / \mathrm{mn}\end{array}$ & dens: $t_{y} / t_{I}$ & 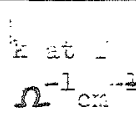 & $\begin{array}{l}\quad \therefore / 2 \\
=1010\end{array}$ \\
\hline 123 & 36 & 4.27 & $32.5^{\circ} \mathrm{C}$ & 20.0 & 12.4 & 2.08 & 0.725 & 30.1 & 5.36 & $1.12250 / 29^{\circ} \mathrm{z}$ & 0.205 & 7.6 \\
\hline 120 & 62 & 2.66 & $27^{\circ} \mathrm{C}$ & 14.6 & 11.2 & 2.13 & 0.695 & 29.5 & 5.42 & $I .12075 / 22.5^{\circ} \mathrm{C}$ & 0.138 & 7.8 \\
\hline 122 & 34 & 4.62 & $30^{\circ} \mathrm{C}$ & 25.1 & 15.8 & 2.83 & 0.735 & 37.2 & 7.65 & $1.12050 / 26.5^{\circ} \mathrm{C}$ & C 0.183 & 7.3 \\
\hline 121 & 63 & 2.74 & $30^{\circ} \mathrm{C}$ & 15.4 & 12.2 & 2.86 & 0.670 & 34.6 & 6.10 & $1.12000 / 23^{\circ} \mathrm{C}$ & 0.186 & 8.0 \\
\hline 219 & 68 & 2.92 & $27^{\circ} \mathrm{C}$ & 20.0 & 15.6 & 3.40 & 0.700 & 40.5 & 7.94 & $1.11975 / 18.5^{\circ} \mathrm{C}$ & 0.170 & 8.2 \\
\hline 124 & 54 & 3.55 & $27^{\circ} \mathrm{C}$ & 20.1 & 27.7 & 4.18 & 0.685 & 48.0 & 9.93 & $1.12050 / 30^{\circ} \mathrm{C}$ & 0.177 & 9.0 \\
\hline 125 & 80 & 3.64 & $27^{\circ} \mathrm{C}$ & 20.2 & 18.5 & 4.80 & 0.675 & 51.7 & 10.84 & $1.12430 / 22^{\circ} \mathrm{C}$ & 0.175 & 9.4 \\
\hline 127 & 45 & 3.35 & $29^{\circ} \mathrm{C}$ & 24.6 & 21.2 & 5.25 & 0.695 & 55.9 & 12.55 & $1.12450: 25^{\circ} \mathrm{C}$ & 0.284 & 2.5 \\
\hline 128 & 48 & 3.20 & $31^{\circ} \mathrm{C}$ & 25.2 & 22.8 & 5.74 & 0.690 & 61.0 & 13.69 & $1.12375 / 28^{\circ} \mathrm{O}$ & 0.198 & 9.7 \\
\hline 129 & 50 & 3.64 & $32^{\circ} \mathrm{C}$ & 25.1 & 25.2 & 6.76 & 0.685 & 68.4 & 25.75 & $1.12425 / 23.5^{\circ} \mathrm{C}$ & $0.20 \div$ & 10.8 \\
\hline 130 & 57 & 2.92 & $30^{\circ} \mathrm{C}$ & 25.2 & 26.2 & 7.45 & 0.680 & 72.1 & 16.17 & $1.12575 / 25.5^{\circ} \mathrm{O}$ & 0.124 & 9.9 \\
\hline 131 & 76 & 3.01 & $31^{\circ} \mathrm{C}$ & 25.4 & 28.0 & 8.36 & 0.675 & 77.1 & 16.58 & $1.12475 / 28.5^{\circ} \mathrm{C}$ & 0.134 & 10.7 \\
\hline 133 & 58 & 3.01 & $27.5^{\circ} \mathrm{C}$ & 29.9 & 33.2 & 9.80 & 0.680 & 91.4 & 22.14 & $1.12825 / 25^{\circ} \mathrm{C}$ & 0.181 & 10.3 \\
\hline 134 & 63 & 3.19 & $30^{\circ} \mathrm{C}$ & 30.0 & 35.7 & 10.75 & 0.675 & 99.8 & 23.76 & $1.12720 / 26^{\circ} \mathrm{C}$ & 0.196 & 10.3 \\
\hline 136 & 66 & 2.65 & $30^{\circ} \mathrm{C}$ & 33.0 & 42.0 & 12.60 & 0.680 & 135.7 & 28.01 & $1.12700 / 26^{\circ} \mathrm{C}$ & 0.191 & 10.3 \\
\hline
\end{tabular}


SUMMARY AND CONCLUSIONS

The use of ECM was proven feasible for the machining of very hard materials, $\mathrm{TiC}, \mathrm{ZrC}, \mathrm{TiB}_{2}$ and $\mathrm{ZrB}_{2}{ }^{\circ}$ The apparent valence for the anodic dissolution of each material was found to be independent of the two electrolytes investigated $\left(2 \mathrm{~N}, \mathrm{KNO}_{3}, 3 \mathrm{~N}, \mathrm{NaCl}\right)$ and are listed in the following table.

\begin{tabular}{|l|cccc|}
\hline Material & TiC & ZrC & $\mathrm{TiB}_{2}$ & $\mathrm{ZrB}_{2}$ \\
\hline z(equiv e-/mole) & 6.7 & 5.7 & 9.3 & 9.8 \\
\hline
\end{tabular}

The overall scheme of the dissolution reaction has been suggested and is suppoxted by the knowledge of the apparent valence of dissolution and of one of the reaction products for the dissolution of TiC and $\mathrm{TIB}_{2}{ }^{\circ}$

The dissolution reaction overvoltages were shown to be constant in the range of current density investigated and in the order of several. volts as listed in the following table

\begin{tabular}{|l|llll|} 
Material & $\mathrm{TiC}$ & $\mathrm{ZrC}$ & $\mathrm{TiB}_{2}$ & $\mathrm{ZrB}_{2}$ \\
\hline $\begin{array}{l}\text { Overvoltage } \\
\text { of reaction (Volts) }\end{array}$ & $5-6 \mathrm{~V}$ & $9-10 \mathrm{~V}$ & $11-12 \mathrm{~V}$ & $13-14 \mathrm{~V}$ \\
\hline
\end{tabular}

Lastly, the surface roughness attainable on $\mathrm{TiC}$ and $\mathrm{ZrC}$ was shown to be in the range of $3-7 \mu \mathrm{m}$ and to be only dependent on the electrolyte used for the ECM of these materials. 
APPENDIX: Design of the Toolpiece

Preliminary experiments carried out using the toolpiece of design A were shown not to be reproducible if meaningful at all. A characteristic recorded data set is txaced in Fig. 43. As seen during the whole course of this run ( $\mathrm{TiC}$ in $\mathrm{KNO}_{3}$ ), the current and the applied voltage oscillated between two very different values without any tendency for reaching a steady state. A further investigation of this phenomenon, using different applied voltages and tool feed rates indicated that:

- the oscillations always occurred abruptly and were large;

- as the current jumps, the applied voltage drops:

- at constant flow rate, the pressure drop in the ECM gap decreased slightly when the curxent was in the high plateau, and increased slightly when the current was at the low plateau;

- the oscillations were not always regular and reproducible;

- the oscillations seemed to disappear at very low flow rates.

A galvanostatic study of the dissolution of copper at high rate in a channel cell (54) showed a similax oscillatory behavior. The voltage oscillations were explained by alternating passivation and breakdown of the anodic surface. The layer of oxides formed during dissolution covered the anode and increased the resistivity of the anode-electrolyte interface. This change in the polarization of the anode resulted in a potential jump until the anodic film formed was flaked off and removed by the flow of the electrolyte. The phenomenon 
was clearly demonstxaced in a movie taken by Kinoshita (22), where the anodic film is continuously formed, and when as it flakes off and is removed by the flowing electrolyte, shedding of the surface film was shown by Kinoshita to result in abrupt decline of the anode potential.

Cooper studied extensively these voltage oscillations and, in contrast to the present observations, found that the Exequency of oscillations depended on the current density and on the pH of the electrolyte but were insensitive to the flow rate. The cell configuration is different in our case, even if the flow rate could be determined accurately, the flow pattern was unknown because of the abrupt change in cross section occurring from the inlet to the outlet of the machining gap.

Large current oscillations, in this apparatus, were already reported by Riggs (31) who used a toolpiece of similar design (design A). These were explained to be due to two different dissolution modes: active dissolution during the high current plateau and transpassive dissolution during the low current plateaw. The peak appearing in the center of the machined area seened to play an important role in the rapid transition from one regime to the other. Riggs showed that the peak is proportional to the ECM driving force ( $\mathrm{K} \Delta \mathrm{V} / \mathrm{Fr}$ ), with increasing current density, the height and the area of the peak decreases. However, experiments carried out with the tool piece A, using high applied voltages and low feed rates to reduce the driving force, always showed the oscillatory behavior, although to a lesser extent. The current oscillations amplitude oscillated within $10-20 \%$ of the average current. 


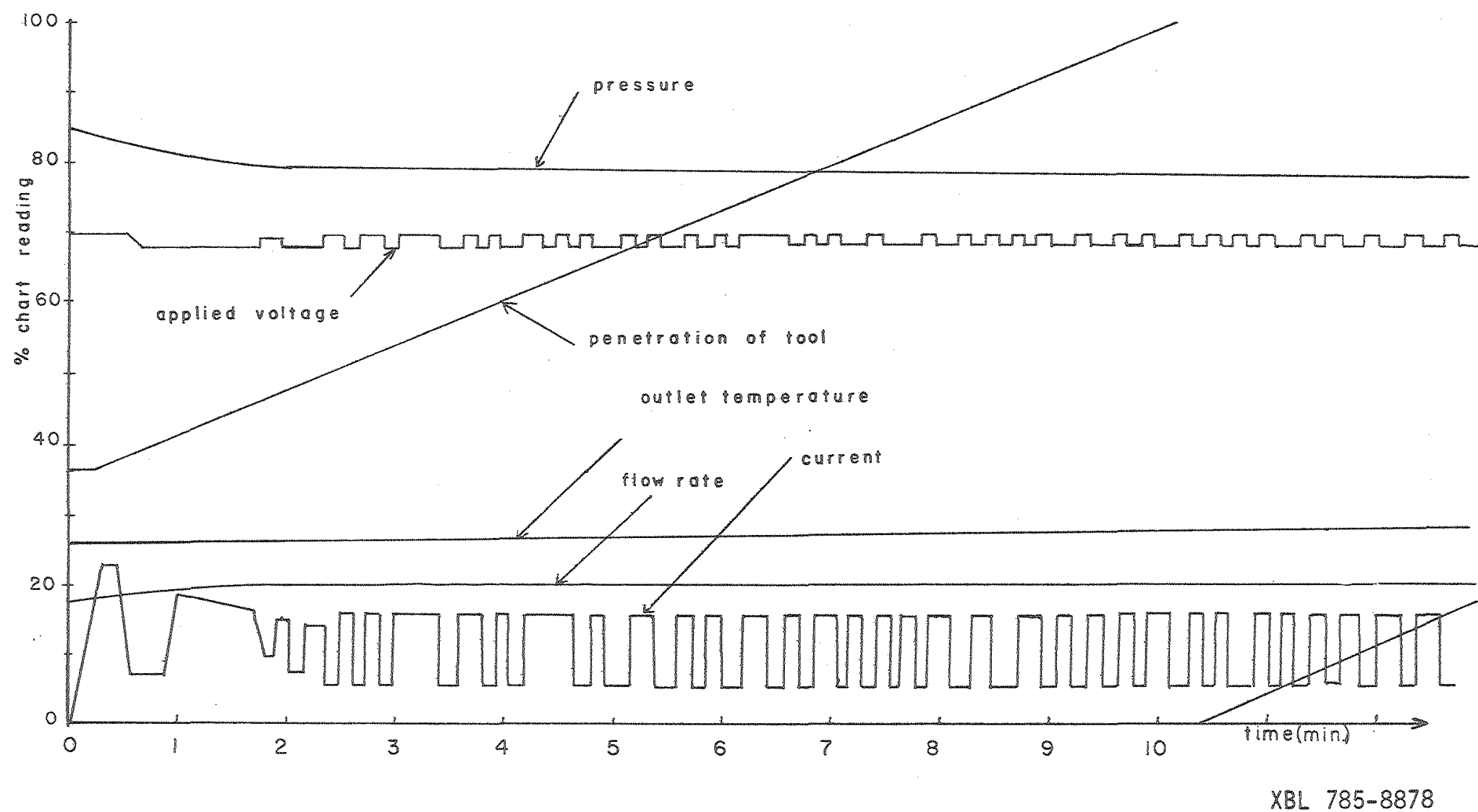

Figure 43. Oscillations recorded using the toolpiece of design A for the ECM of TiC in $\mathrm{KNO}_{3}$ (run 非); low current range: 20.8 Volts at 6 Amps, high current range: 20.4 Volts at 16 Amps. 
The huge variations of the current ( 100 to $150 \%$ in cextain cases) at high values of ECM driving forces cannot be explained by a simple passivation phenomenon. For example, associating the low current plateau periods with the formation of a passivating film in the run illustrated in Fig. 43, this film would be thick enough to close the gap by a third of its normal value. For such a drastic change in the geometrical configuration of the cel1, a similar response would be expected from the flow conditions. Since no such large effect was observed, either in the pressure drop or the flow rate, it was concluded that a passivation phenomenon could not satisfactorily describe this dramatic behavior.

To eliminate this phenomenon, which was probably due to the hydrodynamic characteristics of the system, a different toolpiece (design B) was constructed. This new toolpiece was designed primarily to allow:

- a good distribution of the electrolyte throughout the gap of dissolution;

- a reduction of the effects of a large protuberance on the machining area by suppression of the peak;

- a larger cathodic surface area to ensure a better current distribution over the entire machined area.

This design is shown in Fig. 7 and $5 \mathrm{~A}$. It consists of a toolpiece, the front tip of which is provided with five small holes to deliver the electrolyte into the ECM gap. The diameter of the holes for the delivery of the electrolyte, was chosen to be large 
enough not to cause too large a pressure drop. and small enough so that the peak opposite each hole should create as 1ittle disturbance as possible. The highest peak recorded was 0.1 mm far a ECM gap of 0.7 mm ( $x$ un 65 : TiC in $\mathrm{HNO}_{3}$ ) which can be congidered negligible as compared with design A where the peak height could be from 2 to $4 \mathrm{~mm}$ under the same conditions.

A typical data set is shown on Fig. 5 for TiC machined in $3 N$ Nacl at a toolplece feed rate of $4.4310^{-2} \mathrm{~cm} / \mathrm{mLn}$, using a toolpiece of design $B$. The oscillations have disappeared and the steady state Is reached within 1ess than $15 \%$ of the whole duration of the experiment. The toolpiece of design $B$ was used throughout this work. 


\section{References}

1. John F. Wilson, Practice and Theory of Electrochemical Machining, Chapter III, Wiley Interscience, New York, 1971.

2. A. E. DeBarr and D. A. O1iver, Electrochemical Machining, p 122, McDonald Cy, London, 1968.

3. O.W. Storey, J. E1ectrochem. Soc. 100, 5.53.

4. British patent \# 722-939

5. British patent 非 974-338

6. British patent 非 974-339

7. B. H. Wilkinson and G. R. Stuart, Developments of ECM Techniques, Electronics and Power, Vo1 10, Dec. 1964, p. 420.

8. Developments in ECM Techniques, Machinery, Vo1 107, Dec. 1965, p 1450.

9. British patent 非 753-467

10. British Patent \# 1058-930

11. British patent 非 846-278

12. British patent 非 846-279

13. British patent 非1093-114

14. British patent 非 $854-541$

15. British patent \# 1014-095

16. British patent \# 1004-999

17. US NASA Handbook, April 1968, Machining and Grinding of U1tra High Strength Steels and Stainless Steel Alloys.

18. K. W. Mao and J. P. Hoare, J. Electrochem, Soc. 119 (1972) 419.

19. British patent \# 335-003, W. Gussef

20. J. Bannard, Electrochemical Machining, J, of Applied Electrochem. 7 (1977) 1-29. 
21. K. W. Mao,J Electrochem Soc 118 (1971) 1870 1889.

22. K. Kinoshita, Anodic Dissolution of Copper at High Current Density, PhD thesis, University of California, Berkeley, 1969.

23. J.A. McGeough, Principles of Electrochenical Machining Chapman and Ha11, London, 1974, p 7.

24. Mitche11 A. Laboda and Michael I. Mcililan, New Electrolyte for ECM, J. Electrochem. Soc. 5 (1967) 340.

25. M. A. Laboda, J. P. Hoare and S. E. Beacon, Importance of the Electrolyte in ECM; Collection Czekslovakia Chem. Comm, Vo1 36 (1971) p. 680 .

26. C. F. Noble, S.J. Shine, Electrochemical Drilling with Alternative Current, J. Appl. Electrochem 5 (1975) 215.

27. E. Yeager, A. J. Salkind, Techniques of Electrochemistry, Vol 3, Wyley Interscience Publication, 1973.

28. Designing with Hard Materials - Alloys, Reference manual edited by Kumameta1, Inc. Latiobe, PA, 1977.

29. A. E. DeBart and D. A. Oliver (see Ref. 2) p. 209.

30. Kearton, Steam Turbines, Theory and Practice, Pitman, p. 51.

31. J. B. Riggs, Modeling of Electrochemical Machining of Copper, Ph.D. Thesis, University of California, Berkeley.

32. Proceedings of Workshop on Ceramics and Advanced Heat Engines ERDA Jan. 1977, p. 17.

33. Peter T. B. Shaffer, High Temperature Materials, Plenium Press, NY, 1969.

34. G. L. Miller, Meta1lurgy of the Rare Metals, London Butterworth Scientific pulbication, 2nd Ed. 1971.

35. A. BIuementhal, The chemical behavior of Zirconium, Warrin B., 1958.

36. Edmund K. Storms, The Refractory Carbides, Academic Press, New York and London, 2nd ED. 1967.

37. "Machining Characteristics of High Strength Therma1 Resistant Materials", USAF Machinability Report, Vo1, 4, 1960, Curtiss Wxight Corporation, subcontract to Metart Research Associates, Inc. 
38. Michael Field, William Koster, "Surface Integrity in Machining and Finishing, ASTME Technical paper, July 1967, MR 67-142.

39. J. Bannard, E1ectrochemica1 Machining, J. App1. Electrochem 7 (1977) 1-29,

40. A. T. Kuhn, Industrial Electrochemical Processes "Electrochemical Machining", Elseview Publishing Co. 1971.

41 Yun Petrov, N. N. Parshutin, Influence of Composition of Tempered Carbides on the Productivity and Surface Finish durin Electrochemical Dimension Working, Elektronaya Obrabotka Materialov 4 (1972) p 22.

42. J. Bannard, Effect of Flow on the Dissolution Efficiency of Mild Steel during ECM, J.Appl. Electrochem 7 (1977) p 267-270, Technical note.

43. J. P. Hoare and M. A. Laboda, Investigation of the Differences Between $\mathrm{NaCl}$ and $\mathrm{NaClO}_{3}$ as Electrolytes in $\mathrm{ECl}$, J. Electrochem. Soc. 116 (1969) 199.

44. M. A. Laboda, J. P. Hoare "The Importance of the Electrolyte in ECM", Collection Czechoslov. Chem Commun。Vo. 36 (1971) 680 .

45. J. P. Hoare, M. A. Laboda "ECM of High Temperature Alloys in NaClO Solutions", J。 of Electrochem.Soc. 120 (1973) 1071.

46. M. A. Laboda, M. L. McMillan, A New Electrolyte for Electrochemical Machining, J. Electrochem. Soc. 5 (1967) 340.

47. J. P. Hoare, Oxide Files Studies in ECM Electrolytes, J. Electrochem Soc. 117 (1970) 142.

48. McGeough, Electrochemical Machining (See Ref. 23), Chapter III: Metals and Electrolytes.

49. Alphabetical Index of Inorganic Compounds, International Center for Diffraction Data, Swarthmore, PA 19081, $1977 \mathrm{Ed}$.

50. J. Bannard, "On the ECM of Some Titanium Alloys in Bromide Electro1ytes", J. App1. E1ectrochem 6 (1976) 477-483.

51. C. H. Chen, F. H. Beck and M. G. Fontana, Corrosion 26 (1970) 135.

52. R. D. Cowling and $H \cdot E$, Hintermann, The Anodic Oxidation of Titanium Carbide, J. Electrochem. Soc. 118 (1971) 1912.

53. M. Pourbaix, Atlas of Electrochemica1 Equilibria in Aqueous Solutions, Peyamon Press, London, 1966. 
54. J. Cooper, Periodic Phenomena in Copper Dissolution at High Constant Current, Ph.D. Thesis, University of Calif́ornia, Berkeley.

55. P.J. Boden and J.M. Evans, Reduction of Stray Current Attack in ECM, J. Electrochem. Soc.116 (1971) 1870-1879.

56. O. P. Gamov, The Influence of the Electrolyte and pH on the Strength of Tungsten Carbides during ECM, Applied Electrical Phenomena, 3 (1973) 18.

57. J.P. Hoare, Nature 219 (1968) 1034.

58. J. B. Cotton and I. Dugdale, Corrosion Science 4 (1964) 397.

59. J. Newman, Electrochemical Systems, Prentice Ha11, Englewood Cliffs, 1973 .

60. D. Landolt, R. Muller and G.W.Tobias, Mass Transport in ECM in "Fundamentals of ECM", ed. by Faust, Battelle Memorial Institute.

61. W. G. Clark and J.A. McGeough, Temperature Distriburion Along the Gap in ECM, J. Applied Electrochem. 7 (1977) 277-286.

62. Lange Handbook of Chemistry, 11th Edition, ed. by J. Dean, 1973. 
ACKNOWLEDGEMENTS

I would like to express my gratitude to Professor Tobias and to Dr. Muller for their support during the course of this study. Their comments in the final stage have been of a great help for the presentation of this work.

I am also indebted to Professor Pickus for the review of this manuscript.

I would like to thank Walter Giba for his ability to solve technical problems, Carol Payne and Linda Betters for typing this manuscript. This work was performed under the auspices of the United States Energy Research and Development Administration. 
This report was done with support from the Department of Energy Any conclusions or opinions expressed in this report represent solely those of the author(s) and not necessarily those of The Regents of the University of California, the Lawrence Berkeley Laboratory or the Department of Energy. 
TECHNICAL INFORMATION DEPARTMENT LAWRENCE BERKELEY LABORATORY UNIVERSITY OF CALIFORNIA BERKELEY, CALIFORNIA 94720 